\title{
Allicin Bioavailability and Bioequivalence from Garlic Supplements and Garlic Foods
}

\author{
Larry D. Lawson * (D) and Scott M. Hunsaker \\ Mérieux NutriSciences Corporate Office (Silliker, Inc.), 111 E. Wacker Dr. Ste. 2300, Chicago, IL 60601, USA; \\ scott.huns@gmail.com \\ * Correspondence: llawson2323@yahoo.com; Tel.: +1-801-367-4508
}

Received: 30 May 2018; Accepted: 20 June 2018; Published: 24 June 2018

\begin{abstract}
Allicin is considered responsible for most of the pharmacological activity of crushed raw garlic cloves. However, when garlic supplements and garlic foods are consumed, allicin bioavailability or bioequivalence (ABB) has been unknown and in question because allicin formation from alliin and garlic alliinase usually occurs after consumption, under enzyme-inhibiting gastrointestinal conditions. The ABB from 13 garlic supplements and 9 garlic foods was determined by bioassay for 13 subjects by comparing the area under the 32-h concentration curve of breath allyl methyl sulfide (AMS), the main breath metabolite of allicin, to the area found after consuming a control $(100 \% \mathrm{ABB})$ of known allicin content: homogenized raw garlic. For enteric tablets, ABB varied from $36-104 \%$, but it was reduced to $22-57 \%$ when consumed with a high-protein meal, due to slower gastric emptying. Independent of meal type, non-enteric tablets gave high ABB (80-111\%), while garlic powder capsules gave $26-109 \%$. Kwai garlic powder tablets, which have been used in a large number of clinical trials, gave $80 \%$ $\mathrm{ABB}$, validating it as representing raw garlic in those trials. $\mathrm{ABB}$ did not vary with alliinase activity, indicating that only a minimum level of activity is required. Enteric tablets (high-protein meal) disintegrated slower in women than men. The ABB of supplements was compared to that predicted in vitro by the dissolution test in the United States Pharmacopeia (USP); only partial agreement was found. Cooked or acidified garlic foods, which have no alliinase activity, gave higher ABB than expected: boiled $(16 \%)$, roasted $(30 \%)$, pickled $(19 \%)$, and acid-minced (66\%). Black garlic gave $5 \%$. The mechanism for the higher than expected ABB for alliinase-inhibited garlic was explored; the results for an alliin-free/allicin-free extract indicate a partial role for the enhanced metabolism of $\gamma$-glutamyl S-allylcysteine and S-allylcysteine to AMS. In conclusion, these largely unexpected results (lower ABB for enteric tablets and higher ABB for all other products) provide guidelines for the qualities of garlic products to be used in future clinical trials and new standards for manufacturers of garlic powder supplements. They also give the consumer an awareness of how garlic foods might compare to the garlic powder supplements used to establish any allicin-related health benefit of garlic.
\end{abstract}

Keywords: allicin bioavailability; allicin metabolism; allyl methyl sulfide; alliin; $S$-allylcysteine; garlic supplements; cooked garlic; pickled garlic; black garlic; aged garlic extract

\section{Introduction}

Garlic supplements, mainly dried and pulverized whole clove supplements, have been used in a large number of controlled clinical trials since the mid-1980s, focusing primarily on serum cholesterol and blood pressure [1-3]. The effects on blood pressure have been moderately consistent for hypertensive subjects, while the effects on serum lipids have been inconsistent, even for persons with high baseline cholesterol levels [1,2,4-6]. Of the 23 qualifying trials on serum cholesterol with a garlic powder product, $43 \%$ found no effect [1]. Due to the inconsistencies, the trials have been the subject of several meta-analyses (nine on serum lipids and eight on blood pressure), with the overall conclusions 
being conservative [7]. Authors of the meta-analyses most frequently cite the high heterogeneity among the trials (high variation in dose, variable product types, identification of active compounds, standardization concerns, and unknown bioavailability) as the reason for caution in recommending garlic products for treatment of hypercholesterolemia and hypertension [1,4,5,7-11]. A recent review of the mostly in vitro antimicrobial effects of allicin concluded that determination of allicin bioavailability from various products is necessary before proper clinical studies can be conducted [12]. Hence, it is clear that attention needs to be given to the bioavailability and standardization of garlic's active compounds under a variety of processing conditions, especially because of known or suspected potential issues with their formation, stability, metabolism, and detection in the body.

The allyl thiosulfinates, of which allicin (diallyl thiosulfinate) is the most abundant and most studied member (Figure 1), are enzymatic products of alliin, $S(+)$-allyl-L-cysteine sulfoxide, and alliinase. They are rapidly formed when raw garlic cloves undergo cell rupture (Figure 1) or when dried and pulverized cloves (garlic powder) become wet $[13,14]$. The allyl thiosulfinates have been shown to be responsible for most of the pharmacological activity of crushed raw garlic cloves. Beginning in 1944 it was shown that allicin is responsible for the antibacterial activity of garlic and that selective removal of allicin also removed all activity $[15,16]$. Considerable evidence suggests that the allyl thiosulfinates, or their spontaneous transformation compounds (allyl polysulfides), or their common metabolite (allyl methyl sulfide, AMS), Figures 1 and 2, are responsible for most of the lipid-lowering, antioxidant, anti-atherosclerotic, and anticancer effects of whole garlic, as observed in animals and humans $[13,17]$. Both allicin and $\gamma$-glutamyl-S-allylcysteine (GSAC), as the source of S-allylcysteine (SAC) (Figure 1), appear to be responsible for the hypotensive effects of garlic [18]. Indeed, no other compound has yet been shown to have significant activity at levels present in a normal human dose (3-5 g) of crushed raw garlic. The majority of the clinical trials on the possible cardiovascular effects of garlic have used supplements that are standardized on alliin or allicin potential [1,2].

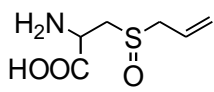

ALLIIN $S(+)$-allyl-L-cysteine sulfoxide (mesophyll cells),

S-methyl- and S-trans-1-propenylcysteine sulfoxides

ALLIINASE (vascular bundle cells; released upon crushing)

Allyl thiosulfinates<smiles>C=CCSS(=O)CC=C</smiles>

Allicin (diallyl thiosulfinate) 70\% (59-83); 82\% (74-91)

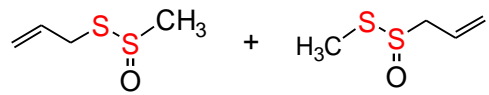

Allyl methyl thiosulfinates $19 \%(8-34) ; 11 \%(5-22)$

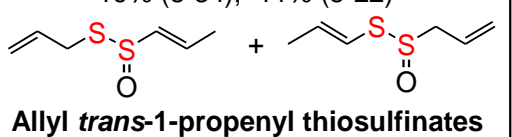

Allyl trans-1-propenyl thiosulfinates $11 \%(5-18) ; 6 \%(3-12)$

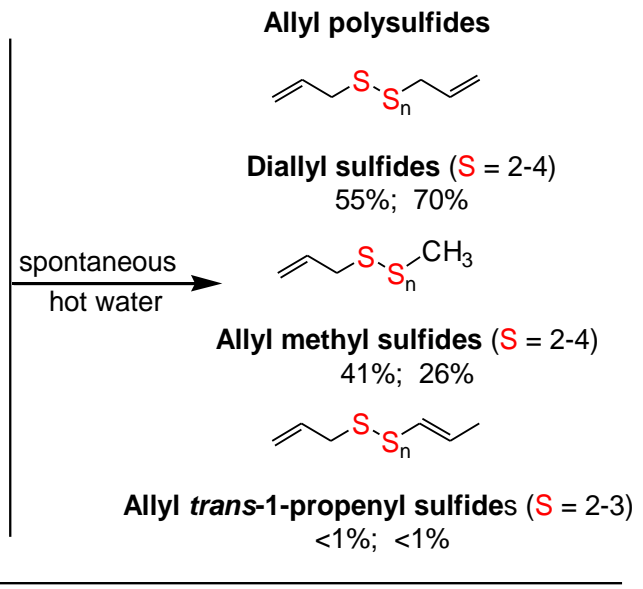

Figure 1. Cont. 

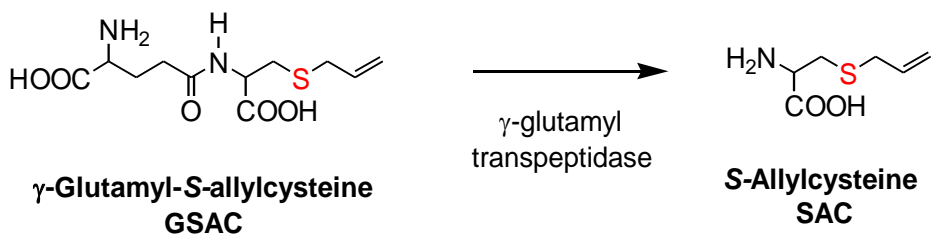

Figure 1. Structures of the known significant $S$-allyl compounds derived from garlic, including transformation reactions. The compounds above the horizontal line comprise alliin and alliin-derived dithioallyl compounds (AADD).The first set of values for the allyl thiosulfinates represent the average, minimum, and maximum mol \% of total allyl thiosulfinates found for 26 samples from six countries; the second set is the $S$-allyl mol \% or percent of the alliin transformed to each thiosulfinates-allicin increased because it is has two $S$-allyl groups $[19,20]$. The values for the allyl polysulfides represent the average $\mathrm{mol} \%$ and $S$-allyl mol \% for five samples of steam-distilled garlic oil capsules; small amounts of penta- and hexasulfides (3\%) are also present in these oils [21,22] (p. 100). Spontaneous formation of the allyl polysulfides from the thiosulfinates (rapid in hot water, slow in ambient water) results in loss of about $25 \%$ of the total $S$-allyl, due to the formation of $\mathrm{SO}_{2}$, propene, and allyl alcohol [23,24].

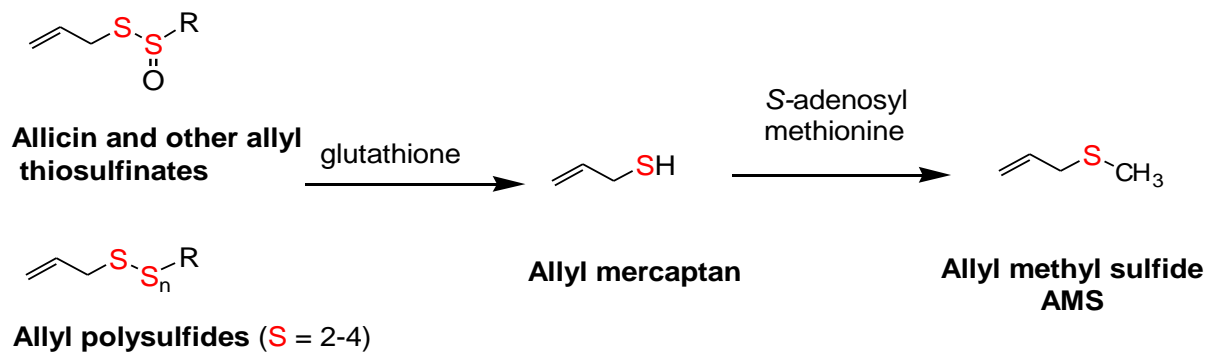

Figure 2. Metabolism of allyl thiosulfinates and allyl polysulfides. R represents allyl, methyl, or trans-1-propenyl. When $\mathrm{R}$ is allyl (allicin or diallyl sulfides), two moles of allyl mercaptan and allyl methyl sulfide (AMS) are formed.

Due to the abundance of alliinase [25], complete formation of allicin takes place in $0.5 \mathrm{~min}$ ( $5 \mathrm{~min}$ for the allyl methyl thiosulfinates) when water is added to garlic powder [14]. However, their formation in the body after consumption of garlic powder supplements is questionable because alliinase is inactive at $\mathrm{pH} 3.5$ or below $[14,26]$, a $\mathrm{pH}$ range commonly found in the stomach, although a moderate to high-protein meal can briefly raise the $\mathrm{pH}$ to 4.4 or higher $[27,28]$, a range in which alliinase is active. Hence, many brands of garlic supplements have been enteric-coated to prevent disintegration in the stomach, and the U.S. Pharmacopeia (USP) has established a monograph for estimating allicin formation and release from such products under simulated gastrointestinal dissolution conditions [29]. However, 21 of 24 enteric brands subjected to this dissolution allicin release test yielded less than $20 \%$ of their allicin potential (the maximum yield of allicin from alliin upon activation of alliinase; the USP monograph refers to it as "potential allicin"), due to low tablet alliinase activity and to slow tablet disintegration [30]. Similarly, dissolution allicin release from non-enteric Kwai (Lichtwer Pharma, Berlin) tablets, the most commonly used garlic supplement in cardiovascular clinical trials [1,2], has also been found to be problematic: $44 \%$ for tablets made before 1993 and only $15 \%$ for tablets made from 1994-1997 [31].

The surprisingly low allicin release found under these standardized in vitro conditions indicates either that allicin release in the body from most garlic supplements is very low or that the U.S.P. dissolution test is not accurate. This dilemma highlights the need to determine the allicin bioavailability in vivo from garlic products, but attempts to do so have been troublesome. Allicin has been shown to be metabolized rapidly (half-life $<1 \mathrm{~min}$ ) to allyl mercaptan (allyl thiol) when added to whole blood [32], but neither allicin nor its transformation compounds (Figure 1) nor allyl mercaptan were found in the blood, urine or stool after volunteers consumed a large amount $(25 \mathrm{~g})$ of chopped raw 
garlic [33] (p. 152). However, it has been known for some time that AMS is a component of human breath after consuming raw garlic and that its rate of appearance and decline in the breath indicated it to be a product of systemic metabolism [34-36]. Lawson and Wang [17] conducted studies on human breath AMS and showed that (a) the area under the 32-h breath AMS concentration curve (AUC) is linearly proportional to the amount of allicin consumed; (b) AMS is the main breath metabolite of allicin, accounting for at least $90 \%$ of the allicin consumed; (c) allyl mercaptan is a temporary intermediate in the formation of AMS from allicin; (d) allicin-derived diallyl disulfide and diallyl trisulfide are also metabolized mainly to AMS; and (e) AMS is an active metabolite, responsible for the ability of allicin to increase breath acetone levels. By the use of a sulfur-selective detector, the sensitivity of the method was improved for the consumption of small amounts of garlic [37]. Hence, a validated method for determining the bioavailability of allicin from any garlic product has been established.

The term "allicin bioavailability" is being used to represent the sum of three processes: enzymatic (garlic alliinase) formation of allyl thiosulfinates (mainly allicin) from alliin, usually in the gastrointestinal tract, followed by their absorption and metabolism to a quantifiable metabolite, AMS. Allicin absorption is known to be highly efficient [38,39], although partial metabolism to the rapidly absorbed intermediate, allyl mercaptan, may occur during absorption [17]. The term "allicin bioequivalence" refers to the metabolic formation of the allicin metabolite, AMS, from any $S$-allyl compound, without the assistance of garlic alliinase, including allyl polysulfides, alliin and possibly other S-allyl compounds, such as GSAC and SAC; the term is being used in particular for products in which garlic alliinase is inactive. Together, the terms are referred to as allicin bioavailability or bioequivalence $(\mathrm{ABB})$.

Although garlic supplements have been used in a large number of clinical trials, garlic is most commonly consumed as a food, usually as a cooked food and often as a commercial product suspended in an acid, such as whole cloves (pickled garlic) or small pieces (minced garlic), but no known clinical trials have been conducted with cooked or acidified garlic foods. However, the general public often wants to know if the results of clinical trials with supplements apply to garlic as a food, especially cooked garlic. In the U.S., cooked garlic is commonly prepared by boiling (soups) or roasting [40,41]. Because cooking or suspending garlic in acid fully inactivates alliinase [14,26], any allicin-related health benefits found with garlic supplements will probably be negligible in such foods. However, this logic assumes that the body itself-in the absence of active garlic alliinase-does not have the ability to metabolize alliin to allicin or allicin metabolites. Now that a method exists for determining the $\mathrm{ABB}$ of any garlic product, the validity of this assumption can be tested for alliinase-inhibited garlic foods.

The primary objective of this study has been to determine the problematic and hitherto unknown bioavailability of allicin from a variety of commonly consumed garlic supplements and garlic foods, in order to provide clinical trial researchers, manufacturers, and consumers with an improved knowledge basis when considering the possible health benefits of garlic products. The study has answered the following questions:

1. Can allicin bioavailability from garlic powder supplements be as high as that from crushed raw garlic?

2. Is the allicin bioavailability of the main garlic powder supplement (Kwai) used in clinical trials significantly less than that of raw garlic?

3. Is the allicin bioavailability of enteric garlic supplements greater than that of non-enteric ones?

4. Does the protein content of the meal being consumed with the supplement influence the allicin bioavailability?

5. How much supplement alliinase activity is necessary to achieve high allicin bioavailability?

6. What standards are recommended for the quality, content, and allicin bioavailability of garlic supplements being used in clinical trials? 
7. Is the in vitro USP. dissolution allicin release test accurate for estimating allicin bioavailability from garlic supplements?

8. Do cooked garlic or acidified commercial garlic products have significant allicin bioequivalence? If so, how much of these foods would one need to consume to obtain the same ABB as raw garlic or a garlic powder supplement used in clinical trials?

9. Do garlic compounds other than alliin-derived compounds have significant allicin bioequivalence?

\section{Materials and Methods}

\subsection{Standards}

$\mathrm{L}(+)$ - and $\mathrm{L}( \pm)$-S-allylcysteine sulfoxides (natural and racemic alliin), S-allylcysteine, diallyl disulfide, and diallyl trisulfide (each $\geq 98 \%$ ) were purchased from LKT Laboratories, Inc. (St. Paul, MN, USA). Allyl methyl sulfide and diallyl sulfide (each 99\%) were purchased from Sigma-Aldrich (St. Louis, MO, USA). $\gamma$-Glutamyl-S-allylcysteine (99\%) was purchased from U.S. Pharmacopeia (Rockville, MD, USA). Allicin ( $98 \%$ ) was prepared by oxidation of diallyl disulfide with hydrogen peroxide, followed by purification, as previously described [30]. Its concentration was validated with a second allicin standard prepared from alliin and crude alliinase [29]. Allyl methyl thiosulfinates, allyl-1-propenyl thiosulfinates, diallyl tetrasulfide, allyl methyl disulfide, allyl methyl trisulfide, and allyl methyl tetrasulfide were identified and quantified based on their relative retention times and relative extinction coefficients, compared to allicin and diallyl trisulfide, as previously described [19,21].

\subsection{Control}

The control for $100 \%$ ABB was prepared by homogenization of $500 \mathrm{~g}$ of peeled raw garlic cloves (California Late variety, Garlic World, Gilroy, CA, USA; 39.5\% dry weight), after addition of water at $0.60 \mathrm{~mL} / \mathrm{g}$, in an Osterizer blender at the highest speed for $2 \mathrm{~min}$. This allowed alliinase to transform all of the alliin to known amounts of allicin and other allyl thiosulfinates. The homogenate was divided into $50-\mathrm{mL}$ jars and stored at $-80^{\circ} \mathrm{C}$, under which condition the allyl thiosulfinates have been shown to be stable for at least 24 months [37]. Prior to consumption, the homogenate was thawed overnight at $4{ }^{\circ} \mathrm{C}$, at which temperature the allyl thiosulfinates have been shown to be stable for at least 3 days [30]. After thawing, the homogenate was further macerated with a high speed Polytron homogenizer (Brinkmann, Kinematica AG, Luzern, Switzerland) with a 12-mm generator for $1 \mathrm{~min}$ at speed 6 of 10. This made it possible for the viscous homogenate to pass through the modified tip (drilled to $3 \mathrm{~mm}$, inside diameter) of a 10-mL disposable syringe. At the time of consumption, a specific weight of the homogenate was transferred by syringe into the bottom of one or more size 0 hypromellose (hydroxypropyl methylcellulose) capsules (vegetarian capsules). The bottom of the size 0 capsule rested inside the bottom of a size 00 capsule to prevent aqueous allicin from coming in contact with the throat. The capsule was then closed with the top of a size 00 capsule. Under these conditions, the outer capsule remained firm and tasteless for $6 \mathrm{~min}$. The standard control was $1.4 \mathrm{~g}$ of garlic homogenate, which was made from $0.88 \mathrm{~g}$ of raw garlic $(0.35 \mathrm{~g}$ dry $\mathrm{wt})$.

\subsection{Supplements}

All garlic supplements used in the study were purchased in 2009 at local stores or from online distributors and stored at ambient temperature. Only $\mathrm{C} 1$ was purchased directly from the manufacturer. All were tested by May 2011, within their claimed expiration dates (typically 2 years from the manufacture date, except 3 years for N1 and N4), with two intended exceptions (E6 and N4). Table 1 identifies the garlic supplements used in the study and includes the claims for garlic powder content (sometimes called garlic extract content or garlic dry weight), the actual tablet or capsule weights (average of at least 10 units), standardization claims, if any, and the recommended dose. All labels stated that the products should be consumed with a meal, except for N3. Table 2 gives the complete list of other ingredients for the supplements, with indications for the likely enteric coating agents when not specifically stated. The 13 supplements contained 51 different ingredients other than garlic powder. 
Table 1. Garlic supplements: identification and claims for garlic powder content and standardization. ${ }^{1}$

\begin{tabular}{|c|c|c|c|c|c|c|}
\hline ID & Brand Name and Lot Number & Manufacturer & $\begin{array}{l}\text { Garlic Powder Claim per } \\
\text { Tablet or Capsule (g) }\end{array}$ & $\begin{array}{l}\text { Weight of Tablet } \\
\text { or Capsule }{ }^{2}(\mathrm{~g})\end{array}$ & $\begin{array}{l}\text { Standardization Claims } \\
\text { (per Tablet or Capsule) }\end{array}$ & Daily Dose $^{3}$ \\
\hline \multicolumn{7}{|c|}{ Enteric coated tablets (all claim to be enteric coated) } \\
\hline E1 & Garlicin (584401) & $\begin{array}{c}\text { Nature's Way Products, } \\
\text { Inc., Springville, } \\
\text { UT, USA }\end{array}$ & 0.35 & 0.66 & $3.2 \mathrm{mg}$ allicin & $1 \times 2$ \\
\hline E2 & Garlique (09A301) & $\begin{array}{c}\text { Chattem, Inc., } \\
\text { Chattanooga, TN, USA }\end{array}$ & $(0.40)^{4}$ & 0.67 & $\geq 5.0 \mathrm{mg}$ allicin & $1 \times 1$ \\
\hline E3 & Garlinase Fresh (95178189) & $\begin{array}{l}\text { Enzymatic Therapy, Inc., } \\
\text { Green Bay, WI, USA }\end{array}$ & 0.32 & 0.48 & $11 \mathrm{mg}$ alliin, $5.0 \mathrm{mg}$ allicin & $1 \times 1$ \\
\hline E4 & Garlic-Gold (8097) & $\begin{array}{l}\text { Olympian Labs, Inc., } \\
\text { Scottsdale, AZ, USA }\end{array}$ & 0.60 & 0.99 & $15.6 \mathrm{mg}$ alliin, $7.2 \mathrm{mg}$ allicin & $1 \times 1$ \\
\hline E5 & $\begin{array}{l}\text { Sundown Naturals Odor-Free } \\
\text { Garlic (239029-09) }\end{array}$ & $\begin{array}{l}\text { Sundown, Inc., Boca } \\
\text { Raton, FL, USA }\end{array}$ & 0.40 & 0.74 & none & $1 \times 2-3$ \\
\hline E6 & NOW Pure-Gar Garlic (104872) & $\begin{array}{c}\text { NOW Foods, Glendale } \\
\text { Heights, IL, USA } \\
\text { (manufactured 1999) }\end{array}$ & 0.60 & 0.90 & $5.0 \mathrm{mg}$ allicin & $1 \times 1$ \\
\hline \multicolumn{7}{|c|}{ Normal (non-enteric) tablets } \\
\hline N1 & Kwai forte 300 mg $^{5}$ (02051450) & $\begin{array}{c}\text { Klosterfrau, Cologne, } \\
\text { Germany }\end{array}$ & 0.30 & 0.75 & $3.9 \mathrm{mg}$ alliin, $1.8 \mathrm{mg}$ allicin & $1 \times 3$ \\
\hline N2 & Odor Free Garlic (197348-04) & $\begin{array}{l}\text { Nature's Bounty, Inc., } \\
\text { Bohemia, NY, USA }\end{array}$ & 0.10 & 0.26 & "contains allicin" & $1 \times 3-6$ \\
\hline N3 & $\begin{array}{c}\text { Natural Brand Odorless Garlic } \\
1000 \text { (2522EJ1818) }\end{array}$ & $\begin{array}{l}\text { General Nutrition Corp., } \\
\text { Pittsburgh, PA, USA }\end{array}$ & 1.00 & 1.80 & none & $1 \times 1-2$ \\
\hline N4 & Kwai ${ }^{5}$ (92021901) & $\begin{array}{l}\text { Lichtwer Pharma, } \\
\text { GmbH, Berlin, Germany } \\
\text { (manufactured 1992) }\end{array}$ & 0.10 & 0.27 & $1.3 \mathrm{mg}$ alliin, $0.6 \mathrm{mg}$ allicin & $2 \times 3$ \\
\hline
\end{tabular}


Table 1. Cont.

\begin{tabular}{|c|c|c|c|c|c|c|}
\hline ID & Brand Name and Lot Number & Manufacturer & $\begin{array}{l}\text { Garlic Powder Claim per } \\
\text { Tablet or Capsule (g) }\end{array}$ & $\begin{array}{l}\text { Weight of Tablet } \\
\text { or Capsule }{ }^{2}(g)\end{array}$ & $\begin{array}{l}\text { Standardization Claims } \\
\text { (per Tablet or Capsule) }\end{array}$ & Daily Dose ${ }^{3}$ \\
\hline \multicolumn{7}{|c|}{ Capsules } \\
\hline $\mathrm{C} 1$ & Garlic (00839138) & $\begin{array}{l}\text { Nature's Sunshine } \\
\text { Products, Inc., Spanish } \\
\text { Fork, UT, USA }\end{array}$ & $\begin{array}{l}0.55 \\
\text { fine }^{6}\end{array}$ & 0.67 & none & $1 \times 2$ \\
\hline $\mathrm{C} 2$ & $\begin{array}{l}\text { Deodorized Garlic } 500 \\
\text { (2040348) }\end{array}$ & $\begin{array}{l}\text { Vitamin Shoppe, Inc., } \\
\text { North Bergen, NJ, USA } \\
\text { (Pure-Gar garlic powder) }\end{array}$ & $\begin{array}{c}0.50 \\
\text { fine }\end{array}$ & 0.69 & none & $1-3^{3}$ \\
\hline C3 & GarliPure 500 mg (2037406) & $\begin{array}{l}\text { Natrol, Inc., Chatsworth, } \\
\text { CA, USA (Pure-Gar } \\
\text { garlic powder) }\end{array}$ & $\begin{array}{c}0.50 \\
\text { coarse }^{6}\end{array}$ & 0.68 & $\begin{array}{l}5.0 \mathrm{mg} \text { alliin, } \\
0.75 \mathrm{mg} \text { allicin } 7\end{array}$ & $2 \times 2$ \\
\hline \multicolumn{7}{|c|}{ 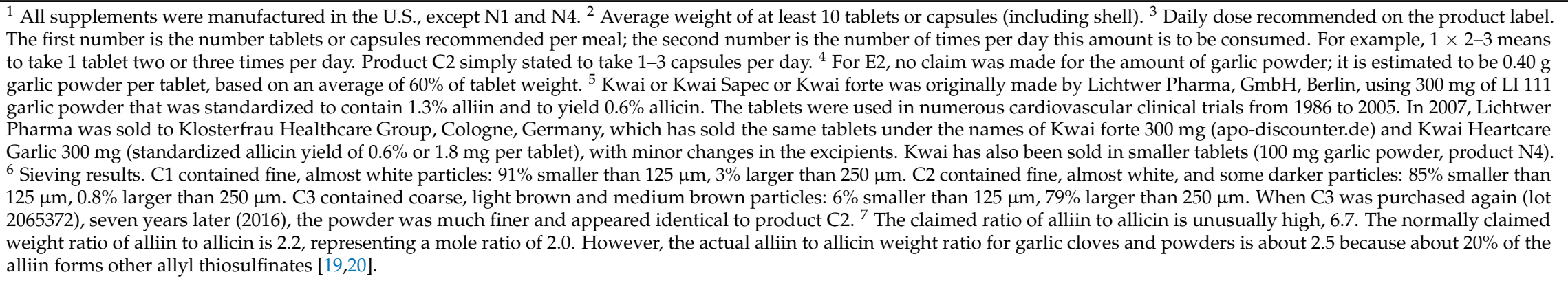 } \\
\hline
\end{tabular}


Table 2. Other ingredients in the garlic supplements, including possible enteric-coating agents: complete list, in the same order as on the label claims.

\begin{tabular}{|c|c|}
\hline Supplement & Other Ingredients \\
\hline \multicolumn{2}{|r|}{ Enteric coated } \\
\hline $\mathrm{E} 1^{1}$ & cellulose, aqueous coating solution, modified cellulose gum, stearic acid ${ }^{2}$, silica \\
\hline E2 & $\begin{array}{l}\text { silicified microcrystalline cellulose, croscarmellose sodium, methacrylic acid, } \\
\text { hypromellose, magnesium stearate, stearic acid }{ }^{2} \text {, magnesium silicate, titanium } \\
\text { dioxide, mineral oil, triacetin }{ }^{2} \text {, polyethylene glycol }{ }^{2} \text {, microcrystalline cellulose, } \\
\text { glycerol monostearate, triethyl citrate }{ }^{2} \text {, sodium lauryl sulfate }\end{array}$ \\
\hline E3 & $\begin{array}{l}\text { cellulose, modified cellulose, modified cellulose gum, silica, titanium dioxide, } \\
\text { calcium stearate, fractionated coconut oil, sodium alginate }{ }^{2} \text {, vegetable glycerin, } \\
\text { stearic acid }{ }^{2}\end{array}$ \\
\hline $\mathrm{E} 4$ & $\begin{array}{l}\text { enteric coating }{ }^{2} \text { (Eudagrit L30D-55, triethyl citrate, methylcellulose), } \\
\text { microcrystalline cellulose, dicalcium phosphate, ascorbyl palmitate, modified } \\
\text { cellulose, silica, stearic acid }{ }^{2}, \text { corn starch }\end{array}$ \\
\hline E5 & $\begin{array}{l}\text { calcium phosphate, cellulose, calcium carbonate, croscarmellose, cellulose } \\
\text { coating }{ }^{2} \text {, titanium dioxide, calcium silicate, food glaze, magnesium stearate, } \\
\text { sodium alginate }^{2}\end{array}$ \\
\hline E6 ${ }^{1}$ & $\begin{array}{l}\text { calcium phosphate, cellulose, magnesium stearate, stearic acid }{ }^{2} \text {, silica, } \\
\text { enteric coating }\end{array}$ \\
\hline \multicolumn{2}{|r|}{ Normal (non-enteric) tablets } \\
\hline N1 & $\begin{array}{l}\text { lactose, cellulose, silica, magnesium stearate, castor oil, polyethylene glycol, } \\
\text { hypromellose, sucrose, magnesium silicate, gelatin, povidone K25, carnauba } \\
\text { wax, bleached wax, quinoline yellow E104, indigo carmine } 132\end{array}$ \\
\hline N2 & $\begin{array}{l}\text { cellulose, dicalcium phosphate, titanium dioxide, silica, magnesium silicate, } \\
\text { calcium carbonate, magnesium stearate, natural flavor }\end{array}$ \\
\hline N3 & calcium carbonate, cellulose, titanium dioxide, acetoglycerides \\
\hline N4 & $\begin{array}{l}\text { lactose, cellulose, silica, magnesium stearate, sucrose, magnesium silicate, } \\
\text { calcium carbonate, gum arabic, shellac, glucose, castor oil, bees wax }\end{array}$ \\
\hline \multicolumn{2}{|r|}{ Capsules } \\
\hline $\mathrm{C} 1$ & gelatin, water \\
\hline $\mathrm{C} 2$ & gelatin, water, magnesium stearate, silicon dioxide \\
\hline $\mathrm{C} 3$ & gelatin, water, magnesium stearate \\
\hline
\end{tabular}

${ }^{1}$ Products E1 and E6 do not list a main enteric coating agent. Later labels for product E1 (ㅇ 2013-(C 2016) omitted the phrase "aqueous coating solution" and included sodium alginate, a common enteric coating agent; however, the newer tablets have a different appearance (less shine) than those used in this study, indicating a change in the coating formulation. ${ }^{2}$ Known enteric coating agents. Stearic acid has additional purposes in tablet formulation. Only product E4 specifically stated which ingredients were used for the enteric coating.

\subsection{Commercially Prepared Garlic Foods}

Three common (purchased at grocery stores) and one less common (black garlic, purchased online) commercially prepared garlic foods were tested for ABB. The manufacturing procedures for all the products inactivates alliinase. Spicy Pickled Garlic (referred to as pickled garlic), manufactured by G.L. Mezzetta, Inc. (Napa Valley, CA, USA) consisted of whole raw cloves suspended in a medium of water, vinegar, crushed chili, and sodium bisulfite; cloves constituted $65 \%$ of the total volume. The $\mathrm{pH}$ of a 1:10 aqueous extract of the cloves was 4.3; the $\mathrm{pH}$ of the undiluted medium was also 4.3. Minced Garlic (referred to as acid-minced garlic), manufactured by Spice World, Inc. (Orlando, FL, USA) consisted of finely minced raw cloves mixed with a minimal amount of water (almost no standing liquid) and phosphoric acid; the $\mathrm{pH}$ of a 1:10 aqueous extract was 3.6. Chopped Garlic (referred to as oil-chopped garlic), manufactured by Christopher Ranch (Gilroy, CA, USA), consisted 
of finely chopped raw garlic mixed with soybean oil, olive oil (almost no standing liquid) and citric acid; the $\mathrm{pH}$ of a 1:10 aqueous extract was 4.3. The manufacturer's web site calls it Chopped Garlic in Oil. Black garlic, manufactured in South Korea and distributed by Black Garlic, Inc. (Hayward, CA, USA), consisted of peeled whole cloves that were black (no additives).

\subsection{Kitchen-Prepared Garlic Foods (Cooked and Raw Diced)}

Roasted. Garlic (California Early variety, Garlic World, Gilroy, CA, USA) was roasted at two different temperatures commonly used for cooking (actual air temperature): $160{ }^{\circ} \mathrm{C}$ for $30 \mathrm{~min}$ and $215^{\circ} \mathrm{C}$ for $60 \mathrm{~min}$. Three garlic bulbs were placed on a rack inside a pre-heated Nesco $6 \mathrm{~L}$ electric roaster oven (Walmart). Wire probes from a calibrated Fluke 52II digital thermometer (Fluke Corp., Everett, WA, USA) were used to measure the temperature (recorded every 5-10 min) of the air inside the oven and the temperature inside the cloves of two different bulbs. The average temperature inside the cloves, after the first $10 \mathrm{~min}$, was $92{ }^{\circ} \mathrm{C}$ for the $160{ }^{\circ} \mathrm{C}$ preparation and $101{ }^{\circ} \mathrm{C}$ for the $215{ }^{\circ} \mathrm{C}$ preparation. Roasting caused $5 \%$ and $25 \%$ loss of total weight, respectively. After cooling, the cloves were peeled and the soft contents thoroughly mashed and mixed. All of the contents of the $160{ }^{\circ} \mathrm{C}$ cloves were soft, but about half of the weight of the $215^{\circ} \mathrm{C}$ cloves was hard and unusable. Roasting decreased the moisture content of the cloves from $63 \%$ to $58 \%$ and $55 \%$, respectively.

Boiled. Unpeeled garlic cloves (California Early variety, Garlic World, Gilroy, CA, USA) were boiled for $4 \mathrm{~min}$ or for $45 \mathrm{~min}$, by adding 24 cloves ( $80 \mathrm{~g}$ for $4 \mathrm{~min}$ or $110 \mathrm{~g}$ for $45 \mathrm{~min}$ ) from six bulbs to $1.5 \mathrm{~L}$ of boiling water. The water resumed boiling about $15 \mathrm{~s}$ after the cloves were added. After boiling, the cloves were cooled, peeled, and thoroughly mashed and mixed. Preliminary studies showed that the temperature inside the cloves reached $95^{\circ} \mathrm{C}$ (boiling point $96^{\circ} \mathrm{C}$ ) by $4 \mathrm{~min}$ if the clove weights were under $5 \mathrm{~g}$ or by $6 \mathrm{~min}$ if the clove weights were 5.5 to $7 \mathrm{~g}$. It was also shown that alliinase activity was completely inhibited in $2 \mathrm{~min}$ for cloves weighing under $5 \mathrm{~g}$. Hence, for the $4 \mathrm{~min}$ preparation, only cloves weighing 1.2 to $5.0 \mathrm{~g}$ were used, while cloves for the $45 \mathrm{~min}$ preparation weighed 1.2 to $9 \mathrm{~g}$. The total weight of the cloves boiled for $4 \mathrm{~min}$ did not change, while the weight of the cloves boiled for $45 \mathrm{~min}$ increased by $5 \%$. To reduce variation, cloves from each of the six bulbs were split into the two groups used for boiling.

Diced (cubed) raw. Raw garlic cloves (California Early variety, Garlic World, Gilroy, CA, USA) were peeled, then placed on a plastic grid of 3-mm lines, and cut with a razor blade into cubes measuring approximately $3 \mathrm{~mm}$ on each side (40 cubes per gram). This size is similar to that of commercial minced garlic. Two cloves from each of the same bulbs used for the boiling preparations were used. The cloves were carefully peeled and cut in order to minimize allicin formation.

\subsection{Special Garlic Extracts}

Protein-free, high-alliin garlic extract (PFHA). A garlic extract was prepared in which $97 \%$ of the soluble protein was removed, without loss of alliin. Garlic cloves (California Early variety, Garlic World, Gilroy, CA, USA) were peeled (100 g), boiled for $15 \mathrm{~min}$ in $1.5 \mathrm{~L}$ water (giving $14 \mathrm{~mL}$ water/g clove after evaporation loss), transferred to an Osterizer blender, homogenized at the highest speed for $1 \mathrm{~min}$, filtered through cheesecloth, centrifuged at $1300 \times \mathrm{g}$ for $20 \mathrm{~min}$, subjected to 11 cycles of freezing at $-22{ }^{\circ} \mathrm{C}$ and thawing, and finally centrifuged at $16,000 \times g$. The soluble protein content decreased from $12.5 \mathrm{mg} / \mathrm{g}$ clove (before boiling) to $0.80 \mathrm{mg} / \mathrm{g}$ clove (before freeze-thawing) to $0.42 \mathrm{mg} / \mathrm{g}$ clove. The final clear extract contained $0.034 \mathrm{mg}$ protein $/ \mathrm{mL}$.

Alliin-free, high-GSAC extract (AFHG). A garlic extract void of alliin and alliin-derived compounds was prepared to examine the effects of GSAC on breath AMS. Cloves $(85 \mathrm{~g})$, from the same 2-kg batch of bulbs that were used to prepare PFHA, were peeled, homogenized ( $2 \mathrm{~min}$ ) in an Osterizer blender after addition of water at $14 \mathrm{~mL} / \mathrm{g}$ (converted all of the alliin to allyl thiosulfinates), filtered through cheesecloth, boiled for $100 \mathrm{~min}$, (causing all of the allyl thiosulfinates and resultant allyl sulfides to evaporate), and centrifuged at $1300 \times g$ for $20 \mathrm{~min}$. Additional water was added as needed during boiling to make up for most of the evaporation loss. The soluble protein content decreased 
from $12.5 \mathrm{mg} / \mathrm{g}$ clove (before homogenization) to $2.4 \mathrm{mg} / \mathrm{g}$ clove ( $81 \%$ loss of protein). The final clear extract contained $0.25 \mathrm{mg}$ protein $/ \mathrm{mL}$.

Alliin-free, high-SAC extract (AFHS). Product AFHG was treated with $\gamma$-glutamyl transpeptidase to convert $95 \%$ of the GSAC to SAC to learn if the two compounds have equal effects on breath AMS. A portion of AFHG $(200 \mathrm{~mL})$ was adjusted to $\mathrm{pH} 8.5$ with $0.1 \mathrm{~N} \mathrm{NaOH}$, followed by the addition of 100 units of equine kidney $\gamma$-glutamyl transpeptidase (9.1 units $/ \mathrm{mg}$ ) (Sigma-Aldrich) and incubation at $37^{\circ} \mathrm{C}$ for $3.5 \mathrm{~h}$.

\subsection{Participants}

A total of 13 self-described healthy persons ( 6 female, 7 male) were recruited for the study in May-June 2009, all of whom continued throughout the 22 months of the study. Persons who had an intestinal disease, used tobacco, or frequently consumed alcohol, were excluded from the study.

The participant age range was 26-62 year (averages: total 35, men 34, women 36), with a body mass index (BMI) range of $22-35 \mathrm{~kg} / \mathrm{m}^{2}$ (averages: total 26 , men 28 , women 25 ). The study was a series of bioassays; hence, it was not blind, nor was there a placebo or randomization Participants were always informed which garlic product they were consuming prior to consumption. Twenty-three types of garlic products were used in 43 tests, with usually 7-13 participants per test. A single set of bioavailability tests required two days to conduct; they were usually conducted two times per week and included 3-4 participants per set. Participants usually participated in two tests per month and were paid for each test. A record of all interactions with the subjects during a test, along with any report of side effects, was maintained on set consumption records. All bioavailability tests with garlic products and garlic extracts, along with the consent form and research protocol, were approved by the Western Institutional Review Board, Olympia, Washington, USA, on 18 March 2009 (study number 1105434).

\subsection{Standard Breakfast Meals and Garlic Product Consumption}

All garlic supplements, the homogenized raw garlic (control), and the extracts, were consumed with either a standardized low-protein meal (LP) or a standardized high-protein meal (HP). The LP meal consisted of two slices of toasted white bread, $19 \mathrm{~g}$ of butter, $30 \mathrm{~g}$ of jam, a banana, and $200 \mathrm{~mL}$ of water; it contained $5.5 \mathrm{~g}$ of protein and $17 \mathrm{~g}$ of fat. The HP meal consisted of a whole wheat tuna sandwich and $200 \mathrm{~mL}$ of whole milk, including two slices of bread, $54 \mathrm{~g}$ of pressed canned albacore solid white tuna, and $34 \mathrm{~g}$ of garlic-free light mayonnaise; it contained $31 \mathrm{~g}$ of protein and $19 \mathrm{~g}$ of fat. The meals were isocaloric ( $460 \mathrm{kcal})$. The gastric $\mathrm{pH}$ is lowest before a meal (av 1.9) and quickly rises (av $14 \mathrm{~min}$ ), depending upon the meal protein content, to a maximum $\mathrm{pH}$ of 4.4-6.7 after starting a meal $[28,42]$. Hence, the supplements were consumed immediately before the LP meal, to allow exposure to approximately the lowest gastric $\mathrm{pH}$ attainable when they are consumed with a meal-or immediately after the HP meal, to allow exposure to a substantially higher gastric $\mathrm{pH}$. The control, in capsules, was always consumed immediately after the LP or HP meals to reduce the chance of stomach disturbance. For the control, gastric $\mathrm{pH}$ was not a concern, as alliinase had been activated before consumption. Garlic foods (cooked garlic, etc.) and their control were consumed inside the LP meal, with the garlic placed between the two slices of buttered bread and the jam omitted. The special extracts (clear aqueous liquids) were consumed with the LP meal.

\subsection{Diet Restrictions}

It was essential to prevent dietary interference with the bioavailability test by restricting the consumption of garlic and onions for two days before each test and for the 1.5 days of each test. The restrictions were as follows: two days before a test, only modest amounts of garlic; one day before the test and during the test, no foods containing garlic or onion, with some exceptions. Some prepared foods listing garlic were found to contain too little garlic to cause breath AMS production: Kraft Miracle Whip, Pace Chunky Salsa, and Doritos Cool Ranch Chips. A small amount of cooked onion caused 
no interference. Prepared foods, such as ketchup, mustard, salad dressing, tomato sauce, and chips, which listed onion as a spice, but not garlic, caused no interference. Participants were discouraged from eating restaurant food unless they were sure garlic and onion were absent from their choices.

On the day of each test, participants were asked to not eat or drink until arriving at the facility, except, if necessary, up to $150 \mathrm{~mL}$ water one hour before arrival. After consuming the standard breakfast meal and garlic product, participants were asked to not eat or drink again until two hours later. However, if they felt discomfort during the two hours, small amounts of non-protein food were permitted. Participants were occasionally asked if they had adhered to these restrictions.

Compliance with the diet restrictions was determined by the absence of AMS and the presence of no more than a modest amount of onion sulfides in a breath sample taken immediately before the test product was consumed. Non-compliance after the test began was monitored by a sudden increase in breath AMS concentration at 2-3 h after consumption of the subsequent meals consumed during the test. If non-compliance was determined, participants were asked to stop the test and repeat it at a later date.

\subsection{Breath Sampling Procedure}

Participants breathed into 1.2-L Tedlar ${ }^{\circledR}$ gas sampling bags (Grace Davison Discovery Sciences, Waukegan, IL, USA), fitted with a septum port, a barbed nickel-plated twist-valve, and a 4-cm length of Tygon ${ }^{\circledR}$ tubing, as a mouthpiece, attached to the valve. They were instructed to exhale a normal breath, starting at the top of the breath (avoiding the natural tendency to first take a deep breath), into the bag, then to empty the bag by flattening it, followed by exhaling a second breath until the bag was at least mostly full and closing the valve. After the flattening, the mouthpiece was placed against the tongue or lip to prevent air from entering the bag until the participant was ready to exhale the second breath. The speed at which one breathes into the bag was found to have no influence on the breath AMS concentration. Participants recorded their name and breath time on each bag.

Whole breath, rather than alveolar breath, was used throughout the study. Although alveolar breath has been shown to contain 18\% higher AMS than whole breath [17], the procedure for sampling alveolar breath was considered too difficult for participants to use away from the laboratory, where most of the 17 breaths per test needed to be collected. Because all tests were conducted in the same manner and because only relative amounts are important, using whole breath was considered sufficient.

\subsection{Breath Bag Quality}

The average rate of disappearance of AMS from the Tedlar ${ }^{\circledR}$ bags was $0.4 \% / \mathrm{h}$ (range $0.05-1.05 \% / \mathrm{h}$ ). The disappearance rate for each bag was determined over a 48 -h period and only the better bags $(<0.50 \%$ loss $/ \mathrm{h}$ ) were used for the breaths that needed to be stored overnight before analysis. Except for the overnight breaths, breaths were usually analyzed within $4-6 \mathrm{~h}$ after sampling. Following these guidelines, losses were considered insignificant and not corrected. Moisture accumulation in the bags was found to have no effect on the AMS concentration.

\subsection{Test Protocol}

After an overnight fast, participants came to the facility, breathed into a bag and then consumed the standardized breakfast meal and the garlic product. After consuming the garlic product, participants left the facility with several empty bags and provided breath samples every hour for the next eight hours, then every two hours, except during sleep, until breath AMS was undetectable (typically 24-30 h), but not longer than $32 \mathrm{~h}$. Participants returned to the facility to deliver breath samples and obtain more bags at about noon and $5 \mathrm{pm}$ of the first day and at about 8 am and $2 \mathrm{pm}$ of the second day. 


\subsection{Breath Analysis for Allyl Methyl Sulfide (AMS)}

Breath samples $(5 \mathrm{~mL}$ ) were injected directly (manually with a 5 -mL gas-tight syringe fitted with a $0.63 \mathrm{~mm}$ side-port needle), one time, into a gas chromatograph (Agilent 6890) fitted with a model 5380 sulfur-selective pulsed flame photometric detector (PFPD, OI Analytical, College Station, TX, USA), PFPD zero-output setting of 10, and a $30 \mathrm{~m} \times 0.32 \mathrm{~mm} \times 4 \mu \mathrm{m}$ SPB-1 Sulfur (bonded polydimethylpolysiloxane) capillary column (Sigma-Aldrich \#24158). Helium was the carrier gas $\left(1.6 \mathrm{~mL} / \mathrm{min}\right.$, constant flow). The column temperature was programmed from $45^{\circ} \mathrm{C}(0.2 \mathrm{~min})$ to $200^{\circ} \mathrm{C}$ $(1.2 \mathrm{~min})$ at $50^{\circ} / \mathrm{min}$, with a hold time of $2 \mathrm{~min}$, giving a retention time of about $4.0 \mathrm{~min}$, a run time of $5 \mathrm{~min}$, and a re-injection time of $11 \mathrm{~min}$. The injection port contained a straight $4 \mathrm{~mm}$ borosilicate liner (Agilent \#19251-60540) and was operated at $175^{\circ} \mathrm{C}$ in the splitless mode, with a purge flow of $45 \mathrm{~mL} / \mathrm{min}$ for $0.8 \mathrm{~min}$. The detector was operated at $250{ }^{\circ} \mathrm{C}$, with the following flow rates: hydrogen $9.5 \mathrm{~mL} / \mathrm{min}$, air $18.5 \mathrm{~mL} / \mathrm{min}$, helium (make-up) $5.5 \mathrm{~mL} / \mathrm{min}$. Due to injection of an overload volume of $5 \mathrm{~mL}$ and a rapid temperature gradient, the baseline did not become stable until 2.9-3.0 min after each injection. Because inserting the column into the detector requires disassembly of the detector and several hours of equilibration time, a $40-\mathrm{cm}$ piece of the column (extension) was attached to the detector, with the other end attached to an Agilent Ultimate Union (G3182-61580). The remainder of the column was then attached to the extension at the union. This allowed for quick removal and replacement of the column for other uses of the gas chromatograph. The PFPD peak area is the square root of the detector response to sulfur. This detector gave about 20 times greater sensitivity (detection limit, 40 area units or $3 \mathrm{ng} / \mathrm{L}$ or $1 \mathrm{ppb}$ at s/n = 2) than the FID (flame ionization detector) detector used in prior allicin bioavailability studies [17], which made it possible to measure the AUC after consuming small amounts of garlic products. AMS is normally absent from human breath [43].

\subsection{AMS Standard Curve}

The stock allyl methyl sulfide vapor standard $(266 \mathrm{ng} / \mathrm{L})$ was prepared by adding $13.0 \mu \mathrm{L}$ of a solution of $88 \mu \mathrm{g}$ allyl methyl sulfide $/ \mathrm{mL}$ in methanol to duplicate 4.3-L glass jugs with lids fitted with septum ports. The concentration in the jugs reached stability by $2-3 \mathrm{~h}$ and remained stable for 24-30 h. Dilutions of this standard gave a curvilinear linear response down to $6 \mathrm{ng} / \mathrm{L}$. Dilutions were prepared by adding various volumes of the stock $(0.25-3 \mathrm{~mL})$ and air $(4.75-2 \mathrm{~mL})$ to a 5-mL syringe and injecting the 5-mL. For volumes less than $1 \mathrm{~mL}$, the stock was added to the 5-mL syringe using a 1-mL syringe. An air-blank was injected daily. When eight standard curves, created over a 14-month period (see examples in Figure 3), were applied to a single set of breath data, the resultant AUC was found to vary by only $5 \%$ (RSD, relative standard deviation), indicating the stability of the PFPD detector response.
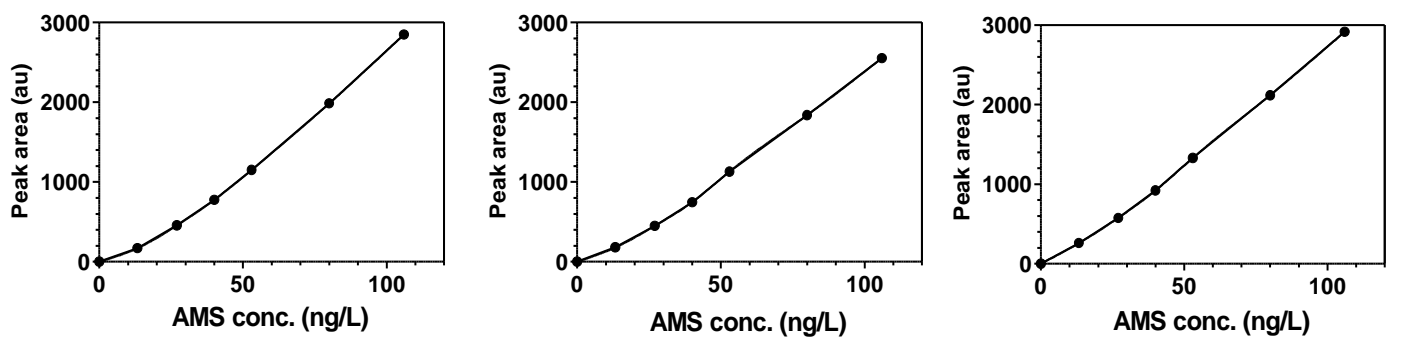

Figure 3. Examples of standard curves for AMS standards, 13-106 ng/L, over the course of 14 months.

\subsection{AMS Concentration Curve (AUC)}

The AUC was measured in ng-h/L by determining the AMS concentration of each breath, based on AMS peak areas and interpolated concentration values (Spline Lowess regression) from the standard curve, followed by determining the AUC over $32 \mathrm{~h}$. All of the calculations were determined using GraphPad Prism 5.0 (San Diego, CA, USA) software. 


\subsection{Allicin Bioavailability or Bioequivalence}

The ABB for each product was based on response factors (RF, RF2, RF3) and calculated as relative response factors (RRF, RRF2, RRF3). RF is the ratio of AUC to the $\mu \mathrm{mol}$ of alliin and alliin-derived dithioallyl compounds (AADD, see Figure 1) consumed. RF2 is the ratio of AUC to the $\mu$ mol of total known $S$-allyl compounds (TKSA) consumed; TKSA is AADD plus GSAC and SAC (G/SAC). RF2 was especially useful when AADD was very low and G/SAC were dominant. RF3 is the ratio of AUC to the weight (g) of product consumed; it was used mainly for "aged" garlic products, such as black garlic, in which most of the alliin has been converted to unidentified S-allyl compounds. The relative response factors were calculated as 100\% times the response factors for the products divided by the response factors for the standard control. When products contained alliinase activity (the supplements and diced raw garlic), allicin bioavailability was determined based on AADD. When the alliinase of garlic products had been inhibited (cooked, acidified), allicin bioequivalence was determined based either on AADD or TKSA. The minimum AUC that could be accurately determined was $15 \mathrm{ng}-\mathrm{h} / \mathrm{L}$, when there was a relatively sharp decline in AMS after Tmax was reached (typical when the product had active alliinase, such as with the control and N1). It was about $45 \mathrm{ng}-\mathrm{h} / \mathrm{L}$ when there was a gradual decline after the Tmax (typical when alliinase was absent, such as with PHFA, AFHG, and alliin). When the product contained active alliinase, $\mathrm{ABB}$ as low as $0.7-11 \%$ could be determined when the AADD consumed was 320-20 $\mu \mathrm{mol}$, respectively. When the product did not contain active alliinase, ABB as low as $2-32 \%$ could be determined when the AADD consumed was 320-20 $\mu$ mol.

\subsection{Dissolution Allicin Release}

The formation and release of allicin from garlic tablets and capsules under simulated gastrointestinal conditions was determined according to the USP-NF (U.S. Pharmacopeia-National Formulary) dissolution method for delayed-release garlic tablets [29]. Using a model VK 700 dissolution apparatus (Agilent/Varian, Palo Alto, CA, USA) equilibrated at $37^{\circ} \mathrm{C}, 2-6$ tablets or capsules (enough to provide $20-30 \mathrm{mg}$ alliin) were placed into each of two covered 1-L round bottom glass vessels containing $750 \mathrm{~mL}$ of $0.1 \mathrm{~N} \mathrm{HCl}$ and paddle-stirred at $100 \mathrm{rpm}$ for $2 \mathrm{~h}$, after which $250 \mathrm{~mL}$ of $0.2 \mathrm{M}$ $\mathrm{Na}_{3} \mathrm{PO}_{4}$ was added and the $\mathrm{pH}$ slightly adjusted, if necessary, giving $1000 \mathrm{~mL}$ at $\mathrm{pH} 6.80 \pm 0.05$. After stirring the buffered medium for $60 \mathrm{~min}, 1 \mathrm{~mL}$ was added to $0.05 \mathrm{~mL}$ of $210 \mathrm{mM}$ (final $10 \mathrm{mM}$ ) carboxymethoxylamine (CMA) (Sigma-Aldrich) alliinase inhibitor, followed by high-performance liquid chromatography (HPLC) analysis of allicin. For tablets that had not completely disintegrated in $60 \mathrm{~min}$ of buffer, an additional $1 \mathrm{~mL}$ aliquot was taken upon complete tablet disintegration. Capsules were loosely wrapped with three winds of plastic-covered wire to keep them from floating. The time to achieve complete disintegration was determined by observation during the dissolution test. The percent dissolution allicin release (DAR) was calculated as the amount of allicin released during the dissolution tests divided by the amount of allicin released when pulverized tablets or capsule contents were incubated $30 \mathrm{~min}$ in water to allow complete allicin formation (allicin potential).

\subsection{Analysis of Garlic Products}

Garlic supplements (tablets and capsule contents) were mortar ground, extracted with $20 \mathrm{mM}$ CMA alliinase inhibitor (50-100 mL/g) for analysis of alliin, GSAC, and SAC, or extracted with $70 \%$ acetonitrile $(\mathrm{ACN}) / 30 \% 40 \mathrm{mM} \mathrm{CMA}(10 \mathrm{~mL} / \mathrm{g})$ for analysis of allyl sulfides. For water activation of alliinase to generate the allyl thiosulfinates, ground tablets or the contents of capsules were mixed with water at $50 \mathrm{~mL} / \mathrm{g}$, rotated rapidly for $10 \mathrm{~min}$, centrifuged for $5 \mathrm{~min}$ at $1000 \times \mathrm{g}$, followed by addition of one volume of ACN (precipitates protein), centrifuged for $3 \mathrm{~min}$ at $16,000 \times g$, and kept at $4{ }^{\circ} \mathrm{C}$ or lower until analyzed [37]. Commercial garlic foods were extracted with a Polytron homogenizer at speed 6 for $15 \mathrm{~s}$, in the presence of either $20 \mathrm{mM} \mathrm{CMA}(10 \mathrm{~mL} / \mathrm{g})$ for analysis of alliin, GSAC, and SAC or in the presence of $75 \% \mathrm{ACN} / 25 \%$ water $(10 \mathrm{~mL} / \mathrm{g})$ for analysis of allyl thiosulfinates and allyl sulfides. The control (raw garlic homogenate) was extracted with $20 \mathrm{mM} \mathrm{CMA}(20 \mathrm{~mL} / \mathrm{g})$ for analysis 
of alliin, GSAC, and SAC, or with 50\% ACN $(10 \mathrm{~mL} / \mathrm{g})$ for analysis of allyl thiosulfinates, or with $70 \%$ ACN $(10 \mathrm{~mL} / \mathrm{g})$ for analysis of allyl sulfides. Diced raw garlic was extracted with a Polytron homogenizer (speed 6, $15 \mathrm{~s}$ ) in the presence of $20 \mathrm{mM} \mathrm{CMA}(25 \mathrm{~mL} / \mathrm{g})$ for analysis of alliin, GSAC, $\mathrm{SAC}$, and, after addition of 1 volume of ACN, for analysis of allyl thiosulfinates and allyl sulfides. Roasted or boiled garlic were extracted with a Polytron homogenizer (speed 6, $15 \mathrm{~s}$ ) in the presence of water $(25 \mathrm{~mL} / \mathrm{g})$ for analysis of alliin, GSAC, and SAC, or in the presence of $75 \% \mathrm{ACN}(10 \mathrm{~mL} / \mathrm{g})$ for analysis of allyl thiosulfinates and allyl sulfides.

Alliin, GSAC, and SAC were analyzed by ion-pair HPLC $(250 \mathrm{~mm} \times 4.6 \mathrm{~mm}$, Agilent/Varian Microsorb-MV 100-5 C18 $250 \mathrm{~mm} \times 4.6 \mathrm{~mm}$ column) at $208 \mathrm{~nm}$ by modification of the method of Arnault et al. [44]. Solvent A consisted of $20 \mathrm{mM}$ sodium heptanesulfonate (ion-pair agent) (Sigma-Aldrich) and $20 \mathrm{mM}$ sodium phosphate monobasic, $\mathrm{pH}$ adjusted to 2.1 with concentrated phosphoric acid. Solvent B was ACN. The column was heated at $38{ }^{\circ} \mathrm{C}$ with a flow rate of $1.0 \mathrm{~mL} / \mathrm{min}$. Gradient: from $0 \% \mathrm{~B}$ to $15 \% \mathrm{~B}$ in $5 \mathrm{~min}$, then to $22 \%$ B by $15 \mathrm{~min}$ and hold until $17 \mathrm{~min}$, then back to $0 \% \mathrm{~B}$ by $18 \mathrm{~min}$ and hold until $24 \mathrm{~min}$. Typical retention times: $\mathrm{L}(-)$-alliin $8.5 \mathrm{~min}, \mathrm{~L}(+)$-alliin $8.8 \mathrm{~min}$, isoalliin $9.1 \mathrm{~min}, \gamma$-glutamyl-S-methylcysteine $11.0 \mathrm{~min}, S$-allylcysteine $13.7 \mathrm{~min}, \gamma$-glutamyl-S-allylcysteine $15.9 \mathrm{~min}, \gamma$-glutamyl-S-cis-1-propenylcysteine $17.3 \mathrm{~min}, \gamma$-glutamyl-S-trans-1-propenylcysteine $17.5 \mathrm{~min}$, $\gamma$-glutamylphenylalanine $18.5 \mathrm{~min}$. The allyl sulfides and allyl thiosulfinates (when their abundance was small) were analyzed, using the same column, isocratically with $70 \% \mathrm{ACN} / 30 \%$ water at $210 \mathrm{~nm}$, as previously described [21] (1991 sulfides pub). When the allyl thiosulfinates were abundant, such as with the control, or when the dissolution allicin release and USP potential allicin (allicin potential) were determined, they were analyzed isocratically with $45 \% \mathrm{ACN} / 55 \%$ water at $240 \mathrm{~nm}$, as previously described [37].

\subsection{Alliinase Assay}

Alliinase activity, as $\mu \mathrm{g}$ allicin produced $\mathrm{min}^{-1} \mathrm{~g}^{-1}$ garlic powder (dry garlic matter), was determined as previously described [30]. Briefly, the capsule contents or mortar-pulverized tablets, without sieving, were added to water at a concentration of $1 \mathrm{~g}$ garlic powder content to $800 \mathrm{~mL}$ water, followed by immediate and vigorous shaking for $7-8 \mathrm{~s}$ and removal of $1 \mathrm{~mL}$ aliquots at 15, 30, 60 , and $120 \mathrm{~s}$ to $0.05 \mathrm{~mL}$ of $210 \mathrm{mM}$ CMA to stop the reaction. After analysis of allicin, the alliinase activity was determined from the time point giving the highest rate of allicin production. If the activity was found to be less than 500, it was redetermined at $200 \mathrm{~mL} / \mathrm{g}$ garlic powder. The garlic powder content for tablets and capsules was based on label claims.

\subsection{Protein Assay}

The protein content of extracts PFHA and AFHG were assayed according to the procedure of Bradford [45], using Brilliant Blue G (Sigma-Aldrich) in methanol as the binding dye and bovine serum albumin (Sigma-Aldrich) as the protein standard (standard curve 10-100 $\mu \mathrm{g} / \mathrm{mL}$ ).

\subsection{Peptide Hydrolysis}

To reveal any possible peptide-bound alliin or SAC, both AFHG extract and roasted garlic prepared at $160{ }^{\circ} \mathrm{C}$ (homogenized with $10 \mathrm{~mL}$ water/g) were incubated while stirring at $\mathrm{pH}$ 8.5 at $37{ }^{\circ} \mathrm{C}$ for one hour with a large excess of either protease from Bacillus licheniformis (9.6 units/mg, Sigma-Aldrich) or alkaline protease from Bacillus subtilis (400 PC units/mg, Bio-Cat, Inc., Troy, VA, USA), followed by one hour of incubation with porcine kidney $\gamma$-glutamyl transpeptidase (3.4 units/mg, Sigma-Aldrich). Aliquots were centrifuged at $16,000 \times g$ and directly assayed for alliin, SAC, and GSAC as described in Section 2.18.

\subsection{Statistical Analysis}

Statistical analyses were conducted using Microsoft Excel Analysis ToolPak software (Redmond, WA, USA). Student's $t$-Test (paired two sample for means; two-tail) was used to determine differences 
between groups. In a few cases, the two-sample $t$-Test was used when $n$ was small $(\leq 4)$. $p$-Values $<0.05$ were considered to be significant. Data are presented as means \pm standard deviation (SD).

\section{Results}

\subsection{AMS Peak Resolution and Interference from Onion Sulfides}

AMS (retention time $4.0 \mathrm{~min}$ ) was well-resolved from other volatile sulfur compounds derived from garlic: allyl mercaptan ( $3.3 \mathrm{~min}$ ), diallyl sulfide ( $4.9 \mathrm{~min})$, and diallyl disulfide ( $6.9 \mathrm{~min})$, although none of these compounds were detected when the breath was sampled at $\geq 0.5 \mathrm{~h}$ after garlic product consumption. AMS was almost baseline separated from XMS (4.2 min), the only volatile sulfur compound detected after consuming $5 \mathrm{~g}$ cooked onion. Upon consuming raw onion, only two peaks were found: XMS and YMS (4.1 min). AMS was not well-separated from YMS; hence, it was important to restrict study participants from eating raw onion. Consumption of small amounts of cooked onion did not cause interference. No sulfur compounds were detected in the breath unless garlic or onion had been consumed.

The identities of XMS and YMS were not confirmed by gas chromatography-mass spectrometry (GC-MS); however, XMS is probably trans-1-propenyl methyl sulfide, which is often found in human breath [43], and YMS co-eluted with pure n-propyl methyl sulfide (Alfa Aesar, Tewksbury, MA, USA). For cooked onion, these sulfides would be metabolites of isoalliin (S-trans-1-propenylcysteine sulfoxide), the main sulfur compound found in onion, and propiin ( $S$-n-propylcysteine sulfoxide), which is only $3-10 \%$ as abundant [46,47]. For raw onion, they would be the metabolites of the respective 1-propenyl and propyl thiosulfinates. In contrast to the much greater abundance of isoalliin than propiin in whole raw onion, consumption of raw onion resulted in 6-fold more YMS than XMS. This probably occurred because, after the action of alliinase and lachrymatory factor synthetase upon crushing raw onion, isoalliin is mainly (80-90\%) transformed to highly volatile lachrymatory factor (propanethial S-oxide, $\mathrm{CH}_{3} \mathrm{CH}_{2} \mathrm{CH}=\mathrm{S}$-O) and only a small amount (5-10\%) to 1-propenyl thiosulfinates, while propiin is transformed only to propyl thiosulfinates [24,46,47]. It is also possible that 1-propenyl thiosulfinates are metabolized to the methyl sulfides less efficiently than are the propyl thiosulfinates. A small amount of XMS was often seen after consuming garlic products, probably due to the presence of a small amount isoalliin in garlic and the subsequent 1-propenyl thiosulfinates found in crushed raw garlic $[19,48]$.

\subsection{Example Breath AMS Concentration Curves}

Typical breath AMS concentration curves for several of the products consumed in the study are illustrated in Figure 4. They depict hourly fluctuations, the Tmax (time to achieve maximum breath concentration), the AUC relative to the amount consumed (AADD), and delays in AMS production $(\mathrm{F}, \mathrm{G}, \mathrm{H}, \mathrm{T})$. They also demonstrate the variation between persons for the standard control (A-C) and $\mathrm{N} 1$ tablets (I-L), the variation between duplicate tests by the same person (C and D), and the effect of a high meal protein content on reduced AUC and delayed AMS production when enteric-coated tablets are consumed $(\mathrm{E}-\mathrm{H})$. The substantial production of breath AMS, even when active garlic alliinase is not present, is shown for both acid-processed and cooked garlic foods (M-P) as well as for extracts and pure $S$-allyl compounds $(\mathrm{Q}-\mathrm{T})$. 

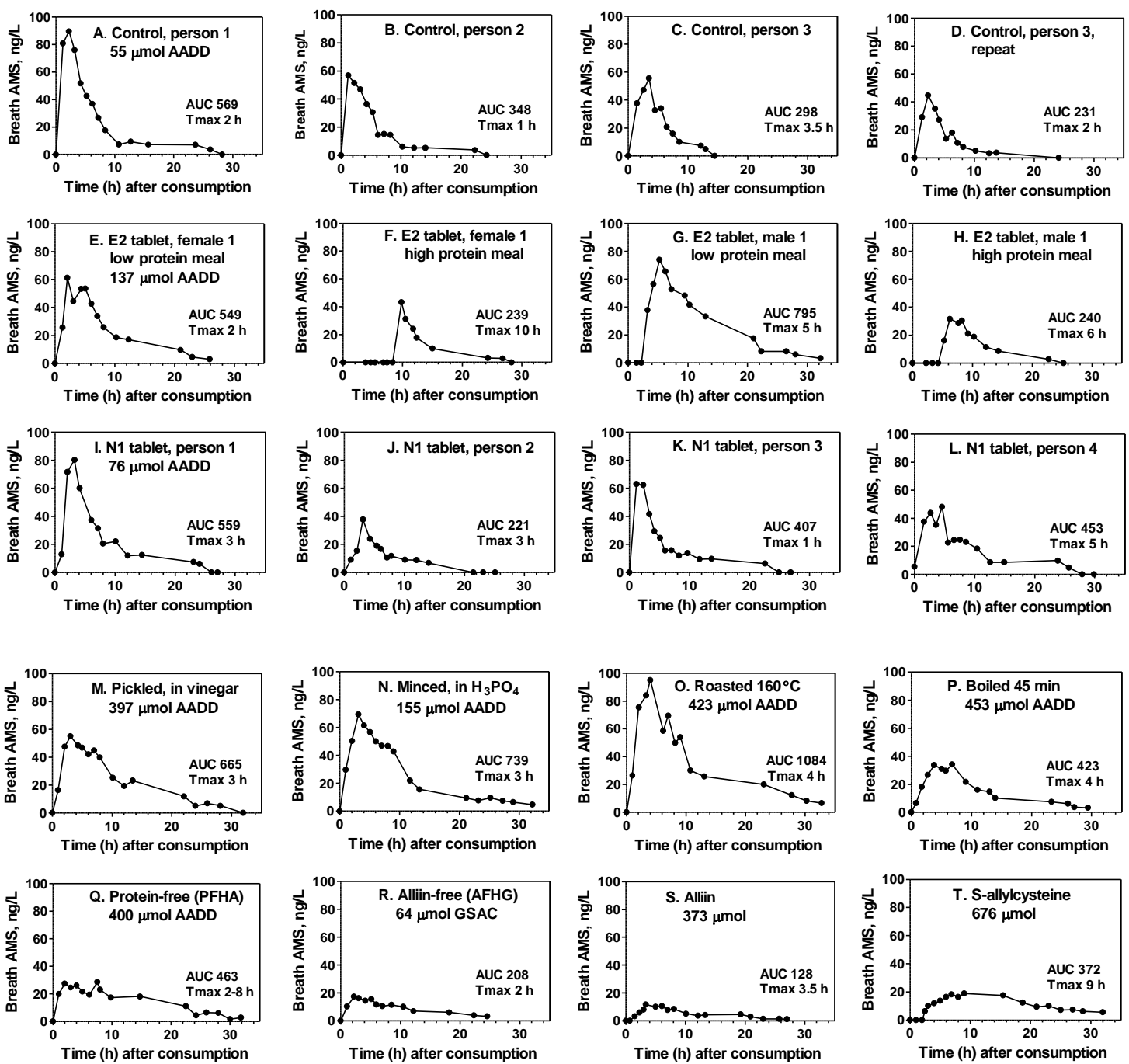

Figure 4. Typical concentration curves for breath AMS, after consumption of various garlic products. (A-D), $1.4 \mathrm{~g}$ of raw garlic homogenate ( $0.88 \mathrm{~g}$ raw garlic) consumed in capsules with low-protein meal (the standard control). (E-H), enteric-coated tablets, brand E2 (2 tablets), consumed with low or high-protein meals by a female or male. (I-L), normal tablets, brand N1 (3 tablets), consumed with low-protein meal (not the same persons as A-D). (M-P), garlic foods consumed with low-protein meals (four different persons): $\mathbf{M}=12 \mathrm{~g}$ pickled garlic; $\mathbf{N}=7 \mathrm{~g}$ acid-minced garlic; $\mathbf{O}=6.1 \mathrm{~g}$ roasted garlic ( $160{ }^{\circ} \mathrm{C}$ for $\left.30 \mathrm{~min}\right) ; \mathbf{P}=5.5 \mathrm{~g}$ boiled garlic $(45 \mathrm{~min})$. (Q-T), garlic extracts and pure compounds: $\mathbf{Q}=$ protein-free high alliin extract (PFHA); $\mathbf{R}=$ alliin-free high GSAC extract (AFHG); $\mathbf{S}=$ pure $\mathrm{L}(+)$-alliin; $\mathrm{T}=$ pure $S$-allylcysteine. $\mathrm{S}$ and $\mathrm{T}$ were consumed by the same person. $\mathrm{Q}$ and $\mathrm{R}$ were consumed by another person, but very similar curves were found when $Q$ and $R$ were consumed by the person who consumed $\mathrm{S}$ and $\mathrm{T}$.

\subsection{Dose Response}

The response of the breath AMS-AUC to consumption of $0.35,0.70,1.4$, and $2.8 \mathrm{~g}$ of the raw homogenate control (0.22-1.76 g raw garlic) under high-protein meal conditions was determined for all 13 participants (Figure 5). The allicin content of the control was 0.87-6.94 mg per dose and was fully present before consumption. The response was dose-dependent $\left(r^{2}=0.9989\right)$ and gave high linearity through $0.35 \mathrm{~g}$. Under low-protein meal conditions, only two doses were used, $0.35 \mathrm{and} 1.4 \mathrm{~g}$, which closely paralleled the result with the high-protein meal. A dose of $1.4 \mathrm{~g}$ with the low-protein meal was chosen as the standard control condition. N1 tablets, where allicin was absent until made 
in the body, were tested at two doses with a high-protein meal. The response was dose-dependent $\left(\mathrm{r}^{2}=0.9975\right)$ and moderately linear.
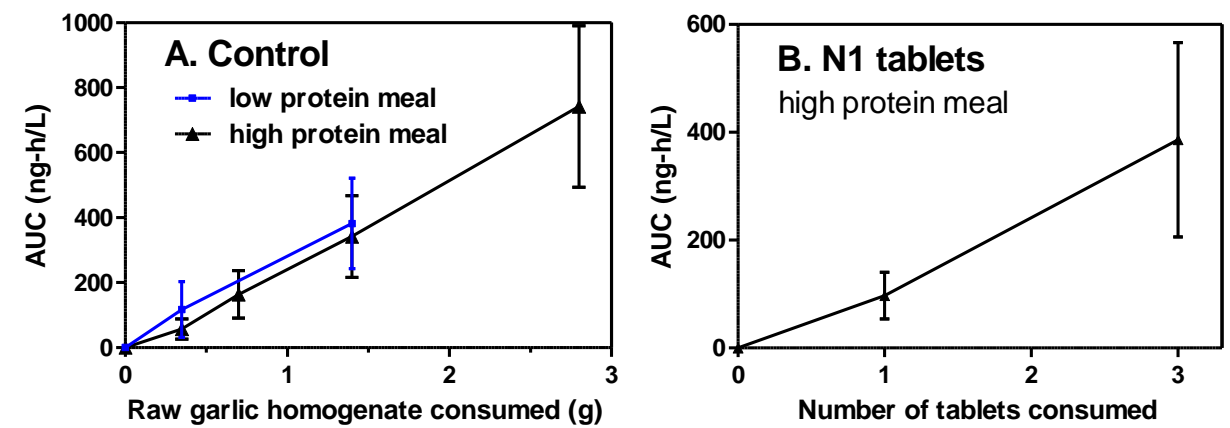

Figure 5. Dose response of the breath AMS concentration curve (AUC) after consumption of A, the control (raw garlic homogenate) or B, N1 tablets, with high- or low-protein meals. Values are means \pm standard deviation (SD) $(n=13)$.

\subsection{Experimental Variation}

The experimental variation is summarized in Table 3. The variation (RSD) in the AMS peak area between triplicate injections of the same breath was $3.4 \%(n=12)$, with no significant difference $(p>0.4)$ between breaths containing a high AMS concentration $(88 \mathrm{ng} / \mathrm{L}$, peak area $2110 \mathrm{au})$, a moderate concentration (42 ng/L, peak area $860 \mathrm{au})$, or a low concentration $(10 \mathrm{ng} / \mathrm{L}$, peak area $180 \mathrm{au})$. The variation between triplicate breaths taken $1 \mathrm{~min}$ apart was a little greater, $5.6 \%$, as determined for four persons, and also includes the variation between replicate injections of the same breath. The average variation in the AUC between all 13 persons consuming the same product was $42 \pm 7.5 \%$ (range 32-63\%) for 21 tests with garlic supplements and the control. However, this variation decreased to $32 \pm 9.9 \%$, a significant $(p<0.001) 24 \%$ decrease, by comparing the AUC for a product to the control AUC value found for each person, the relative response (AUC/ $A U C_{\text {control }}$ ). The variation was independent of meal type and supplement type.

Table 3. Summary of the experimental variation.

\begin{tabular}{lcc}
\hline \multicolumn{1}{c}{ Source of Variation } & Variation (RSD, \%) & Measurement \\
\hline $\begin{array}{l}\text { Between triplicate injections of the } \\
\text { same breath }\end{array}$ & $3.4(n=12$ sets $)$ & Peak area \\
\hline $\begin{array}{l}\text { Between triplicate breaths taken } \\
1 \text { min apart }\end{array}$ & $5.6(n=4$ sets $)$ & Peak area \\
\hline $\begin{array}{l}\text { Between } 13 \text { persons consuming } \\
\text { the same product }\end{array}$ & $42(n=21$ sets $)$ & AUC \\
\hline $\begin{array}{l}\text { Between duplicate consumptions } \\
\text { of a garlic product by the same } \\
\text { person (within person) }\end{array}$ & $17(n=21$ sets $)$ & AUC $_{\text {product }} /$ AUC $_{\text {control }}$ \\
\hline $\begin{array}{l}\text { Between duplicate sets of tests } \\
\text { with } 13 \text { persons (between test sets) }\end{array}$ & $4.7(n=3$ sets $)$ & AUC \\
\hline
\end{tabular}

RSD: relative standard deviation; AUC: area under the 32-h breath AMS concentration curve.

The variation in the AUC for duplicate consumption of a garlic product by the same person was determined three times for all 13 participants, which revealed an overall average within-person variation of $16.9 \%$. When $1.4 \mathrm{~g}$ of the raw homogenate control was consumed with a low-protein meal, the variation was $14.4 \pm 11.5 \%$. When $1.4 \mathrm{~g}$ of the raw homogenate control was consumed with a high-protein meal, the variation was $17.4 \pm 15.4 \%$. When three $\mathrm{N} 1$ tablets were consumed with 
a high-protein meal, the duplicate variation was $18.7 \pm 14.0 \%$. The variation in the average AUC for duplicate sets of tests with the same product, same dose, and same meal type for the 13 persons was $4.7 \%$. Duplicate test sets were conducted three times: $1.4 \mathrm{~g}$ of control with the low-protein meal (1.2\% RSD), $1.4 \mathrm{~g}$ of control with the high-protein meal (3.9\% RSD), and three N1 tablets with the high-protein meal (9.0\% RSD).

\subsection{Composition}

The TKSA content of the garlic products consumed in the study is described in Table 4. Alliin was absent from the homogenized raw garlic used as the control because it had been converted to allicin and other allyl thiosulfinates during homogenization; however, the original alliin content of the cloves—calculated from the allyl thiosulfinates produced-was $154 \mu \mathrm{mol} / \mathrm{g}$ dry wt $(60.9 \mu \mathrm{mol} / \mathrm{g}$ fr wt) or $27.3 \mathrm{mg} / \mathrm{g}$ dry wt $(10.8 \mathrm{mg} / \mathrm{g}$ fr wt), which values are close to the average values reported for 46 samples: $156 \pm 33 \mu \mathrm{mol} / \mathrm{g}$ dry wt $(54.7 \mu \mathrm{mol} / \mathrm{g}$ fr wt $)$ or $27.7 \pm 5.8 \mathrm{mg} / \mathrm{g}$ dry wt $(9.7 \pm 2.0 \mathrm{mg} / \mathrm{g}$ fr wt) [49-51]. Among the garlic supplements and foods, alliin was usually the most abundant $S$-allyl compound, typically accounting for 65 to $85 \%$ of the total, but it was lower, 30-40\%, for products E5, $\mathrm{N} 2$, and oil-chopped garlic, while being undetectable in black garlic. The alliin concentration in the garlic powders used in the supplements varied 7.5-fold $(6.5-49 ; 21.0 \pm 12.2 \mathrm{mg} / \mathrm{g}$ ) (Table 4, second set of alliin values). This range is substantially broader than the 2-fold range consistently found for garlic bulbs among sets of 13,9, and 24 cultivars [49-51]; this indicates variable loss of alliin upon manufacture of garlic powders and validates the need for the allicin potential or alliin standardization label claims found for most brands (Table 1).

Alliin consists of both the $\mathrm{L}(+)$-isomer and the $\mathrm{L}(-)$-isomer. The $\mathrm{L}(-)$-isomer, which tends to increase with age, constituted $<6 \%$ of the alliin for most of the products, the exceptions being E4 ( $8 \%$ ), E5 (14\%), E6 (24\%), N1 (8\%), N2 (10\%), N4 (19\%), C2 (9\%), C3 (15\%), pickled (11\%), acid-minced (18\%), and oil-chopped (24\%). Second in abundance was GSAC, which accounted for 8-35\% of the total $S$-allyl, with E5 and N2 being exceptionally high (57-58\%). SAC accounted for 2-6\% of the total, except $13 \%$ for C3 and $86 \%$ for black garlic. Of the total SAC (GSAC + SAC), SAC typically accounted for $1-15 \%$, exceptions being E3 (36\%), pickled garlic (44\%), and black garlic (87\%).

As intended, alliin, allyl thiosulfinates and allyl polysulfides were absent from the AFHG and AFHS extracts, and treatment of AFHG with $\gamma$-glutamyl transpeptidase to produce AFHS converted 95\% of the GSAC to SAC. Allicin and other allyl thiosulfinates were absent from all supplements because alliinase had not been activated. Upon activation in water (Section 2.18), the following average yields and ranges were found $(n=13$, not shown in Table 4): (a) as $\mathrm{mg} / \mathrm{g}$ garlic powder (powder weight claims are in Table 1) —allicin $7.8 \pm 4.8$ (2.4-16.8), allyl methyl thiosulfinates $1.7 \pm 1.1(0.5-4.6)$, allyl trans-1-propenyl thiosulfinates $0.3 \pm 0.4(0.01-1.4)$; (b) as $\mathrm{mg} /$ tablet or capsule-allicin $3.6 \pm 2.9$ (0.3-10.8), allyl methyl thiosulfinates $0.8 \pm 0.6(0.05-2.1)$, allyl trans-1-propenyl thiosulfinates $0.2 \pm 0.2$ (0.002-0.6). The allyl thiosulfinates were absent from homogenized commercial garlic foods because alliinase had been inhibited by the processing acids (vinegar, phosphoric acid, citric acid). They were abundant in the homogenized control, where allicin accounted for $80.3 \mathrm{~S}$-allyl mol \% or $70.3 \mathrm{wt} \%$ of the allyl thiosulfinates, and they were slightly present in the roasted, boiled, and diced raw garlic preparations. Dicing cloves into $3 \mathrm{~mm}$ cubes caused only about $3 \%$ of the alliin to be transformed to thiosulfinates, while homogenization in water caused complete transformation.

The allyl polysulfides, which are metabolized to AMS to the same extent as allicin [17], were significant ( $>5 \%$ of the AADD) only in E5 (14\%), acid-minced garlic (14\%), and oil-chopped garlic (51\%). Oil-chopped garlic uniquely contained cyclic vinyldithiins, 2-vinyl-4H-1,3-dithiin and 3-vinyl-4H-1,2-dithiin $(5.4 \mu \mathrm{mol} / 2.5 \mathrm{~g})$, which are not metabolized to AMS, and a small amount of ajoene $(0.1 \mu \mathrm{mol} / 2.5 \mathrm{~g})$, which is metabolized to AMS [17]. Of these products, the diallyl sulfides comprised $82-94 \%$ of the total allyl sulfides, with diallyl trisulfide always dominant, as detailed in the footnotes of Table 4. AMS itself was not found in any product except in oil-chopped garlic $(0.7 \%$ of the AADD). 
Table 4. Composition of the garlic products: $S$-allyl ${ }^{1}$ compounds, as $\mu \mathrm{mol}$ of $S$-allyl per dose consumed.

\begin{tabular}{|c|c|c|c|c|c|c|c|c|}
\hline Code or Name & Dose & Alliin ${ }^{2}$ & $\begin{array}{c}\text { Allyl } \\
\text { Thiosulfinates }\end{array}$ & $\begin{array}{c}\text { Allyl } \\
\text { Polysulfides }\end{array}$ & GSAC & SAC & AADD $^{5}$ & TKSA $^{6}$ \\
\hline $\begin{array}{l}\text { Control, raw } \\
\text { homogenate }\end{array}$ & $1.4 \mathrm{~g}^{7}$ & nd, $<0.2$ & $53.3^{3}$ & $1.4^{4}$ & 10.7 & 0.13 & 54.7 & 65.5 \\
\hline \multicolumn{9}{|c|}{ Garlic supplements } \\
\hline \multicolumn{9}{|c|}{ Enteric tablets } \\
\hline E1 & $2 \mathrm{tab}$ & $132(33)^{2}$ & $\mathrm{nd},<0.1$ & 0.4 & 33.2 & 6.0 & 132 & 171 \\
\hline E2 & $2 \mathrm{tab}$ & $134(30)$ & nd, $<0.1$ & 2.4 & 12.9 & 5.3 & 137 & 155 \\
\hline E3 & $3 \mathrm{tab}$ & $264(49)$ & nd, $<0.1$ & $13.5^{4}$ & 29.3 & 16.4 & 278 & 323 \\
\hline $\mathrm{E} 4$ & $2 \mathrm{tab}$ & $174(26)$ & nd, $<0.1$ & 5.8 & 63.6 & 10.6 & 180 & 254 \\
\hline E5 & $3 \mathrm{tab}$ & $44(6.5)$ & nd, $<0.1$ & 7.3 & 62.7 & 6.8 & 52 & 121 \\
\hline E6 & $2 \mathrm{tab}$ & $106(16)$ & nd, $<0.1$ & 3.9 & 41.0 & 5.8 & 110 & 157 \\
\hline \multicolumn{9}{|c|}{ Normal tablets } \\
\hline N1 & 3 tab & $72(14)$ & nd, $<0.1$ & 3.8 & 48.5 & 4.1 & 75.8 & 128 \\
\hline N2 & 9 tab & $40(7.9)^{2}$ & nd, $<0.1$ & 5.6 & 52.9 & 4.3 & 45.2 & 102 \\
\hline N3 & $1 \mathrm{tab}$ & $155(28)$ & nd, $<0.1$ & 0.5 & 44.7 & 7.7 & 155 & 207 \\
\hline N4 & 9 tab & $57(11)$ & nd, $<0.1$ & 2.4 & 47.4 & 6.4 & 58.8 & 113 \\
\hline \multicolumn{9}{|c|}{ Capsules } \\
\hline $\mathrm{C} 1$ & 1 cap & $73(24)$ & nd, $<0.1$ & 0.2 & 28.4 & 5.1 & 73.0 & 106 \\
\hline $\mathrm{C} 2$ & 3 cap & $167(20)$ & nd, $<0.1$ & 2.5 & 97.7 & 14.1 & 169 & 281 \\
\hline $\mathrm{C} 3$ & 4 cap & $98(8.7)$ & $\mathrm{nd},<0.1$ & 1.9 & 77.5 & 26.1 & 99.5 & 203 \\
\hline \multicolumn{9}{|c|}{ Commercial garlic foods } \\
\hline Pickled $^{8}$ & $12 \mathrm{~g}$ & 388 & nd, $<0.2$ & 9.0 & 32.6 & 25.7 & 397 & 455 \\
\hline Acid-minced & $7 \mathrm{~g}$ & 134 & nd, $<0.2$ & $21^{4}$ & 81.9 & 14.5 & 155 & 251 \\
\hline Oil-chopped & $2.5 \mathrm{~g}$ & 36 & nd, $<0.2$ & $36^{4}$ & 31.5 & 10.8 & 71.5 & 114 \\
\hline Black garlic & $10.2 \mathrm{~g}$ & nd, $<2$ & nd, $<0.2$ & 0.8 & 5.9 & 40.1 & 0.8 & 46.8 \\
\hline \multicolumn{9}{|c|}{ Kitchen-prepared garlic foods } \\
\hline Roasted $160^{\circ} \mathrm{C}$ & $6.1 \mathrm{~g}$ & 400 & 4.0 & $19.6^{4}$ & 92.7 & 5.4 & 423 & 521 \\
\hline Roasted $215^{\circ} \mathrm{C}$ & $5.5 \mathrm{~g}$ & 400 & 0.4 & 7.9 & 82.0 & 8.6 & 409 & 499 \\
\hline Boiled 4 min & $7.6 \mathrm{~g}$ & 451 & 2.6 & 1.7 & 97.3 & 6.2 & 455 & 558 \\
\hline Boiled $45 \mathrm{~min}$ & $5.5 \mathrm{~g}$ & 450 & 0.2 & 2.2 & 86.4 & 0.9 & 452 & 540 \\
\hline Raw, diced & $1.5 \mathrm{~g}$ & 110 & 2.1 & $\mathrm{nd},<0.2$ & 24.5 & 3.2 & 112 & 140 \\
\hline \multicolumn{9}{|c|}{ Special extracts $^{9}$} \\
\hline PFHA & $68 \mathrm{~mL}$ & 399 & nd, $<0.1$ & 0.05 & 68.7 & 2.7 & 399 & 470 \\
\hline AFHG & $57 \mathrm{~mL}$ & nd, $<0.4$ & nd, $<0.1$ & $\mathrm{nd},<0.03$ & 63.6 & 7.0 & nd, $<0.5$ & 70.6 \\
\hline AFHS & $57 \mathrm{~mL}$ & nd, $<0.4$ & nd, $<0.1$ & $\mathrm{nd},<0.03$ & 3.4 & 67.2 & nd, $<0.5$ & 70.6 \\
\hline $\mathrm{AFHG}+\mathrm{SAC}$ & $57 \mathrm{~mL}$ & nd, $<0.4$ & nd, $<0.1$ & $\mathrm{nd},<0.03$ & 63.6 & 148 & nd, $<0.5$ & 212 \\
\hline
\end{tabular}

${ }^{1}$ Allicin and the diallyl polysulfides have two $S$-allyl groups per molecule; allyl methyl thiosulfinates, allyl methyl polysulfides, alliin, $\gamma$-glutamyl-S-allylcysteine (GSAC) and S-allylcysteine (SAC) have one S-allyl. ${ }^{2}$ For alliin, a second set of values is included (in parentheses) for the supplements: mg alliin per gram garlic powder content claimed (Table 1); for product N2 the garlic powder content was not stated, but it was estimated (Table 1). ${ }^{3}$ Allyl thiosulfinates $=$ sum of allicin, allyl methyl thiosulfinates, and allyl-trans-1-propenyl thiosulfinates. Distribution for the control product, as mol \% of S-allyl (allicin has two per molecule) and as mol \% of compounds = allicin $80.3 \%$ and $67.1 \%$, allyl methyl thiosulfinates $17.0 \%$ and $28.3 \%$, and allyl-trans-1-propenyl thiosulfinates $2.7 \%$ and $4.6 \%$. ${ }^{4}$ Allyl polysulfides $=$ sum of diallyl di-, tri- and tetrasulfides $\left(\mathrm{DAS}_{2}, \mathrm{DAS}_{3}, \mathrm{DAS}_{4}\right)$ and allyl methyl di-, tri-, and tetrasulfides $\left(\mathrm{AMS}_{2}, \mathrm{AMS}_{3}, \mathrm{AMS}_{4}\right.$ ). Diallyl sulfide (DAS) was typically $<3 \%$ of the total allyl sulfides, and AMS was undetectable. Distribution for the control and the more abundant samples, as $S$-allyl mol \%: control, $\mathrm{DAS}_{2}$ $72 \%, \mathrm{DAS}_{3} 25 \%, \mathrm{AMS}_{3} 3 \%$; E3, $\mathrm{DAS}_{2} 22 \%, \mathrm{DAS}_{3} 38 \%, \mathrm{DAS}_{4} 22 \%, \mathrm{AMS}_{2} \mathrm{3} \%, \mathrm{AMS}_{3} 10 \%, \mathrm{AMS}_{4} 5 \%$; Acid-minced, $\mathrm{DAS}_{2} 7 \%, \mathrm{DAS}_{3} 69 \%, \mathrm{DAS}_{4} 18 \%, \mathrm{AMS}_{2}<1 \%, \mathrm{AMS}_{3}$ 4\%, $\mathrm{AMS}_{4}$ 2\%; Oil-chopped, $\mathrm{DAS}_{2} 28 \%, \mathrm{DAS}_{3}$ 51\%, $\mathrm{DAS}_{4}$ $8 \%, \mathrm{AMS}_{2} 1 \%, \mathrm{AMS}_{3} 10 \%, \mathrm{AMS}_{4} 2 \%$, ajoene $0.3 \%$; Roasted $160{ }^{\circ} \mathrm{C}, \mathrm{DAS}_{2} 16 \%, \mathrm{DAS}_{3} 70 \%, \mathrm{DAS}_{4} 8 \%, \mathrm{AMS}_{2}<1 \%$, $\mathrm{AMS}_{3} 6 \%$, AMS 4 1\%. ${ }^{5} \mathrm{AADD}=$ alliin and alliin-derived dithioallyl compounds (alliin, allyl thiosulfinates, allyl polysulfides), expressed as $\mu \mathrm{mol} S$-allyl per dose consumed. ${ }^{6}$ TKSA $=$ total known $S$-allyl compounds (AADD + GSAC + SAC), expressed as $\mu \mathrm{mol} S$-allyl per dose consumed. ${ }^{7}$ Control: $1.4 \mathrm{~g}$ of homogenate obtained from $0.88 \mathrm{~g}$ raw garlic $\left(0.35 \mathrm{~g}\right.$ dry wt). ${ }^{8}$ The liquid in which the pickled garlic was immersed (35\% of the container contents), although not normally consumed, contained substantial amounts of alliin (43\% of the container contents), GSAC $(43 \%)$, and SAC $(41 \%)$, as the result of diffusion. ${ }^{9}$ PFHA = protein-free, high alliin extract. AFHG = alliin-free, high GSAC extract. AFHS = alliin-free, high SAC extract.

\subsection{Control: Allicin Bioavailability or Bioequivalence}

The response factor (RF) for $1.4 \mathrm{~g}$ of the control was used for determining the $\mathrm{ABB}$ of all other products. Hence, it was important to establish its variation between duplicate tests, its variation with respect to meal types, its variation with the mode of consumption, and its variation over the duration 
of the study. The results for the individual duplicate tests and their averages for consumption with the high-protein or low-protein meals are shown in Table 5. The variation in the AUC and RF between duplicate tests was low for both the high-protein meal (RSD 3.9\%) and the low-protein meal (RSD $1.2 \%)$. Compared to the low-protein meal, consuming the control with a high-protein meal significantly decreased ( $p=0.023$ ) the RF by $18 \%$ (7.37 vs. 6.25), delayed the Tmax by $0.7 \mathrm{~h}$ and decreased the Cmax by $25 \%$. Apparently, some of the allicin binds to or reacts with the milk protein or tuna protein or other components in the high-protein meal without forming a reaction product that can be transformed to AMS. The RF was not significantly different between men and women for either the low-protein tests $(p=0.56)$ or the high-protein tests $(p=0.78)$.

Table 5. Breath AMS after consumption of the control (raw garlic homogenate) at the standard dose. ${ }^{1,2}$

\begin{tabular}{|c|c|c|c|c|c|c|c|c|}
\hline Test & $\begin{array}{c}\text { Meal } \\
\text { Protein }\end{array}$ & Mode & $n$ & $\operatorname{Tmax}(\mathrm{h})$ & $\begin{array}{l}\text { Cmax } \\
(\mathrm{ng} / \mathrm{L})\end{array}$ & $\begin{array}{l}\% \text { Cmax } \\
\text { at } 1 h^{3}\end{array}$ & $\begin{array}{l}\mathrm{AUC}^{4} \\
(\mathrm{ng}-\mathrm{h} / \mathrm{L})\end{array}$ & $\begin{array}{c}\text { RF } \\
\text { (AUC/AADD) }\end{array}$ \\
\hline $1 \mathrm{a}$ & high & capsules & 13 & $3.1 \pm 1.0$ & $54 \pm 20$ & $31 \pm 28$ & $351 \pm 143$ & $6.41 \pm 2.62$ \\
\hline $1 b$ & high & capsules & 13 & $3.5 \pm 1.1$ & $47 \pm 13$ & $25 \pm 16$ & $332 \pm 108$ & $6.08 \pm 1.97$ \\
\hline $1 \mathrm{av}$ & high & capsules & 13 & $3.3 \pm 0.95^{\mathrm{a}}$ & $51 \pm 15^{\mathrm{c}}$ & $28 \pm 18^{t}$ & $342 \pm 119^{a}$ & $6.25 \pm 2.17^{\mathrm{a}}$ \\
\hline $2 a$ & low & capsules & 13 & $2.5 \pm 0.6$ & $69 \pm 21$ & $34 \pm 21$ & $399 \pm 142$ & $7.30 \pm 2.60$ \\
\hline $2 b$ & low & capsules & 13 & $2.6 \pm 0.6$ & $69 \pm 29$ & $49 \pm 26$ & $406 \pm 162$ & $7.43 \pm 2.97$ \\
\hline $2 \mathrm{av}$ & low & capsules & 13 & $2.6 \pm 0.45^{\mathrm{a}}$ & $68 \pm 22^{c}$ & $41 \pm 20^{t}$ & $403 \pm 144^{\mathrm{a}}$ & $7.37 \pm 2.64^{a}$ \\
\hline $2 c^{2}$ & low & capsules & 13 & $2.7 \pm 0.8$ & $51 \pm 15$ & $44 \pm 24$ & $342 \pm 113$ & $6.25 \pm 2.07$ \\
\hline 2 final $^{5}$ & low & capsules & 13 & $2.6 \pm 0.46^{\mathrm{c}}$ & $63 \pm 19^{n}$ & $42 \pm 17^{c}$ & $383 \pm 131^{n}$ & $6.99 \pm 2.39^{n, 6}$ \\
\hline $3^{7}$ & low & sandwich & 13 & $1.4 \pm 0.8^{c}$ & $60 \pm 20^{n}$ & $88 \pm 13^{c}$ & $400 \pm 157^{n}$ & $7.31 \pm 2.87^{n}$ \\
\hline
\end{tabular}

${ }^{1}$ Standard dose: $1.4 \mathrm{~g}$ homogenate from $0.88 \mathrm{~g}$ raw garlic $(0.35 \mathrm{~g}$ dry $\mathrm{wt})$; AADD $=54.7 \mu \mathrm{mol} S$-allyl. ${ }^{2}$ Tests $1 \mathrm{a}$ to $2 \mathrm{~b}$ (four tests) were conducted over a two month period. Tests $2 \mathrm{a}$ and $2 \mathrm{~b}$ were conducted the same month. Test $2 \mathrm{c}$ was conducted nine months after tests $2 a$ and $2 b$. Test 3 was conducted one month after test $2 c$. Values are mean $\pm S D$ (standard deviation). Statistical comparisons (share same letter) were made between (1) capsules consumed with high or low-protein meals ( 1 av vs. 2 av) and (2) consumption in capsules or sandwich for the low-protein meal (2 final vs. test 3). Designations for significance: $\mathrm{n}=$ not significant $(p>0.05) ; \mathrm{t}=$ trend $(p=0.05-0.1), \mathrm{a}=p<0.05$, $\mathrm{c}=p<0.001 .{ }^{3}$ The $\%$ Cmax at $1 \mathrm{~h}$ value provides an evaluation of Tmin; the true Tmin is often not known because the first breath sampled after consuming the product was usually taken at $1 \mathrm{~h} .{ }^{4}$ AUC $=$ area under the $32 \mathrm{~h}$ concentration curve for breath AMS. ${ }^{5}$ The standard control: average for all three tests conducted with the low-protein meal in capsules $(2 \mathrm{a}, 2 \mathrm{~b}, 2 \mathrm{c}) .{ }^{6}$ The individual average response factor values (RF) for all 13 participants were, from low to high: $2.49,4.37,4.80,4.93,5.12,7.31,7.82,7.97,8.10,8.72,9.42,9.90,9.92$ (av 6.99). ${ }^{7}$ In test 3, the garlic homogenate was placed directly inside the bread and butter sandwich, immediately before consumption, rather than inside capsules.

The control was also consumed in the same two modes in which the various garlic products were consumed. Similar to the consumption of supplements, it was consumed in capsules, giving the gastrointestinal tract initial contact with allicin and other garlic compounds. Garlic foods were consumed inside a low-protein sandwich, giving the mouth initial contact with the garlic compounds; hence, the control was also consumed inside the same sandwich. The RF for the control consumed inside the sandwich (Table 5, test 3) was not found to be significantly different $(p=0.48)$ than consumption in capsules (7.31 vs. 6.99). As expected, consumption in a bread sandwich significantly decreased the Tmax from $2.6 \mathrm{~h}$ to $1.4 \mathrm{~h}$ and doubled the breath AMS concentration at $1 \mathrm{~h}$ after consumption (\% of Cmax at $1 \mathrm{~h}$, an evaluation of Tmin).

It was critical to the validity of the bioavailability control to consume it under conditions that allowed for maximum allicin availability (maximum RF). Based on the factors presented in Table 5, the standard control RF used was the value found upon consumption of the control in capsules with the low-protein meal (test 2 ). Tests $2 \mathrm{a}$ and $2 \mathrm{~b}$ were conducted just prior to the tests with the supplements. Because of the long duration needed to conduct most of the supplement tests, 10 months, an additional standard control test (test 2c) was conducted 9 months after the initial tests. The average RF for all three standard tests (test 2, final $=6.99 \pm 2.39$ ) was used for determining ABB for all the garlic products, regardless of the type of meal with which they were consumed. 


\subsection{Garlic Supplements: Allicin Bioavailability}

\subsubsection{Dose Basis}

The dose used for the supplement bioavailability tests was not based on manufacturer recommendations (Table 1), which varied from 1-6 units per day (garlic powder range of 0.3 to $2.0 \mathrm{~g}$, average 1.0) or from 1-3 units per meal (garlic powder range of $0.1-1.5 \mathrm{~g}$, average $0.6 \mathrm{~g}$ ). Rather, it was based on the amount needed to give an AUC value within or near the tested linear range that was found for the control (100-750 ng-h/L, Figure 5a), as determined from a preliminary test for each product with a person who gave a typical response. It was also desired to consume at least two units to obtain a better average response. In one case, N3, only 1 tablet was consumed because of its very large size (1.8 g) and high AUC. If there was low alliinase activity, a higher dose was used. Typically, the dose consumed was 1-2 times the recommended daily dose or 2-3 times the recommended dose per meal.

\subsubsection{Enteric-Coated Tablets}

Under low-protein meal conditions, allicin bioavailability from brands E1, E4, and E5 was not significantly different from that of the $100 \%$ bioavailability control, but the bioavailability for brands E2 and E3 was significantly lower, especially for E3 (Table 6). Four of the five brands gave medium to high allicin bioavailability ( $>65 \%$ ), while E3 gave moderate bioavailability (35-65\%). Even brand E6, which was 12 years old, also gave moderate bioavailability. The delay in tablet disintegration and allicin formation caused by the enteric coatings is indicated by both the Tmax and the Tmin (the first measured time for AMS to appear in the breath), relative to the garlic homogenate control that contained allicin before consumption. However, because the first breath was not sampled until one hour after consumption, the true Tmin is not known for any garlic product with a Tmin of less than $1 \mathrm{~h}$. The true Tmin for the control was determined for one person by taking breath samples every 6-8 $\mathrm{min}$ for the first hour and was found to be $26 \mathrm{~min}$ if consumed immediately after the low-protein meal or $15 \mathrm{~min}$ if consumed immediately before the same meal. As learned from the \% of Cmax at $1 \mathrm{~h}$, which was $35-50 \%$ among products with a designated Tmin of less than about $1 \mathrm{~h}$, it is apparent that the true Tmin for these products is indeed less than $1 \mathrm{~h}$. The Tmin for the low-protein meal was delayed, relative to the control, by about $1.5-2.0 \mathrm{~h}$ for brands E1 and E2, with similar delays for the Tmax. However, for brands E3, E4, and E5, the Tmin and Tmax were not significantly different from the control, indicating that the coatings of these products did not delay tablet disintegration in vivo, even though that was their intended purpose.

Three of the EC brands, E1, E2, E3, were also consumed with the high-protein meal. All three gave significantly lower bioavailability than the low-protein control and significantly lower bioavailability than the same product consumed with the low-protein meal. Brands E2 and E3 gave low bioavailability $(<35 \%)$ with the high-protein meal. The Tmin and Tmax for E1 and E2 were increased (delayed) by 4-8 $\mathrm{h}$ relative to the control and by $3-5.6 \mathrm{~h}$ compared to consumption with the low-protein meal. Even for product E3, which gave no delay in the Tmin and Tmax for the low-protein meal, the high-protein meal caused a $1.5 \mathrm{~h}$ delay in the Tmin and a $2 \mathrm{~h}$ delay in the Tmax. For E1, the decreased bioavailability and greatly delayed (by $7 \mathrm{~h}$ ) tablet disintegration time caused by the high-protein meal (54 $\mathrm{g}$ tuna in whole wheat sandwich plus milk, $31 \mathrm{~g}$ total protein), were not caused by the low-protein meal (no tuna, $5.5 \mathrm{~g}$ total protein). Prior studies with E1 showed that these effects were not caused by moderate protein meals ( $25 \mathrm{~g}$ tuna in whole wheat sandwich plus water, $13 \mathrm{~g}$ total protein; or $280 \mathrm{~g}$ yoghurt, $10 \mathrm{~g}$ total protein), where allicin bioavailability was $90-94 \%$, the Tmax was $6-6.3 \mathrm{~h}$ and the delay in Tmax, relative to the control, was $2.9-3.1 \mathrm{~h}[17,37]$. 
Table 6. Allicin bioavailability for garlic supplements, based on breath AMS-AUC. ${ }^{1}$

\begin{tabular}{|c|c|c|c|c|c|c|c|c|c|c|}
\hline Product & $\begin{array}{l}\text { Dose and } \\
\text { AADD }^{2}\end{array}$ & $\begin{array}{c}\text { Meal } \\
\text { Protein }\end{array}$ & $n$ & $\begin{array}{l}\text { Alliinase } \\
\text { Activity }^{3}\end{array}$ & $\operatorname{Tmin}^{4}(\mathrm{~h})$ & $\operatorname{Tmax}(\mathrm{h})$ & $\%$ Cmaxat $1 \mathrm{~h}$ & $\begin{array}{c}\text { AUC } \\
\text { (ng-h/L) }\end{array}$ & $\begin{array}{c}\text { RF } \\
\text { (AUC/AADD) }\end{array}$ & $\begin{array}{c}\text { Allicin } \\
\text { Bioavailability } \\
\operatorname{RRF}^{5}(\%)\end{array}$ \\
\hline Control $^{2}$ & $1.4 ; 54.7$ & low & 13 & -3 & $<1.1 \pm 0.2$ & $2.6 \pm 0.5$ & $42 \pm 17$ & $383 \pm 131$ & $7.0 \pm 2.4^{5}$ & $100 \pm 34$ \\
\hline & $1.4 ; 54.7$ & high & 13 & - & $1.4 \pm 0.3^{\mathrm{b}}$ & $3.3 \pm 0.95^{\mathrm{a}}$ & $28 \pm 18^{\mathrm{a}}$ & - & - & - \\
\hline \multicolumn{11}{|c|}{ Enteric tablets } \\
\hline \multirow[t]{2}{*}{ E1 } & $2 ; 132$ & low & 12 & 12,650 & $2.6 \pm 1.7^{\mathrm{a}}$ & $4.7 \pm 2.1^{b}$ & $20 \pm 35^{a}$ & $802 \pm 342$ & $6.1 \pm 2.6^{n}$ & $91 \pm 28^{n}$ \\
\hline & $2 ; 132$ & high & 13 & & $9.1 \pm 6.5^{\mathrm{bb}}$ & $10.3 \pm 6.5^{b a}$ & $<1 \mathrm{ct}$ & $496 \pm 178$ & $3.8 \pm 1.4^{\mathrm{cb}}$ & $57 \pm 17^{\mathrm{bb}}$ \\
\hline \multirow[t]{2}{*}{ E2 } & $2 ; 137$ & low & 8 & 2360 & $2.2 \pm 1.4^{\mathrm{a}}$ & $4.1 \pm 1.9^{\mathrm{t}}$ & $27 \pm 39^{n}$ & $782 \pm 471$ & $5.4 \pm 3.1^{\mathrm{a}}$ & $69 \pm 29^{a}$ \\
\hline & $2 ; 137$ & high & 13 & & $6.1 \pm 2.4^{\mathrm{cc}}$ & $7.1 \pm 3.1^{\mathrm{ca}}$ & $<1^{\mathrm{ct}}$ & $324 \pm 205$ & $2.7 \pm 1.6^{\mathrm{ct}}$ & $33 \pm 16^{\mathrm{ca}}$ \\
\hline \multirow[t]{2}{*}{ E3 } & $3 ; 278$ & low & 4 & 1950 & $<1.0 \pm 0.1^{\mathrm{n}}$ & $2.6 \pm 1.7^{n}$ & $50 \pm 34^{n}$ & $720 \pm 235$ & $2.7 \pm 0.7^{\mathrm{a}}$ & $36 \pm 12^{a}$ \\
\hline & $3 ; 278$ & high & 7 & & $2.6 \pm 0.8^{\mathrm{ab}}$ & $4.9 \pm 2.0^{\text {tn }}$ & $11 \pm 29^{\mathrm{nn}}$ & $432 \pm 192$ & $1.6 \pm 0.7^{\mathrm{ca}}$ & $22 \pm 7^{\mathrm{ba}}$ \\
\hline E4 & $2 ; 180$ & low & 7 & 13,500 & $<1.0 \pm 0.1^{\mathrm{n}}$ & $3.3 \pm 1.2^{\mathrm{n}}$ & $38 \pm 26^{n}$ & $826 \pm 473$ & $4.6 \pm 2.6^{n}$ & $71 \pm 33^{n}$ \\
\hline E5 & $3 ; 51.7$ & low & 7 & 520 & $<1.4 \pm 0.5^{\mathrm{n}}$ & $3.6 \pm 1.4^{\mathrm{n}}$ & $35 \pm 30^{n}$ & $407 \pm 156$ & $7.9 \pm 3.0^{\mathrm{n}}$ & $104 \pm 31^{n}$ \\
\hline $\mathrm{E}^{6}{ }^{6}$ & $2 ; 106$ & low & 3 & 550 & $4.6 \pm 0.5^{\mathrm{a}}$ & $6.3 \pm 0.6^{\mathrm{a}}$ & $0.8 \pm 1.9^{c}$ & $496 \pm 160$ & $4.7 \pm 1.5^{\mathrm{a}}$ & $52 \pm 12^{b}$ \\
\hline \multicolumn{11}{|c|}{ Normal tablets } \\
\hline \multirow[t]{3}{*}{ N1 } & $3 ; 75.8$ & low & 13 & 6520 & $<1.3 \pm 0.3^{t}$ & $3.0 \pm 1.0^{\mathrm{n}}$ & $47 \pm 29^{n}$ & $400 \pm 137$ & $5.3 \pm 1.8^{b}$ & $80 \pm 26^{n}$ \\
\hline & $3 ; 75.8$ & high & 13 & & $1.6 \pm 0.5^{\mathrm{nn}}$ & $3.9 \pm 1.1$ aа & $12 \pm 13^{\mathrm{ab}}$ & $385 \pm 169$ & $5.1 \pm 2.2^{\mathrm{cn}}$ & $73 \pm 17$ an \\
\hline & $3 ; 75.8$ & high-w ${ }^{7}$ & 13 & & $1.5 \pm 0.4^{\mathrm{nn}}$ & $3.9 \pm 1.4^{\mathrm{nn}}$ & $27 \pm 32^{n t}$ & $457 \pm 230$ & $6.0 \pm 3.0^{\mathrm{nn}}$ & $85 \pm 33^{\mathrm{nn}}$ \\
\hline \multirow[t]{2}{*}{ N2 } & $9 ; 41.5$ & low & 13 & 360 & $<1.2 \pm 0.3^{\mathrm{n}}$ & $2.1 \pm 0.6^{\mathrm{b}}$ & $66 \pm 27^{a}$ & $294 \pm 135$ & $6.5 \pm 3.0^{\mathrm{n}}$ & $93 \pm 32^{n}$ \\
\hline & $9 ; 41.5$ & high & 13 & & $<1.3 \pm 0.5^{\mathrm{nn}}$ & $3.5 \pm 0.9^{\mathrm{nc}}$ & $18 \pm 14^{\text {tc }}$ & $263 \pm 128$ & $5.8 \pm 2.8$ an & $82 \pm 30^{\mathrm{nn}}$ \\
\hline N3 & $1 ; 155$ & low & 4 & 10,700 & $<0.9 \pm 0.1^{\mathrm{n}}$ & $2.2 \pm 0.5^{n}$ & $47 \pm 19^{n}$ & $1247 \pm 357$ & $8.0 \pm 2.3^{n}$ & $111 \pm 38^{n}$ \\
\hline $\mathrm{N} 4^{6}$ & $9 ; 58.8$ & low & 4 & 1160 & $1.6 \pm 0.6^{\mathrm{t}}$ & $3.9 \pm 0.6^{\mathrm{a}}$ & $8 \pm 12^{\mathrm{a}}$ & $345 \pm 168$ & $5.9 \pm 2.9^{n}$ & $76 \pm 31^{\mathrm{n}}$ \\
\hline \multicolumn{11}{|c|}{ Capsules } \\
\hline \multirow{2}{*}{$\mathrm{C} 1$} & $1 ; 73$ & low & 13 & 10,800 & $<1.0 \pm 0.3^{n}$ & $2.3 \pm 0.7^{\mathrm{t}}$ & $51 \pm 24^{\mathrm{n}}$ & $267 \pm 96$ & $3.7 \pm 1.3^{c}$ & $54 \pm 14^{b}$ \\
\hline & $1 ; 73$ & high & 12 & & $<1.2 \pm 0.4^{\mathrm{nn}}$ & $3.6 \pm 0.6^{\mathrm{ac}}$ & $22 \pm 14^{\mathrm{nb}}$ & $281 \pm 132$ & $3.9 \pm 1.8^{\mathrm{cn}}$ & $53 \pm 13^{c n}$ \\
\hline \multirow[t]{2}{*}{$\mathrm{C} 2$} & $3 ; 169$ & low & 13 & 210 & $1.5 \pm 0.5^{\mathrm{a}}$ & $3.6 \pm 1.2^{\mathrm{a}}$ & $19 \pm 24^{b}$ & $290 \pm 119$ & $1.7 \pm 0.7^{\mathrm{c}}$ & $26 \pm 11^{c}$ \\
\hline & $3 ; 169$ & high & 13 & & $2.2 \pm 0.7^{b a}$ & $4.8 \pm 2.0^{\text {aа }}$ & $2 \pm 6^{\mathrm{ca}}$ & $314 \pm 123$ & $1.9 \pm 0.7 \mathrm{cn}$ & $27 \pm 8^{c n}$ \\
\hline $\mathrm{C} 3$ & $4 ; 99.5$ & high & 13 & 250 & $<1.3 \pm 0.8^{n}$ & $3.8 \pm 1.0^{\mathrm{t}}$ & $6 \pm 4^{b}$ & $733 \pm 245$ & $7.4 \pm 2.5^{n}$ & $109 \pm 24^{n}$ \\
\hline
\end{tabular}

${ }^{1}$ Values are mean \pm SD for $n$ persons. For Tmin, Tmax and \% Cmax at $1 \mathrm{~h}$, statistical comparisons were made between (1) products and the control of the same meal type (first set of designators) and (2) the high-protein and low-protein meal tests for the same product, when both were conducted (second set). For RF and allicin bioavailability, the first set of comparisons was made between the products and the standard, low-protein, control; the second set was made between meal types of the same product. Unpaired $t$-Test was used in three cases, where $n$ was 3-4. Designations for significance: $\mathrm{n}=$ not significant $(p>0.05) ; \mathrm{t}=$ trend $(p=0.05-0.1) \mathrm{a}=p<0.05, \mathrm{~b}=p<0.01, \mathrm{c}=p<0.001$. ${ }^{2}$ The dose consumed is expressed as: (left) the number of tablets or capsules or the weight of the control and (right) the AADD value (see Table 4). Control: $1.4 \mathrm{~g}$ of homogenate, made from $0.88 \mathrm{~g}$ raw garlic. ${ }^{3}$ Alliinase activity is expressed as $\mu \mathrm{g}$ allicin $\mathrm{min}^{-1} \mathrm{~g}^{-1}$ garlic powder content. When the control was prepared, the alliinase activity was sufficient to rapidly convert all of the alliin to allyl thiosulfinates. ${ }^{4}$ Tmin $=$ the time (h) after consumption until AMS was first detected in the breath, with the limitation that the first breath was taken at about $1 \mathrm{~h}$ after consumption. ${ }^{5}$ Allicin bioavailability $=\mathrm{RRF}=100 \% \times$ $\left(\mathrm{RF}_{\text {product }} / \mathrm{RF}_{\text {control }}\right)$. The $\mathrm{RF}_{\mathrm{control}}$, determined with the low-protein meal (standard control, see Table 5), was used for all determinations, regardless of product meal type. ${ }^{6}$ Products E6 and N4 were consumed 12 and 19 years, respectively, after their manufacture; they were stored at ambient temperature. Nine tablets of N4 contained the same amount of garlic powder as three tablets of N1. ${ }^{7}$ Extra water $(225 \mathrm{~mL}$ ) was consumed with the high-protein meal (high-w). 
The alliinase activity of each product is also given in Table 6. For the six brands of enteric tablets consumed with the low-protein meal, there was no correlation between alliinase activity (26-fold range) and allicin bioavailability (2.9-fold range) $\left(\mathrm{r}^{2}=0.07\right)$ or the Tmax (1.9-fold range) $\left(\mathrm{r}^{2}=0.02\right)$. The products with both the highest (E1 and E4) and the lowest (E5) alliinase activity also gave the highest bioavailability, possibly indicating that the lowest observed alliinase activity was sufficient to allow for maximum conversion of alliin to allyl thiosulfinates. When E1, E2, and E3 were consumed with the high-protein meal, there was a moderate correlation $\left(r^{2}=0.92\right)$ between alliinase activity and allicin bioavailability, but it was not significant $(p=0.094)$. A correlation between type of enteric coating agent (Table 2) and allicin bioavailability could not be established. Brands E1 and E6 did not list their coating agents. Sodium alginate was used by the brands that gave both the highest (E5) and lowest (E3) bioavailability. Hence, the variation found among brands of enteric tablets appears to be more related to unknown manufacturing procedures than to coating agents or alliinase activity.

\subsubsection{Normal (Non-Enteric) Tablets}

Allicin bioavailability from all of the normal tablets was found to be high, even though they disintegrated rapidly and their alliinase activity varied 30-fold (Table 6). Only the N1 tablets, when consumed with the high-protein meal, gave significantly lower bioavailability $(73 \%)$ than the control; however, when an additional $225 \mathrm{~mL}$ of water was consumed with the meal, the bioavailability increased insignificantly to $85 \%$, and the difference from the control disappeared. Even N4 tablets (same brand as N1), which were consumed 19 years after their manufacture, gave high bioavailability. Two brands, N1 and N2, were consumed with both the low-protein and high-protein meals. Unlike with enteric tablets, the high-protein meal did not significantly decrease allicin bioavailability. Normal tablets rapidly achieved maximum allicin production. The Tmin was not significantly different than the controls for any of the tests with normal tablets, while the Tmax was significantly longer only for $\mathrm{N} 1$ consumed with the high-protein meal and for the old N4, but the delay was only $0.6-1.3 \mathrm{~h}$.

\subsubsection{Capsules}

Although capsules were expected to give very low allicin bioavailability $(<5 \%)$, due to their assumed rapid disintegration in stomach acid at a low $\mathrm{pH}$, the three brands tested gave a broad range of bioavailability (26-109\%, Table 6). For capsules containing fine particles ( $\mathrm{C} 1$ and C2, Table 1), the difference in bioavailabilities ( $54 \%$ and $26 \%$ ) appears to be due to differences in alliinase activity (10,840 and 210). However, products C2 and C3 had similar alliinase activity (210 and 250) with large differences in bioavailability ( $26 \%$ and $109 \%$ ), even though they were made by the same manufacturer and had almost the same listed ingredients (Tables 1 and 2). The only known difference between $\mathrm{C} 2$ and $\mathrm{C} 3$ is that $\mathrm{C} 3$ was substantially more coarse and darker in color (Table 1). It appears that the larger particle size of C3 offered more protection against gastric acid inhibition of alliinase, although such a dramatic protection seems unexpected. The results also indicate that alliinase activity as low as about $250 \mu \mathrm{g}$ allicin $\mathrm{min}^{-1} \mathrm{~g}^{-1}$ garlic powder, if protected, is sufficient to allow for maximum possible allicin formation from alliin. Consumption of $\mathrm{C} 1$ and $\mathrm{C} 2$ with the high-protein meal, rather than with the low-protein meal, had no effect on allicin bioavailability. Capsules disintegrated and produced allicin almost as rapidly as the controls, with the Tmax values being an average of $0.35 \mathrm{~h}$ longer with the low-protein meal and $0.77 \mathrm{~h}$ longer with the high-protein meal.

\subsection{Garlic Supplements: Gender Comparisons}

No significant gender differences for allicin bioavailability or the Tmax were found for the raw homogenate control or for any of the supplements, with two exceptions: the Tmax when enteric E1 and E2 were consumed with a high-protein meal (Table 7). The Tmax is a close measure of their disintegration times, as breath AMS levels were undetectable for enteric tablets at $1-2 \mathrm{~h}$ before the Tmax was reached. Very long disintegration times (Tmax 11-24 h) were found with the high-protein meal for 4 of 6 women (av $18 \mathrm{~h}$ ) and 1 of 7 men (11 h) consuming E1 and for 2 of 6 women (av $15 \mathrm{~h})$ 
and 0 of 7 men consuming E2. When E1 and E2 were consumed with the low-protein meal, very long disintegration times were found only for 1 woman $(18 \mathrm{~h})$ consuming E1. Similarly, consumption of enteric-coated aspirin tablets with a meal ( $22 \mathrm{~g}$ protein, estimate) has been found to give substantially longer gastric residence times $(8.4 \mathrm{~h}$ vs. $3.5 \mathrm{~h})$ and plasma salicylate Tmin $(10.8 \mathrm{~h}$ vs. $5.0 \mathrm{~h})$ for women than for men (Tmax not reported). However, when the aspirin tablets were simply consumed with water and no food, both the gastric residence time $(0.8 \mathrm{~h})$, Tmin $(2.7 \mathrm{~h})$, and Tmax $(8.3 \mathrm{~h})$ were much shorter and showed no gender differences [52].

Table 7. Gender comparisons for Tmax upon consumption of enteric-coated tablets with high-protein (HP) and low-protein (LP) meals.

\begin{tabular}{cccccccccc}
\hline \multirow{2}{*}{ Product } & \multirow{2}{*}{ Meal } & \multicolumn{3}{c}{ Female } & \multicolumn{2}{c}{ Male } & \multicolumn{3}{c}{ Female:Male } \\
\cline { 3 - 10 } & & $n$ & Tmax (h) & Range (h) & $\boldsymbol{n}$ & Tmax (h) & Range (h) & $\boldsymbol{p}$-Value & Ratio \\
\hline E1 & HP & 6 & $14.5 \pm 7.3$ & $6.1-24$ & 7 & $6.6 \pm 2.6$ & $3.0-11$ & 0.04 & 2.2 \\
E1 & LP & 6 & $7.2 \pm 5.5$ & $4.9-18$ & 7 & $4.2 \pm 2.5$ & $1.2-8.4$ & $>0.2$ & 1.7 \\
E2 & HP & 6 & $9.5 \pm 2.8$ & $5.3-16$ & 7 & $5.1 \pm 1.5$ & $3.1-6.7$ & 0.004 & 1.9 \\
E2 & LP & 4 & $4.5 \pm 2.0$ & $2.1-7.0$ & 4 & $3.7 \pm 1.8$ & $1.1-5.3$ & $>0.2$ & 1.2 \\
\hline
\end{tabular}

Values are mean $\pm \mathrm{SD}$. $p$-Values are based on the $t$-test with unequal variances.

\subsection{United States Pharmacopeia (USP) Dissolution Allicin Release (In Vitro) Compared to Actual Allicin Release (In Vivo)}

\subsubsection{Enteric-Coated Tablets}

The dissolution test (Table 8 ) revealed that the quality of the coating of all tested brands of enteric tablets was sufficient to prevent tablet disintegration after $2 \mathrm{~h}$ in acid, as required in the USP monograph [29]. In fact, all brands had the appearance of being undisturbed at the end of the 2-h acid stage, except that E4 tablets were swollen and blistered and E6 had one small blister per tablet. After entering the buffer stage ( $\mathrm{pH}$ 6.8), three brands (E1, E2, E5) disintegrated rapidly, within the time specified $(1 \mathrm{~h})$ in the USP monograph, while the other brands (E3, E4, E6) disintegrated much slower, requiring 2.5-5.7 $\mathrm{h}$. However, the average Tmax for breath AMS with the low-protein meal was similar for both sets of tablets $(\sim 4 \mathrm{~h})$, indicating that they disintegrated at similar average rates in the body. Considerably higher dissolution allicin release (\%) was found for brands with rapid disintegration times than for those with slow disintegration times ( $88 \pm 5 \%$ vs. $5 \pm 2 \%$ at 1 h in buffer or $88 \pm 5 \%$ vs. $18 \pm 9 \%$ at the time of complete disintegration), even though the average alliinase activity for both groups was similar. However, in vivo, there was a smaller non-significant difference between the same groups ( $88 \pm 18 \%$ vs. $53 \pm 18 \%, p=0.07)$. Only one brand (E1) met the USP requirement of releasing at least $90 \%$ of the label claim (Table 1 ) for potential allicin.

For the rapidly disintegrating tablets (E1, E2, E5), there was moderately good agreement between percent dissolution allicin release and percent allicin bioavailability, when consumed with the low-protein meal (ratio near 1). Overall, the USP in vitro dissolution test was partly accurate for predicting in vivo results when enteric tablets were consumed with a low-protein meal, but not when consumed with a high-protein meal (Table 6). That is, when dissolution allicin release, as percent of allicin potential, was high (>80\%), allicin bioavailability was medium to high (69-104\%, av 88\%) with the low-protein meal and moderate (32-57\%, a 45\%, Table 6) with the high-protein meal. Furthermore, for the slowly disintegrating tablets (E3, E4, E6), the actual allicin bioavailability (36-71\%, av 53\%) was about 11 times greater than that predicted (av 5\%) by the USP dissolution method. Hence, the USP dissolution method is not reliable for predicting disintegration times in vivo or allicin bioavailability from enteric tablets. 
Table 8. Comparison between USP dissolution allicin release (in vitro) and allicin bioavailability (in vivo) for garlic supplements.

\begin{tabular}{|c|c|c|c|c|c|c|c|c|c|}
\hline \multirow[b]{2}{*}{ Product } & \multirow[b]{2}{*}{$\begin{array}{l}\text { Alliinase } \\
\text { Activity }^{2}\end{array}$} & \multirow[b]{2}{*}{$\begin{array}{l}\text { Potential } \\
\text { Allicin }{ }^{3}(\mathrm{mg} ; \\
\% \text { of Claim) }\end{array}$} & \multicolumn{4}{|c|}{ Dissolution Results (In Vitro) } & \multicolumn{3}{|c|}{ In Vivo Results (LP meal) ${ }^{1}$} \\
\hline & & & $\begin{array}{l}\text { Disinteg Ration } \\
\text { Time }^{4}(\mathrm{~h})\end{array}$ & $\begin{array}{l}\text { Allicin } \\
\text { Release }^{5} \\
\text { (mg) }\end{array}$ & $\begin{array}{c}\text { Allicin } \\
\text { Release }^{6} \\
(\%)\end{array}$ & $\begin{array}{c}\text { Allicin } \\
\text { Release }^{7} \\
\text { (\% of } \\
\text { Claim) }\end{array}$ & $\begin{array}{l}\text { Allicin } \\
\text { Bioavailability, } \\
\text { RRF (\%) }\end{array}$ & $\begin{array}{c}\text { Ratio: }^{8} \\
\text { In Vivo/In } \\
\text { Vitro }\end{array}$ & $\underset{\text { (h) }}{\operatorname{Tmax}}$ \\
\hline \multicolumn{10}{|c|}{ Enteric tablets (rapid in vitro disintegration) } \\
\hline E1 & 12,650 & $3.92(123)$ & $2+1$ & 3.37 & 86 & 105 & 91 & 1.1 & 4.7 \\
\hline E2 & 2360 & $4.20(84)$ & $2+0.75$ & 3.90 & 93 & 78 & 69 & 0.7 & 4.1 \\
\hline E5 & 520 & $0.85(\mathrm{nc})$ & $2+1$ & 0.71 & 84 & nc & 104 & 1.2 & 3.6 \\
\hline \multicolumn{10}{|c|}{ Enteric tablets (slow in vitro disintegration) } \\
\hline E3 & 1950 & $5.17(103)$ & $2+2.5$ & 0.13 & $3(12)^{9}$ & 3 & 36 & 12 & 2.6 \\
\hline E4 & 13,500 & $5.45(76)$ & $2+5.7$ & 0.33 & $6(13)^{9}$ & 5 & 71 & 12 & 3.3 \\
\hline E6 & 550 & $3.31(66)$ & $2+3.5$ & 0.21 & $6(28)^{9}$ & 4 & 52 & 9 & 6.3 \\
\hline \multicolumn{10}{|c|}{ Normal tablets } \\
\hline N1 & 6520 & $1.65(92)$ & $1.5+0$ & 0.20 & 12 & 13 & 80 & 7 & 3.0 \\
\hline N2 & 360 & 0.27 (nc) & $1.75+0$ & 0.015 & 6 & $\mathrm{nc}$ & 93 & 16 & 2.1 \\
\hline N3 & 10,700 & 11.1 (nc) & $1.75+0$ & 1.84 & 17 & nc & 111 & 7 & 2.2 \\
\hline \multicolumn{10}{|c|}{ Capsules $^{1}$} \\
\hline $\mathrm{C} 1$ & 10,840 & 5.0 (nc) & $2+1$ & 2.1 & 42 & $\mathrm{nc}$ & 54 & 1.3 & 2.3 \\
\hline $\mathrm{C} 2$ & 210 & 3.08 (nc) & $2+0$ & $<0.03$ & $<1$ & $\mathrm{nc}$ & 26 & $>27$ & 3.6 \\
\hline $\mathrm{C} 3$ & 250 & $1.27(170)$ & $0.25+0$ & $<0.03$ & $<1$ & $<4$ & 109 & $>109$ & 3.8 \\
\hline
\end{tabular}

${ }^{1}$ The in vivo results for allicin bioavailability (RRF) and Tmax are from Table 6. All products were consumed with the low-protein (LP) meal, except $\mathrm{C} 3$ was consumed with the high-protein (HP) meal. ${ }^{2}$ Alliinase activity is expressed as $\mu \mathrm{g}$ allicin $\mathrm{min}^{-1} \mathrm{~g}^{-1}$ garlic powder content. ${ }^{3}$ Potential allicin (allicin potential): allicin found $(\mathrm{mg} /$ tablet or capsule) after pulverized tablets or capsule contents were stirred in water for $30 \mathrm{~min}$; it is also given as \% of label claim reported in Table 1, except when there was no claim (nc) for allicin. ${ }^{4}$ Time to achieve complete disintegration in the dissolution test. The first $2 \mathrm{~h}$ was in acid; the remaining time was in buffer. Values are the average of two tests. ${ }^{5}$ Dissolution allicin release $(\mathrm{mg})$ : allicin found $(\mathrm{mg} /$ tablet or capsule) at the United States Pharmacopeia (USP) standard time of $1 \mathrm{~h}$ in buffer, after $2 \mathrm{~h}$ in acid. Values are the average of two tests. ${ }^{6}$ Dissolution allicin release (\%): allicin found, as percent of potential allicin, at the USP standard time of $1 \mathrm{~h}$ in buffer, after $2 \mathrm{~h}$ in acid. ${ }^{7}$ Dissolution allicin release (\% of claim): dissolution allicin release $(\mathrm{mg})$ compared to label claim (Table 1$)$, except when there was no claim (nc). ${ }^{8}$ Ratio (in vivo/in vitro): allicin bioavailability (\%)/dissolution allicin release $(\%) .{ }^{9}$ Dissolution allicin release $(\%)$, at the time of complete disintegration, when greater than $1 \mathrm{~h}$ in buffer.

\subsubsection{Normal (Non-Enteric) Tablets}

Although the USP dissolution method was designed for enteric (delayed-release) tablets, it was prepared under the assumption that only acid-resistant enteric tablets would be able to provide high allicin release in the body. The method does present the general simulated gastrointestinal conditions to which all supplements are exposed. Hence, the same conditions were applied to normal tablets and capsules, where two hours of acid exposure should strongly inhibit alliinase activity and substantially decrease allicin release. As expected, all of the brands tested under dissolution conditions (N1, N2, $\mathrm{N} 3)$ completely disintegrated in the $2 \mathrm{~h}$ acid stage $(1.5-1.75 \mathrm{~h})$ and dissolution allicin release was small (6-17\%), even though alliinase activity ranged from low to high (Table 8$)$. However, the in vivo allicin bioavailability averaged $95 \%$ with the low-protein meal, an average of eight times greater than expected based on the dissolution test.

\subsubsection{Capsules}

Because capsules contain loose powder and shells that dissolve quickly, they were expected to undergo rapid disintegration, resulting in nearly complete inactivation of alliinase, and very low dissolution allicin release. The results for the three brands tested were partly unexpected (Table 8 ). Only C3 disintegrated rapidly in the acid stage $(0.25 \mathrm{~h})$, perhaps because it uniquely consisted of coarse particles, while $\mathrm{C} 2$ required the full $2 \mathrm{~h}$ in acid and $\mathrm{C} 1$ required the acid stage and $1 \mathrm{~h}$ of the buffer stage. Hence, C3 and C2 fully disintegrated in the acid stage, resulting in alliinase inhibition and undetectable levels of allicin release, as expected, while $\mathrm{C} 1$ released nearly half of its potential allicin.

Actually, the shells of $\mathrm{C} 1$ and $\mathrm{C} 2$ did disintegrate rapidly in the acid stage, but in both cases the capsule contents, rather than immediately disintegrating upon loss of the shell, congealed into a solid mass that disintegrated slowly. Three other brands of garlic powder capsules were also observed 
for their disintegration patterns in the acid stage (not shown); only one disintegrated rapidly (5 min; this product contained predominantly rice powder), while the other two also formed congealed masses that disintegrated slowly, by 30 and $60 \mathrm{~min}$ in acid. Hence, congealing of the garlic powder in the acid stage is a consistent pattern among garlic powder capsules comprising mainly fine garlic powder and is independent of other ingredients in the capsule; $\mathrm{C} 1$ listed no other ingredient (Table 2), yet it congealed the most. When tested in water, all four of the capsule products that had congealed in acid disintegrated about 4-fold faster; hence, the congealing is probably the effect of acid on the protein of fine garlic powder. In vivo, however, congealing appears to not occur. This conclusion is based on observation that similar times (5-12 $\mathrm{min}$ ) were found for the occurrence of side effects associated with allicin release after capsule disintegration (garlic burp, heart burn, gastric disturbance) after consuming capsules $\mathrm{C} 1$ and $\mathrm{C} 3$.

There was not a consistent correlation between dissolution allicin release and allicin bioavailability of the capsules. Although the $42 \%$ allicin release for $\mathrm{C} 1$ agreed well with the $53 \%$ allicin bioavailability, the brands that gave undetectable allicin release gave $26-109 \%$ bioavailability. A large difference in disintegration times between $\mathrm{C} 1$ and $\mathrm{C} 3$ was found in vitro, but no difference was found in vivo, based on Tmax times for the high-protein meal.

\subsection{Garlic Foods: Allicin Bioequivalence}

Garlic foods prepared in the kitchen are usually made by the cooking of raw cloves or bulbs, such as by roasting or boiling or stir-frying, all methods of which completely inhibit alliinase. It is also common to simply dice (cut into small cubes) raw garlic and add it to various foods, a method which does not inhibit alliinase. Commercial garlic foods are normally treated with an organic acid or phosphoric acid, which acidity ( $\mathrm{pH}$ 3.6-4.3) fully inactivates alliinase [14], especially under long-term storage. However, for garlic products that are cut into small pieces (the acid-minced and oil-chopped products), alliinase is active during chopping process, allowing for small to modest amounts of allyl thiosulfinates to form, depending upon the extent and coarseness of the chopping. After formation, the allyl thiosulfinates are gradually transformed at ambient temperature to allyl polysulfides.

An attempt was made to predict the amount of AMS produced by the body after consuming these garlic foods, especially when alliinase has been inhibited. It has been shown that allyl thiosulfinates account for $>90 \%$ of the AMS produced when crushed raw garlic is consumed [17]. This was demonstrated by comparing the breath AMS produced upon consuming crushed raw garlic (all of the alliin previously converted to allyl thiosulfinates) with the AMS produced upon consuming pure allicin. Furthermore, it has been shown that allyl thiosulfinates and allyl polysulfides produce equimolar amounts of breath AMS [17]. Hence, it should be possible to predict the breath AMS-AUC for any garlic product, including alliinase-inhibited garlic, based on the content (Table 4) or expected yield (if alliinase is active) of allyl thiosulfinates and allyl polysulfides, relative to the raw garlic homogenate control. These predictions assume, as indicated from crushed raw garlic, that no other $S$-allyl compound present in garlic is metabolized to significant amounts of AMS. They also assume that the body does not contain significant endogenous alliinase activity. However, these predictions were found to be incorrect (Table 9). Typical concentration curves are found in Figure 4M-P. 
Table 9. Kitchen-prepared and commercial garlic foods: allicin bioequivalence. ${ }^{1,2}$

\begin{tabular}{|c|c|c|c|c|c|c|c|c|c|c|}
\hline Garlic Food & $\begin{array}{l}\text { Dose and } \\
\text { AADD }^{3}\end{array}$ & $n$ & $\begin{array}{l}\text { Alliinase } \\
\text { Activity }{ }^{4}\end{array}$ & $\operatorname{Tmax}(\mathbf{h})$ & $\%$ Cmax at $1 \mathrm{~h}$ & $\underset{\text { (ng-h/L) }}{\text { AUC }}$ & $\begin{array}{l}\text { Predicted AUC } \\
\quad \text { and Ratio: } \\
\text { Actual/Predicted }\end{array}$ & $\begin{array}{c}\text { RF } \\
\text { (AUC/AADD) }\end{array}$ & $\begin{array}{c}\text { Allicin } \\
\text { Bioequivalence } \\
\left(\text { AADD, RRF) }{ }^{6}(\%)\right.\end{array}$ & $\begin{array}{c}\text { Allicin } \\
\text { Bioequivalence } \\
\text { (TKSA, RRF2) }^{7}(\%)\end{array}$ \\
\hline Control $^{8}$ & $1.4 ; 54.7$ & $7 a^{8}$ & - & $1.8 \pm 1.4^{8}$ & $87 \pm 14^{8}$ & $396 \pm 147$ & - & $7.23 \pm 2.68$ & $100 \pm 37$ & $100 \pm 37$ \\
\hline Control & $1.4 ; 54.7$ & $7 \mathrm{~b}$ & - & $1.3 \pm 0.8$ & $91 \pm 12$ & $392 \pm 129$ & - & $7.17 \pm 2.35$ & $100 \pm 33$ & $100 \pm 33$ \\
\hline \multicolumn{11}{|c|}{ Kitchen-prepared garlic foods (alliinase-inhibited, except raw, diced) } \\
\hline Roasted $160^{\circ} \mathrm{C}$ & $6.1 ; 423$ & $7 \mathrm{~b}$ & nd & $4.2 \pm 1.0^{\mathrm{b}}$ & $30 \pm 15^{c}$ & $955 \pm 214$ & $169(6)$ & $2.3 \pm 0.5^{b}$ & $34 \pm 11^{b}$ & $33 \pm 11^{b}$ \\
\hline Roasted $215^{\circ} \mathrm{C}$ & $5.5 ; 409$ & $7 \mathrm{~b}$ & nd & $3.6 \pm 1.1^{\mathrm{bn}}$ & $27 \pm 8^{\mathrm{cn}}$ & $773 \pm 191$ & $64(12)$ & $1.9 \pm 0.5^{b n}$ & $27 \pm 5$ bn & $27 \pm 5^{\text {bn }}$ \\
\hline Boiled 4 min & $7.6 ; 455$ & $7 a$ & nd & $4.2 \pm 1.0^{\mathrm{b}}$ & $19 \pm 6^{c}$ & $580 \pm 209$ & $31(19)$ & $1.3 \pm 0.5^{c}$ & $18 \pm 2^{b}$ & $17 \pm 2^{b}$ \\
\hline Boiled $45 \mathrm{~min}$ & $5.5 ; 452$ & $7 \mathrm{a}$ & nd & $3.8 \pm 1.2$ an & $26 \pm 6^{\mathrm{cn}}$ & $428 \pm 116$ & $17(25)$ & $1.0 \pm 0.3^{\mathrm{ca}}$ & $14 \pm 4^{\mathrm{ba}}$ & $14 \pm 4^{\mathrm{ba}}$ \\
\hline Raw, diced ${ }^{1}$ & $1.5 ; 112$ & $7 \mathrm{~b}$ & 19,000 & $3.1 \pm 0.9^{b}$ & $53 \pm 20^{a}$ & $618 \pm 207$ & $803(0.8)$ & $5.5 \pm 1.8^{\mathrm{t}}$ & $80 \pm 28^{n}$ & $77 \pm 27^{n}$ \\
\hline \multicolumn{11}{|c|}{ Commercial garlic foods (alliinase-inhibited) } \\
\hline Pickled & $12 ; 397$ & $7 a$ & nd & $3.1 \pm 0.8^{\mathrm{n}}$ & $20 \pm 8^{c}$ & $560 \pm 211$ & $65(9)$ & $1.4 \pm 0.5^{c}$ & $19 \pm 2^{b}$ & $21 \pm 3^{b}$ \\
\hline Acid-minced & $7 ; 155$ & $7 \mathrm{~b}$ & nd & $3.7 \pm 0.5^{c}$ & $31 \pm 14^{c}$ & $717 \pm 227$ & $153(5)$ & $4.6 \pm 1.5^{b}$ & $66 \pm 15^{b}$ & $49 \pm 11^{a}$ \\
\hline Oil-chopped & $2.5 ; 71.5$ & $7 a$ & nd & $4.4 \pm 1.3^{\mathrm{a}}$ & $21 \pm 9^{c}$ & $410 \pm 169$ & $260(1.5)$ & $5.7 \pm 2.4^{\mathrm{a}}$ & $79 \pm 14^{\mathrm{t}}$ & $59 \pm 10^{\mathrm{a}}$ \\
\hline Black garlic & $10.2 ; 0.8$ & 4 & nd & $3.2 \pm 0.6^{\mathrm{t}}$ & $34 \pm 8^{\mathrm{b}}$ & $228 \pm 72$ & $6(39)$ & -9 & -9 & $5.0 \pm 0.4^{c, 9}$ \\
\hline
\end{tabular}

${ }^{1}$ All garlic foods were consumed with the low-protein meal, inside the sandwich. For raw, diced garlic, the allicin bioequivalence values represent allicin bioavailability because it has active alliinase. ${ }^{2}$ Values are mean \pm SD for $n$ persons. Statistical comparisons were made between the foods and the controls (first set of designators) and between the intensity of cooking for the same kitchen food (boiled, roasted; second set). Designations for significance: $\mathrm{n}=$ not significant $(p>0.05) ; \mathrm{t}=$ trend $(p=0.05-0.1)$, $\mathrm{a}=p<0.05, \mathrm{~b}=p<0.01, \mathrm{c}=p<0.001$. cooking for the same kitchen food (boiled, roasted, second set). Designations for significance. $\mathrm{n}=$ not significant $(p>0.05), \mathrm{t}=$ trend $(p=0.05-0.1), \mathrm{a}=p<0.05, \mathrm{~b}=p<0.01, \mathrm{c}=p<0.001$. $<1 .{ }^{5}$ The predicted AMS-AUC is based only on the content of allyl thiosulfinates and allyl polysulfides (Table 4) times the average RF for the raw homogenate control (7.23 or 7.17 ); for diced raw garlic, it also includes alliin because active alliinase is present. ${ }^{6}$ Allicin bioequivalence $(\mathrm{AADD})=\mathrm{RRF}=100 \% \times\left(\mathrm{RF}_{\mathrm{product}} / \mathrm{RF}_{\text {control }}\right) \cdot{ }^{7} \mathrm{Allicin}$ bioequivalence $(\mathrm{TKSA})=$ $\mathrm{RRF} 2=100 \% \times\left(\mathrm{RF} 2_{\text {product }} / \mathrm{RF} 2_{\text {control }}\right) . \mathrm{RF} 2=\mathrm{AUC} / \mathrm{TKSA} ; \mathrm{RF} 2_{\text {control }}=394 / 65.5=6.02 .{ }^{8}$ Control: $1.4 \mathrm{~g}$ of homogenate from $0.88 \mathrm{~g}$ raw garlic. The control values for two groups of seven persons ( $7 \mathrm{a}, 7 \mathrm{~b}$, with one person common to both groups) were matched to the individuals who consumed the garlic foods. The values for Tmax and \% $\mathrm{Cmax}$ at $1 \mathrm{~h}$ are for the "in sandwich" control (Table 5, test 3). ${ }^{9}$ Black garlic: allicin bioequivalence was determined on product weight basis, $\mathrm{RRF} 3 . \mathrm{RRF} 3=100 \% \times\left(\mathrm{RF} 3{ }_{\text {product }} / \mathrm{RF} 3_{\text {control }}\right) . \mathrm{RF} 3=\mathrm{AUC} / \mathrm{wt}$ consumed. $R F 3_{\text {product }}=228 / 10.2$. RF3 $3_{\text {control }}=394 / 0.88 . R R 3=100 \% \times 22.4 / 448=5.0 \%$ 
As expected, nearly all of the alliinase-inhibited garlic foods produced substantially less AMS (smaller RF) than did the homogenized raw garlic control; the exceptions were oil-chopped and acid-minced garlic, due to their relatively high content of allyl polysulfides (Table 4). Nevertheless, the amount of AMS (AUC) produced from alliinase-inhibited garlic foods was 5-25 times higher than predicted (see ratio: actual/predicted)—except for oil-chopped garlic_giving an allicin bioequivalence of $14-34 \%$ for cooked garlic and $19-79 \%$ for acidified commercial products. Overall, these results demonstrate that the body can produce substantial amounts of AMS from S-allyl compounds in garlic by a mechanism that is independent of garlic's alliinase activity, but this mechanism appears to be significant only when garlic's alliinase activity is inhibited.

\subsubsection{Cooked Garlic}

The intensity and duration of cooking made little difference in the allicin bioequivalence. Roasting at $215^{\circ} \mathrm{C}$ (internal temperature $101^{\circ} \mathrm{C}$ ) for $60 \mathrm{~min}$ did not produce significantly less AMS than roasting at $160^{\circ} \mathrm{C}$ (internal temperature $92^{\circ} \mathrm{C}$ ) for $30 \mathrm{~min}$. Similarly, boiling (internal temperature $95^{\circ} \mathrm{C}$ ) for $45 \mathrm{~min}$ reduced allicin bioequivalence from $18 \%$ to only $14 \%(p<0.05)$, compared to boiling for $4 \mathrm{~min}$. However, the method of cooking made a difference. The roasted preparations gave about two times $(p<0.01)$ as much allicin bioequivalence as either of the boiled preparations. This was unexpected, as the internal temperature for roasting at $215^{\circ} \mathrm{C}$ was higher than that which was found upon boiling. The difference is probably due to the higher content of allyl polysulfides in roasted garlic (Table 4).

\subsubsection{Acidified Garlic Products}

The acid-minced and the oil-chopped commercial garlic products gave high allicin bioequivalence (66-79\%) because of major tissue disruption before alliinase was inhibited by acidification. Both products were minced by an industrial process that was probably harsh (unlike the careful use of a razor blade for the diced raw garlic in Table 9). Based on visual examination, the oil-chopped garlic product also appears to have been partially crushed. These industrial procedures gave the products a desired and substantial garlic flavor. The comparatively low levels of alliin and high levels of allyl polysulfides in acid-minced and oil-chopped products (allyl polysulfides were 14\% and $50 \%$ of the AADD, respectively, compared to $<5 \%$ for pickled garlic, cooked garlic, and most of the supplements, Table 4) validate the substantial amount of tissue disruption that occurred in the preparation of these products. However, when undisturbed whole cloves were suspended in acid (pickled garlic), both allyl polysulfides and allicin bioequivalence were low.

\subsubsection{Tmin and Tmax}

Although the Tmin for the alliinase-inhibited garlic foods could not be determined (less than the first measure, $1 \mathrm{~h}$ ), the $\%$ of Cmax achieved at $1 \mathrm{~h}$ provides an estimate of Tmin. To improve the accuracy of comparison to the control, the control values for \% Cmax at $1 \mathrm{~h}$ and Tmax shown in Table 9 are for the "in sandwich" control (Table 5, test 3), rather than for the "in capsules" control (the standard for AUC and RF), because the garlic foods were also consumed inside sandwiches; the \% Cmax at $1 \mathrm{~h}$ and Tmax are dependent on the initial time of body contact, which is delayed when consumed in capsules. The \% Cmax at $1 \mathrm{~h}$ for the garlic foods was found to be $19-31 \%$, indicating that AMS production began about $30 \mathrm{~min}$ after consumption. The Tmax for almost all of the garlic foods (3.1-4.4 h) was significantly longer than that of the in-sandwich control (1.3-1.8 h, Table 9). This difference was expected, due to (a) the lack of allicin and alliinase activity in the garlic foods, (b) the immediate contact of allicin with the body (starting in the mouth) for this control, and (c) the fact that allicin is lipophilic, readily passing through epithelial cell membranes, in contrast to the lipophobic alliin and $\gamma$-glutamyl-S-allylcysteine, the main $S$-allyl sources in the garlic foods. The similarity among the Tmax values for the alliinase-inhibited garlic foods indicates that they all have a similar and moderately effective mechanism by which AMS is produced. 


\subsubsection{Diced Raw Garlic}

For finely diced raw garlic, where active alliinase and about $97 \%$ of the initial alliin content (prior to cutting) were still present, predicting the amount of AMS production is not as straightforward as it is with crushed or homogenized raw garlic. This is because of the unpredictable amount of allyl thiosulfinates produced by alliinase upon chewing the diced garlic (about 60 cubes) in the bread and butter sandwich. It appears that consuming the sandwich caused only a small percent of the garlic cells to have ruptured, exposing alliin to alliinase. When the seven participants were asked if they felt a "garlic burn" in the throat, which burn is caused by allicin, only one person reported a noticeable burn, one that was mild. In a separate test, when a single cube was chewed without other food, there was an immediate and strong burn. Hence, only minor crushing of the garlic cubes occurred during consumption of the sandwich.

The significantly longer Tmax for the diced garlic, compared to the control (3.1 vs. $1.3 \mathrm{~h}$ ), and its high allicin bioavailability, demonstrate that garlic alliinase was active enough to convert most of the alliin to allyl thiosulfinates after entering the stomach. This was possible because the gastric $\mathrm{pH}$ was likely elevated to at least 4.0 for about $0.5 \mathrm{~h}$ by the buffering effect of the meal [28]; alliinase has some activity at $\mathrm{pH} 4.0$ and maximum activity at $\mathrm{pH} 4.5$ [14]. The amount of AMS produced upon consuming the diced garlic was close to that which was predictable based on the assumption that all of the alliin was converted to allyl thiosulfinates (ratio: actual AUC/predictable AUC $=0.8$, Table 9). This confirms prior evidence that alliin-derived compounds account for nearly all of the AMS produced from garlic products in which active alliinase is present [17].

\subsubsection{Black Garlic}

Black garlic is produced by incubating garlic bulbs at medium heat $\left(60-90^{\circ} \mathrm{C}\right)$ and high humidity $(80-90 \%)$ for 30-40 days, a process loosely referred to as "fermenting" or "aging," during which the cloves turn black due to the Maillard reaction [53,54]. The process eliminates the sharp taste (mainly due to allicin) associated with raw garlic and replaces it with a sweet taste due to the reactions between sugars and free amino acids. Because of the virtual absence of AADD in black garlic (Table 4), the relative production of AMS from this garlic food gave an impossibly high value for RRF $(285 / 7.2=3960 \%$; RF $=228 / 0.8=285)$. If the allicin bioequivalence for black garlic is based on the remaining known $S$-allyl compounds in garlic (G/SAC), it would give a high RRF2 value $(4.87 / 6.8=72 \%$; RF2 $=228 / 46.8=4.87)$, which also seems excessive and indicates the presence of unknown $S$-allyl compounds. Because whole garlic bulbs were heated for a long time, alliinase was never significantly activated; hence, the absence of alliin in black garlic indicates that alliin was converted to new compounds unrelated to allicin, the identity of which is unknown.

If the new compounds could be identified and quantified, the TKSA value would increase, giving lower values for RF2 and RRF2. It is possible to estimate the amount of new $S$-allyl compounds produced, based on the alliin loss. Although the initial content of alliin in the bulbs used to prepare the black garlic is not known, if one assumes it to be the average value among 46 garlic varieties, $55 \mu \mathrm{mol}$ alliin/g fresh weight [49-51], then the amount of new $S$-allyl compounds generated from alliin would have been $561 \mu \mathrm{mol}(55 \times 10.2 \mathrm{~g}$ consumed). Hence, the new value for TKSA would be $608 \mu \mathrm{mol}(47 \mu \mathrm{mol} \mathrm{G} / \mathrm{SAC}$ plus $561 \mu \mathrm{mol}$ new $S$-allyl compounds), giving a much lower RF2 $(228 / 608=0.38)$ and much lower allicin bioequivalence of $6 \%(100 \% \times 0.38 / 6.8)$. Furthermore, when allicin bioequivalence was estimated based simply on the weight (RRF3) of black garlic consumed, it was found to give a value of $5 \%(22.4 / 448)$, as calculated from the product RF3 $(228 / 10.2 \mathrm{~g}=22.4)$ and the control RF3 (394/0.88 $\mathrm{g}=448)$. The RRF3 values for both roasted garlic products $(35 \%$ and $32 \%$, respectively) and both boiled garlic products (17\% and $17 \%$ ) were similar to their RRF2 values (Table 9), indicating the validity of estimating allicin bioequivalence on a weight basis. The agreement between RRF3 and the new estimated RRF2 indicates that the allicin bioequivalence of black garlic is close to $5 \%$ and that the new alliin-derived compounds are only poorly metabolized to AMS. 
The new S-allyl compounds are most likely the products of the Maillard reaction [53] between reducing sugars and alliin. The Maillard reaction may have also occurred to a lesser extent with G/SAC. A $25 \%$ loss of G/SAC has been reported when black garlic is produced [53]. Further evidence for a decrease in the content of G/SAC during the manufacture of the black garlic used in the current study is that its content $(4.5 \mu \mathrm{mol} / \mathrm{g})$ is below the range found for 13 varieties of garlic $(26.2 \pm 9.0 \mu \mathrm{mol} / \mathrm{g}$ fresh wt, range 8-38) [49].

\subsubsection{Aged Garlic Extract}

Also tested was a commercial aged garlic extract supplement (not shown) that has some similarities to and differences from black garlic. It is sold under the name of Kyolic Aged Garlic Extract and is manufactured by Wakunaga of America, Mission Viejo, California, USA. Both black garlic and Kyolic AGE are promoted as "aged" garlic products; both contain S-allylcysteine (derived from GSAC) as their main identified $S$-allyl compound; neither contains active alliinase; and both contain little or no alliin or alliin-derived thiosulfinates or sulfides. While black garlic consists of whole bulbs incubated in heated, moist air for 30-40 days, Kyolic AGE is made by incubating sliced raw garlic in $20 \%$ ethanol for up to 20 months at ambient temperature [55,56]. The extract has been used in a large number of experimental and clinical studies.

A single test for allicin bioequivalence was conducted, in which nine tablets of Kyolic Formula 100 were consumed with the standard meal. The product label claims that each tablet contains $300 \mathrm{mg}$ of "Aged Garlic Extract Powder (bulb)". The composition of the product (same lot number) has been previously reported [37]. Nine tablets contained $0.86 \mu \mathrm{mol}$ alliin, $16.8 \mu \mathrm{mol} \mathrm{SAC}$, and $12.4 \mu \mathrm{mol}$ GSAC, but no allyl sulfides $(<0.2 \mu \mathrm{mol})$, giving a TKSA value of 30.1. The breath AMS curve revealed a Tmax of $2 \mathrm{~h}(\mathrm{Cmax}=8 \mathrm{ng} / \mathrm{L} ; 31 \%$ of $\mathrm{Cmax}$ at $1 \mathrm{~h})$, a plateau at Tmax that lasted about $10 \mathrm{~h}$ before returning to baseline at $20 \mathrm{~h}$, and an AUC of $92 \mathrm{ng}-\mathrm{h} / \mathrm{L}$. The RF2 was 3.1 (92/30.1), while that for the control was 8.3 (543/65.5, Table 10), giving an allicin bioequivalence (RRF2) of 37\% (3.1/8.3), which was higher than expected. When allicin bioequivalence was based on the weight of product consumed (RRF3), it was found to be only $2 \%(34 / 1551)$, as calculated from the product RF3 $(92 / 2.7 \mathrm{~g}$ dry garlic $=34)$ and the control RF3 $(543 / 0.35 \mathrm{~g}$ dry $w \mathrm{t}=1551)$. As with black garlic, the large discrepancy between RRF2 and RRF3 (37\% vs. $2 \%$ ) indicates that much of the $S$-allyl (mainly alliin) lost during the aging process was converted to unidentified $S$-allyl compounds that were partly metabolized to AMS.

\subsection{Special Garlic Extracts and Pure Compounds: Allicin Bioequivalence}

The unexpectedly high results found for the allicin bioequivalence of alliinase-inhibited garlic foods (Table 9) indicates that the body itself contains either (a) substantial alliinase activity; (b) the ability to partially reactivate inactivated garlic alliinase; or (c) enzymes that can metabolize the $S$-allyl compounds in garlic (alliin, GSAC, SAC) to AMS without using allicin as an intermediate. In order to examine these possibilities, AMS production was examined after consuming pure alliin or pure SAC, as well as extracts in which the protein had been removed (PFHA) or the alliin selectively removed (AFHG). The results are summarized in Table 10.

\subsubsection{Alliin}

After consuming L(+)-alliin in a sandwich, breath AMS was detectable at $0.2 \mathrm{~h}$, reached Cmax at 3-3.5 $\mathrm{h}$ and gradually decreased almost to baseline by about $27 \mathrm{~h}$ (Figure $4 \mathrm{~S}$ ). About $5 \%$ of the alliin was metabolized to AMS (RRF2). This represents the maximum contribution that intestinal bacterial alliinase could make to in vivo production of allicin from alliin. Two tests with synthetic $\mathrm{L}( \pm)$-alliin were also conducted with the same person who consumed L(+)-alliin (not shown). No significant differences in the Tmax, RF2, or RRF2 values were found between natural L(+)-alliin and synthetic $\mathrm{L}( \pm)$-alliin. 
Table 10. Special garlic extracts and pure compounds: allicin bioequivalence. ${ }^{1,2}$

\begin{tabular}{|c|c|c|c|c|c|c|c|c|c|c|}
\hline Name & Dose & $n$ & $\begin{array}{l}\text { Alliin } \\
(\mu \mathrm{mol})\end{array}$ & $\begin{array}{l}\text { GSAC } \\
(\mu \mathrm{mol})\end{array}$ & $\begin{array}{c}\text { SAC } \\
(\mu \mathrm{mol})\end{array}$ & $\begin{array}{l}\text { TKSA } \\
(\mu \mathrm{mol})\end{array}$ & $\operatorname{Tmax}(\mathrm{h})$ & $\underset{(n g-h / L)}{\text { AUC }}$ & $\begin{array}{c}\text { RF2 } \\
\text { (AUC/TKSA) }\end{array}$ & $\begin{array}{c}\text { Allicin } \\
\text { Bioequivalence } \\
\text { (TKSA, RRF2) (\%) }\end{array}$ \\
\hline Control & $1.4 \mathrm{~g}^{3}$ & 4 & $\mathrm{nd},<0.2^{3}$ & 10.7 & 0.13 & 65.5 & $1.6 \pm 0.6^{4}$ & $446 \pm 116$ & $6.8 \pm 1.8$ & $100 \pm 26$ \\
\hline Control & $1.4 \mathrm{~g}$ & $1(3)$ & nd, $<0.2$ & 10.7 & 0.13 & 65.5 & $1.6 \pm 0.9$ & $543 \pm 44$ & $8.3 \pm 0.7$ & $100 \pm 8$ \\
\hline \multicolumn{11}{|c|}{ Special extracts ${ }^{5}$} \\
\hline PFHA & $68 \mathrm{~mL}$ & 4 & 399 & 68.7 & 2.7 & 470 & $\begin{array}{c}3.6 \pm 1.3^{\mathrm{t}} \\
\text { (vs. AFHG) }^{n}\end{array}$ & $472 \pm 78$ & $\begin{array}{l}1.01 \pm 0.18^{\mathrm{b}} \\
\text { (vs. AFHG) }^{\mathrm{b}}\end{array}$ & $\begin{array}{l}14.7 \pm 2.6^{\mathrm{b}} \\
\text { (vs. AFHG) }^{\mathrm{b}}\end{array}$ \\
\hline AFHG & $57 \mathrm{~mL}$ & 4 & nd, $<0.5$ & 63.6 & 7.0 & 70.6 & $2.9 \pm 1.5^{\mathrm{t}}$ & $203 \pm 15$ & $2.85 \pm 0.17^{\mathrm{a}}$ & $42 \pm 3^{a}$ \\
\hline AFHG & $57 \mathrm{~mL}$ & $1(2)$ & $\mathrm{nd},<0.5$ & 63.6 & 7.0 & 70.6 & $2.3 \pm 0.4^{\mathrm{n}}$ & $212 \pm 4$ & $3.01 \pm 0.06^{b}$ & $36.4 \pm 0.7^{b}$ \\
\hline AFHS & $57 \mathrm{~mL}$ & $1(2)$ & nd, $<0.5$ & 3.4 & 67.2 & 70.6 & $\begin{array}{c}2.5 \pm 0.7^{\mathrm{n}} \\
(\text { vs. AFHG) }\end{array}$ & $216 \pm 32$ & $\begin{array}{l}3.05 \pm 0.45^{b} \\
(\text { vs. AFHG) }\end{array}$ & $\begin{array}{l}36.8 \pm 5.5^{\mathrm{b}} \\
\left(\text { vs. AFHG) }{ }^{\mathrm{n}}\right.\end{array}$ \\
\hline $\mathrm{AFHG}+\mathrm{SAC}$ & $57 \mathrm{~mL}+141 \mu \mathrm{mol}$ & $1(2)$ & $\mathrm{nd},<0.5$ & 63.6 & 148 & 212 & $\begin{array}{c}3.5 \pm 0.7^{\mathrm{n}} \\
\left(^{(\mathrm{vs} . \mathrm{AFHG})^{\mathrm{n}}}\right.\end{array}$ & $277 \pm 1.4$ & $\begin{array}{l}1.31 \pm 0.01^{b} \\
\left(^{b s} . A F H G\right)^{c}\end{array}$ & $\begin{array}{l}15.8 \pm 0.1^{\mathrm{b}} \\
(\text { vs. AFHG) }\end{array}$ \\
\hline \multicolumn{11}{|c|}{ Pure compounds ${ }^{6}$} \\
\hline Alliin, $\mathrm{L}(+)$ & $373 \mu \mathrm{mol}$ & $1(2)$ & 373 & - & - & 373 & $3.2 \pm 0.3^{n}$ & $143 \pm 21$ & $0.38 \pm 0.06^{c}$ & $4.6 \pm 0.7^{c}$ \\
\hline S-allyl-cysteine & $676 \mu \mathrm{mol}$ & $1(3)$ & - & - & 676 & 676 & $\begin{array}{l}8.4 \pm 1.3^{\mathrm{b}, 4} \\
\text { (vs. alliin) }^{\mathrm{a}}\end{array}$ & $333 \pm 34$ & 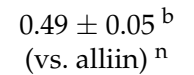 & $\begin{array}{l}6.0 \pm 0.6^{b} \\
\text { (vs. alliin) }{ }^{n}\end{array}$ \\
\hline Diallyl sulfide & $696 \mu \mathrm{mol}$ & $1(3)$ & - & - & - & $696^{4}$ & $\begin{array}{l}5.8 \pm 1.1^{\mathrm{a}, 4} \\
\text { (vs. alliin) }^{\mathrm{t}} \\
\text { (vs. SAC) }^{\mathrm{t}}\end{array}$ & $188 \pm 84$ & $\begin{array}{l}0.27 \pm 0.12^{\mathrm{b}} \\
\text { (vs. alliin) }^{\mathrm{n}} \\
\text { (vs. SAC) }^{\mathrm{a}}\end{array}$ & $\begin{array}{l}3.3 \pm 1.5^{\mathrm{b}} \\
\text { (vs. alliin) }^{\mathrm{n}} \\
\text { (vs. SAC) }^{\mathrm{a}}\end{array}$ \\
\hline
\end{tabular}

${ }^{1}$ All products were consumed with the low-protein meal, as liquids (PFHA, AFHG, AFHG + SAC, AFHS) or inside the sandwich (alliin) or in capsules (control, S-allylcysteine (SAC), diallyl sulfide). ${ }^{2}$ Values are mean $\pm \mathrm{SD}$ for $n$ persons. The control, PFHA and AFHG were consumed by the same four persons. When $n$ is 1 , it was the same person; the number in parentheses is the number of tests for that person. Statistical comparisons were made between the products and the controls and (in parentheses) between designated products. Unpaired $t$-tests were used for products consumed by only one person. Designations for significance: $\mathrm{n}=$ not significant $(p>0.05), \mathrm{t}=$ trend $(p=0.05-0.1), \mathrm{a}=p<0.05, \mathrm{~b}=p<0.01, \mathrm{c}=p<0.001$. ${ }^{3}$ Control: $1.4 \mathrm{~g}$ of homogenate from $0.88 \mathrm{~g}$ raw garlic. It contained no alliin, but it contained 54.7 AADD (Table 4). ${ }^{4}$ The control value for Tmax is the "in sandwich" control (Table 5 , Test 3), closely matching how the extracts were consumed. For $S$-allylcysteine and diallyl sulfide (consumed in capsules), the matched control Tmax value is $2.8 \pm 0.3 \mathrm{~h}$. ${ }^{5}$ Special extracts. PFHA: protein-free, high alliin (high GSAC) extract. AFHG: alliin free, high GSAC extract. AFHS: alliin-free, high SAC (low GSAC) extract. AFHG + SAC: AFHG plus added SAC. For composition, see Table 4 . None of these extracts contain active alliinase. ${ }^{6}$ Purity: $99 \%$, Section 2.1 


\subsubsection{S-Allylcysteine (SAC)}

After consuming SAC, breath AMS (measured initially every $30 \mathrm{~min}$ ) was undetectable until $2.5 \mathrm{~h}$, reached $\mathrm{Cmax}$ at about $8 \mathrm{~h}$ and gradually decreased almost to baseline by about $35 \mathrm{~h}$ (Figure $4 \mathrm{~T}$ ). About $6 \%$ of the SAC was metabolized to AMS (RRF2). The difference in Tmin between alliin (0.2 h) and SAC $(2.5 \mathrm{~h})$ indicates a difference in metabolic pathways, which is even more prominent in the difference in the Tmax values ( $3.2 \mathrm{~h}$ vs. $8.4 \mathrm{~h}$; Table 10$)$. In a previous report, breath AMS was not detectable after consuming a similar amount of AMS $(730 \mu \mathrm{mol})$ because the method used was about 20 times less sensitive [17].

\subsubsection{Diallyl Sulfide (DAS)}

Diallyl sulfide (DAS), a monosulfide, is not present in crushed raw garlic [21,37]. It is typically less than $3 \%$ of the small amount of sulfides found in garlic powder products (Table 4), and it is only about $2 \%$ of the large amount of sulfides found in commercial steam-distilled garlic oil [21]. Although its abundance is minor in garlic products, it has been included in Table 10 because it has been used in a large number of experimental studies [57,58]. After consuming DAS, breath AMS was undetectable until $4 \mathrm{~h}$, reached Cmax at about $6 \mathrm{~h}$ and remained at Cmax (plateau) for about $23 \mathrm{~h}$, and became undetectable at about $35 \mathrm{~h}$ (not shown). About 3\% of the DAS was metabolized to AMS (RRF2). Possible impurities in DAS that are known to be fully metabolized to AMS are diallyl disulfide and allyl mercaptan [17]; however, analysis of the DAS used in the study revealed that allyl mercaptan was undetectable $(<0.037 \%)$ and that the diallyl disulfide content was only $0.04 \%$. Hence, impurities are not responsible for the breath AMS found after DAS consumption. A previous failure to detect AMS in the breath after DAS consumption was due to the use of a less-sensitive detector [17].

\subsubsection{Protein-Free, High-Alliin Garlic Extract (PFHA)}

It was shown in Table 9 that AMS production from alliinase-inhibited garlic products is much greater than expected, based on the amount of alliin-derived dithioallyl compounds present. One possible explanation for these results, although unlikely, is that the body might be partially re-activating alliinase. To examine this possibility, an extract (PFHA) was prepared in which 97\% of the protein of boiled garlic was removed, without reducing alliin. Alliinase is among the most abundant proteins in garlic and constitutes about $10 \%$ of the total clove protein [25,59]; hence, removal of $97 \%$ of the protein likely removed virtually all of the alliinase, and any amount remaining would have been inactive. Upon consuming PFHA, breath AMS was detectable in less than $0.25 \mathrm{~h}$, reached $48 \%$ of $\mathrm{Cmax}$ in $1 \mathrm{~h}$, reached $\mathrm{Cmax}$ in $3.6 \mathrm{~h}$ and remained at Cmax until about $8 \mathrm{~h}$ after consumption, followed by a gradual decline to near zero by 30-32 h (Figure 4Q). About 15\% of the TKSA (RRF2) was metabolized to AMS (Table 10). Because alliinase and alliin-derived S-allyl compounds were absent in this product, and because GSAC and SAC have been shown to be metabolized to AMS at equal efficiencies (see product AFHS), the expected AUC, based on the response factors for pure $\mathrm{L}(+)$-alliin and pure SAC and their content, would be $152 \mathrm{ng}-\mathrm{h} / \mathrm{L}(399 \times 0.38)$ for alliin plus $35 \mathrm{ng}-\mathrm{h} / \mathrm{L}(71.4 \times 0.49)$ for SAC, for a total of 187. In reality, the AUC was found to be 2.5 -fold higher (472 ng-h/L). Similar enhanced ratios were found for boiled garlic, roasted garlic and pickled garlic (av 2.4, not shown). The nature of this enhancing factor is unknown, but it is unlikely to be a protein. The similarity found in the RRF2 values for PFHA (14.7) which contains almost no protein, and boiled garlic (14-18, Table 9), where protein has not been removed, demonstrates that the inactivated alliinase present in these garlic foods was not reactivated in the body to a measurable extent.

\subsubsection{Alliin-Free, High $\Gamma$-Glutamyl-S-Allylcysteine (GSAC) Extract (AFHG)}

An extract (AFHG) void of alliin and alliin-derived compounds was prepared for the purpose of determining the effect of the remaining known S-allyl compounds (G/SAC) in garlic on breath AMS production. AFHG and PFHA were made from the same small batch of bulbs and extracted at the 
same ratio ( $14 \mathrm{~mL}$ water/g clove). Different amounts were consumed ( $57 \mathrm{~mL}$ and $68 \mathrm{~mL}$ ) to obtain the same amount of G/SAC. Similar to consuming PFHA, consumption of AFHG resulted in breath AMS that was detectable in less than $0.25 \mathrm{~h}$, reached $50 \%$ of $\mathrm{Cmax}$ in $1 \mathrm{~h}$, and reached $\mathrm{Cmax}$ in $2.9 \mathrm{~h}$, followed by a gradual decline to near zero at about 24-25 h (Figure 4R). The loss in AMS production, due to removal of alliin in preparing AFHG, was determined by comparing the allicin bioequivalence (RF3) of PFHA and AFHG on the basis of the weight of garlic clove in the consumed extracts: $4.9 \mathrm{~g}$ for PFHA and $4.1 \mathrm{~g}$ for AFHG. The RF3 for PFHA was 97 (AUC 472/4.9 g), while the RF3 for AFHG was 50 (AUC 203/4.1 g). Hence, only about 50\% (50/97) of the allicin bioequivalence of PFHA was lost upon removal of alliin, demonstrating that about $50 \%$ of the AMS production from PFHA was due to G/SAC and that the body is capable of metabolizing significant amounts of G/SAC to AMS when alliinase is inhibited.

Because GSAC and SAC are the only known $S$-allyl compounds in this extract, and because they have been shown to be metabolized to AMS at equal efficiencies (see product AFHS), the expected AUC for AFHG was calculated-based on the response factor for pure SAC and the content of G/SAC-to be $35 \mathrm{ng}-\mathrm{h} / \mathrm{L}(70.6 \times 0.49)$. In reality, the AUC was found to be 5.8-fold higher than expected (203 ng-h/L, Table 10), giving a response factor (RF2) of 2.85 for G/SAC when they are present in garlic, compared to an RF value of 7.2 for the allyl thiosulfinates in the raw homogenate control (Table 9). As with PFHA and alliin, something is enhancing the metabolism of G/SAC to AMS in the absence of active alliinase, and it is more effective in doing so for G/SAC than it is for alliin.

\subsubsection{Alliin-Free, High-SAC Extract (AFHS)}

The kinetic difference between AMS production from GSAC or SAC in garlic was examined after converting $95 \%$ of the GSAC in AFHG to SAC with added $\gamma$-glutamyl transpeptidase. The kinetics of the AMS concentration curve for AFHS was essentially identical to that of AFHG (Tmin $<0.25 \mathrm{~h}, 43 \%$ of Cmax reached in $1 \mathrm{~h}$, Cmax reached in $2.5 \mathrm{~h}$, followed by gradual decline to near zero in 23-24 h). Both products gave the same RRF2 value (Table 10). Hence, GSAC and SAC are metabolized to AMS with equal efficiency, which also indicates that the body is highly efficient at cleaving GSAC to form SAC. Surprisingly, conversion of the GSAC to SAC did not change the Tmax (2.4 h), even though the Tmax for pure SAC was $8.4 \mathrm{~h}$. Hence, the factor that is enhancing the amount of SAC being metabolized to AMS is also enhancing the rate of AMS formation from SAC.

\subsubsection{AFHG Plus Added SAC}

To test the proposal that something in enzyme-inactivated garlic is enhancing the percent of metabolism of SAC to AMS, pure SAC was added to AFHG, followed by consumption. Because the addition of $141 \mu \mathrm{mol}$ pure SAC to the AFHG increased the total SAC content three-fold (from 70.6 to $212 \mu \mathrm{mol}$ ), the AUC for this product was expected to be three-fold higher than for AFHG alone, or $636 \mathrm{ng}-\mathrm{h} / \mathrm{L}(3 \times 212)$. In reality, the AUC was found to be only $277 \mathrm{ng}-\mathrm{h} / \mathrm{L}$ (Table 10), which is only about 30\% higher than for AFHG. This low increase is either due to a highly non-linear dose response or something else is involved.

Although AFHG was consumed at only one dose, consumption of another alliinase-inhibited garlic product, acid-minced garlic (Table 9), at $7 \mathrm{~g}$ and $20 \mathrm{~g}$, gave a fairly linear response (AUC/wt ratio: 1.2) in the AUC range of 740 to $2600 \mathrm{ng}-\mathrm{h} / \mathrm{L}$ (not shown). Hence, non-linearity is unlikely to be the reason for the low response to the added SAC. The AUC value of $277 \mathrm{ng}-\mathrm{h} / \mathrm{L}$ for AFHG + SAC is very close to the calculated value of $281 \mathrm{ng}-\mathrm{h} / \mathrm{L}$ that is found if the added SAC was metabolized to AMS in an unenhanced manner [AUC from AFHG (212) and from added pure SAC $(141 \mu \mathrm{mol} \times$ $0.49, \mathrm{RF})=281$ ] . Hence, the factor in garlic that enhances the metabolism of SAC to AMS appears to be present only in sufficient quantity to enhance the amount of G/SAC naturally present in garlic, an unlikely situation. 


\subsubsection{Search for Unknown S-Allyl Compounds}

Rather than the proposed presence of an enhancing factor to explain the higher than expected amounts of breath AMS from alliin-free or alliinase-inhibited garlic, another explanation could be the possible presence of substantial amounts of previously undiscovered $S$-allyl compounds, such as peptides containing $S$-allylcysteine, $S$-allylcysteine sulfoxide (alliin), $\gamma$-glutamyl $S$-allylcysteine, or $\gamma$-glutamyl $S$-allylcysteine sulfoxide. To explore this possibility, both AFHG extract and roasted garlic (prepared at $160^{\circ} \mathrm{C}$ ) were incubated with a large excess of either protease or alkaline protease, followed by incubation with $\gamma$-glutamyl transpeptidase (see Section 2.21). Protease alone caused no change in alliin, SAC, or GSAC. Alkaline protease alone or $\gamma$-glutamyl transpeptidase alone caused complete depletion of the free GSAC present before incubation and increased SAC only by the amount expected from hydrolysis of the free GSAC, with no change in alliin. Combining the proteases with $\gamma$-glutamyl transpeptidase also did not increase the amount of SAC beyond that expected from hydrolysis of the free GSAC, also with no change in alliin. Hence, no hidden or unknown $S$-allyl sources were revealed by this hydrolysis protocol. Thus, the real reason for the enhanced metabolism of SAC to AMS in PFHA, AFHG, AFHS, and alliinase-inhibited garlic foods cannot be explained based on the present work and remains unknown.

\subsection{Accounting for the AMS Formed upon Consumption of Alliinase-Inhibited Garlic Products}

To determine the individual contribution of alliin and G/SAC to the breath AMS content after consuming alliinase-inhibited garlic foods, their in-garlic response factors were determined, in contrast to using the response factors found after consuming the pure compounds ( 0.38 for alliin and 0.49 for SAC, Table 10). Based on the results with AFHG, where GSAC and SAC are the exclusive known $S$-allyl compounds, the in-garlic response factor for G/SAC, in the absence of active alliinase, was found to be 2.85 (Table 10), a 5.8-fold enhancement (2.85/0.49). Based on the results with PFHA, where alliin is $85 \%$ of the known $S$-allyl compounds, the in-garlic response factor for alliin, after correcting for the amount of GSAC and SAC present, was calculated to be 0.67 (Table 11, footnote 2) when alliinase is inactive, a 1.8-fold enhancement $(0.67 / 0.38)$, in contrast to a response factor of 7.2 when alliinase is active.

An important concern is whether or not enough is known about the composition and response factors for the $S$-allyl compounds in alliinase-inhibited garlic foods to be able to approximately predict the AMS-AUC values. As shown in Table 11, the average predicted AUC was 93\% of the actual, compared to 19\%, when only the alliin-derived allyl thiosulfinates and allyl polysulfides (AllylTS/Sx) were included. A range of 72 to $133 \%$ indicates that some of the actual AUC may be unaccounted for, especially for roasted garlic and acid-minced garlic, or that it is in the range of experimental or interpretive error. Alternatively, perhaps the in-garlic response factors for G/SAC and alliin are not the same in each of these garlic foods as it is for AFHG or PFHA, due to different methods of preparation. However, a prediction that is at least $72 \%$ accurate represents a reasonably good understanding of the $S$-allyl sources and their response factors.

Using the in-garlic response factors, it was found that alliin, AllylTS/Sx, and G/SAC accounted for an average of $36 \%, 19 \%$, and $39 \%$ (total $94 \%$ ) of the actual AUC. If all contribution from G/SAC had been eliminated, alliin and AllylTS/Sx would have accounted for only 55\% of the actual AUC, demonstrating that GSAC and SAC are important contributors to breath AMS for alliinase-inhibited garlic products. Additionally, if the response factors found for pure SAC and pure alliin had been applied, G/SAC and alliin would have accounted for only $27 \%$, rather than $75 \%$ of the actual AUC. This would have left most of the actual AUC unaccounted for and demonstrates the importance and approximate accuracy of the in-garlic response factors. 
Table 11. Accounting for the AMS-AUC values for alliinase-inhibited garlic foods.

\begin{tabular}{cccccc}
\hline \multirow{2}{*}{ Garlic Food } & \multicolumn{3}{c}{ Predicted Contribution to the AUC ${ }^{\mathbf{1}}$ (and \% of Actual AUC) } & \multirow{2}{*}{ AUC ${ }^{\mathbf{1}}$ (ng-h/L) } \\
\cline { 2 - 4 } & Alliin ${ }^{\mathbf{2}}$ & AllylTS/Sx ${ }^{\mathbf{3}}$ & G/SAC & Total & \\
\hline Response factor & $0.67^{2}$ & $7.2^{3}$ & $2.85^{4}$ & & \\
Roasted $160^{\circ} \mathrm{C}$ & $268(28)$ & $168(18)$ & $280(29)$ & $716(75)$ & 955 \\
Roasted $215^{\circ} \mathrm{C}$ & $268(35)$ & $60(8)$ & $258(33)$ & $586(76)$ & 773 \\
Boiled 4 min & $302(52)$ & $31(5)$ & $295(51)$ & $628(108)$ & 580 \\
Boiled 45 min & $302(71)$ & $17(4)$ & $249(58)$ & $569(133)$ & 428 \\
Pickled garlic & $260(46)$ & $65(12)$ & $166(30)$ & $491(88)$ & 560 \\
Acid-minced & $90(13)$ & $153(21)$ & $275(38)$ & $518(72)$ & 717 \\
Oil-chopped & $24(6)$ & $259(63)$ & $121(30)$ & $404(99)$ & 410 \\
Average (\%) & $(36)$ & $(19)$ & $(39)$ & $(93)$ & \\
\hline
\end{tabular}

${ }^{1}$ Predicted AMS-AUC (ng-h/L) for each compound, calculated as the in-garlic response factor times $\mu$ mol consumed. For $\mu$ mol consumed, see Table 4. The actual AUC values for seven persons each is given in Table 9. ${ }^{2}$ Alliin. The in-garlic $\mathrm{RF}_{\text {alliin }}$ has been calculated based on the AUC for PFHA, where $85 \%$ of the TKSA is alliin, minus the AUC contribution from G/SAC. Calculation: $\mathrm{RF}_{\text {alliin }}=\left(\mathrm{AUC}_{\mathrm{PFHA}}-\mathrm{AUC}_{\mathrm{G} / \mathrm{SAC}}\right) / \mu \mathrm{mol}$ alliin; $\mathrm{AUC}_{\mathrm{PFHA}}=472$ (Table 10); $\mathrm{AUC}_{\mathrm{G} / \mathrm{SAC}}=\mathrm{RF}_{\mathrm{G} / \mathrm{SAC}}(2.85) \times 71.4 \mu \mathrm{mol}=203 ; \mathrm{RF}_{\text {alliin }}=(472-203) / \mu \mathrm{mol}$ alliin $(399)=0.67 .{ }^{3}$ AllylTS $/ \mathrm{Sx}$ (allyl thiosulfinates and allyl polysulfides). This is the same RF as for the raw homogenate control (7.2, Table 9), where all of the alliin had been converted to AllylTS/Sx and where G/SAC account for only 1-8\% of the AUC. ${ }^{4} \mathrm{G} / \mathrm{SAC}\left(\mathrm{GSAC}+\mathrm{SAC}\right.$ ). The in-garlic $\mathrm{RF}_{\mathrm{G} / \mathrm{SAC}}(2.85)$ is the same as the RF for AFHG (Table 10, $n=4$ ), where $>99 \%$ of the TKSA is due to G/SAC.

\subsection{Accounting for the AMS Formed upon Consumption of Alliinase-Active Garlic Supplements}

Because G/SAC contributed about $40 \%$ of the breath AMS found after consuming alliinaseinhibited garlic foods (Table 11), it can no longer be assumed that G/SAC makes no contribution to the AMS found after consuming garlic products that have active alliinase, even though SAC is known to not be a substrate for alliinase [26]. The data in Table 12, arranged in order of decreasing allicin bioavailability (RRF), attempts to explain the extent to which the various $S$-allyl sources contribute to the breath AMS found after consuming garlic supplements containing active alliinase. Determining the contribution of each $S$-allyl source is more complex than it is for alliinase-inhibited garlic foods. The complexity is mainly due to the different levels of protection of alliinase from gastric acid among supplements. Alliinase protection appears to vary with coating type, buffering capacity of the garlic powder, the influence of added excipients (Table 2) [30], particle size of garlic powders used in capsules (Section 3.7.4), and reversibility of alliinase activity inhibition when the local gastric $\mathrm{pH}$ does not go below 3.0-3.5 [14]. With enteric-coated tablets, additional variability is caused by the effect of meal protein content on allicin bioavailability (Table 6). A further significant complication is the unknown extent to which the metabolism of G/SAC to AMS is enhanced when alliinase activity is inhibited to variable degrees, which enhancement has been demonstrated to be 5.8-fold when alliinase is fully inactivated prior to consumption, as with cooked or acid-treated garlic foods (Section 3.11.5).

The contribution of each $S$-allyl source to the observed AMS-AUC has been determined based on the in-garlic response factors for alliin, allyl polysulfides, and G/SAC, but the values for these response factors for alliin and G/SAC are not straightforward. The RF for alliin has been calculated (Table 12, footnote 2) based on the RF for allyl polysulfides (7.2), which is independent of alliinase activity, and the RF for G/SAC, which value is uncertain, especially when alliinase inhibition is substantial. Two values are proposed in Table 12 for $\mathrm{RF}_{\mathrm{G} / \mathrm{SAC}}$ : the unenhanced value of 0.49 , which is used when the allicin bioavailability is $>50 \%$ (above the line in Table 12), and a four-fold enhanced value of 2.0 when alliinase inhibition is substantial, but not complete, as indicated by allicin bioavailability $<40 \%$. The proposed $\mathrm{RF}_{\mathrm{G} / \mathrm{SAC}}$ value of 2.0 is less than the value found (2.85) when alliinase is completely inhibited. The in-garlic response factor for alliin $\left(\mathrm{RF}_{\text {alliin }}\right)$ was found to vary for each product, but it generally declined according to the in vivo inhibition of alliinase, as indicated by the percent allicin bioavailability. The $\mathrm{RF}_{\text {alliin }}$ can also be used to calculate (Table 12, footnote 3 ) the percent conversion of alliin to AMS, which value closely reflects the percent allicin bioavailability. 
When the allicin bioavailability was $>50 \%$ (presumed $\mathrm{RF}_{\mathrm{G} / \mathrm{SAC}}=0.49, n=10$ ), alliin and the small amounts of allyl polysulfides-formed during manufacture of the garlic powders-accounted for an average of $95 \%$ of the AMS-AUC. In these cases, the contribution from G/SAC was small (1-10\%, average $5 \%$ ), which was true for all brands of normal tablets, for 4 of 5 brands of enteric tablets consumed with the low-protein meal, and for 2 of 3 brands of capsules. When the allicin bioavailability was $<40 \%$ (presumed $\mathrm{RF}_{\mathrm{G} / \mathrm{SAC}}=2.0, n=4$ ), the contribution from $\mathrm{G} / \mathrm{SAC}$ was elevated to $13-21 \%$ (av 15\%), excluding capsule brand C2, which was exceptionally high at $77 \%$, presumably due to its very low initial alliinase activity (Table 6), the fineness of the garlic powder, and perhaps to its exceptionally high content of G/SAC (Table 4). Hence, G/SAC is not a significant contributor to breath AMS from garlic supplements, except when inhibition of alliinase activity substantially reduces allicin bioavailability.

Table 12. Accounting for the AMS-AUC values for garlic supplements having active alliinase.

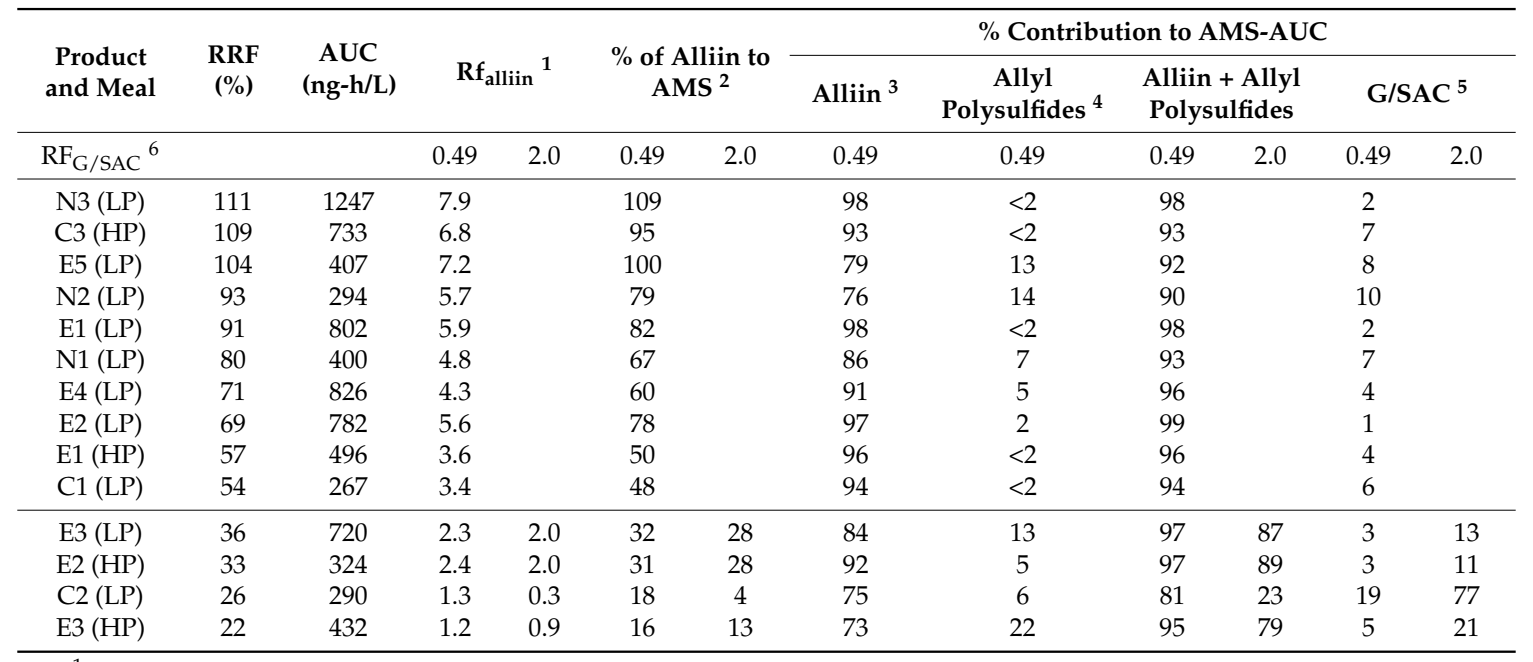

${ }^{1}$ The $\mathrm{RF}_{\text {alliin }}$ value needed to obtain the observed $\mathrm{AUC}=\left(\mathrm{AUC}-\mathrm{AUC}_{\text {allyl polysulfides }}-\mathrm{AUC}_{\mathrm{G} / \mathrm{SAC}}\right) / \mu \mathrm{mol}$ alliin. $\mathrm{AUC}_{\text {allyl polysulfides }}=\mathrm{RF}_{\text {allyl polysulfides }}(7.2) \times \mu \mathrm{mol}$ allyl polysulfides; $\mathrm{AUC}_{\mathrm{G} / \mathrm{SAC}}=\mathrm{RF}_{\mathrm{G} / \mathrm{SAC}}(0.49$ or 2.0$) \times \mu \mathrm{mol}$ G/SAC; amounts of alliin, allyl polysulfides, and G/SAC are in Table $4 .{ }^{2}$ Percent of the alliin in the product that has been metabolized to AMS through garlic's alliinase activity $=100 \times \mathrm{RF}_{\text {alliin }}$ divided by the RF value for alliin (7.2) when alliinase is not inhibited. The small amount of alliin metabolized to AMS independent of alliinase $\left(\mathrm{RF}_{\text {alliin }}<0.67\right)$ has not been included. ${ }^{3}$ Percent of breath AMS-AUC that comes from alliin $=\mathrm{RF}_{\text {alliin }} \times \mu \mathrm{mol}_{\text {alliin }}$ consumed $\times 100 /$ AUC. ${ }^{4}$ Percent of breath AMS-AUC that comes from allyl polysulfides $=R_{\text {allyl polysulfides }} \times$ $\mu_{\text {mol }_{\text {allyl }} \text { polysulfides }}$ consumed $\times 100 /$ AUC. ${ }^{5}$ Percent of breath AMS-AUC that comes from G/SAC $=\mathrm{RF}_{\mathrm{G} / \mathrm{SAC}}$ $(0.49$ or 2.0$) \times \mu \mathrm{mol}_{\mathrm{G} / \mathrm{SAC}}$ consumed $\times 100 / \mathrm{AUC} .{ }^{6}$ Response factors for G/SAC. The value of 0.49 is based on consumption of pure SAC. The value of 2.0 represents the estimated enhanced in-garlic response factor when alliinase is mostly, but probably not completely, inhibited in vivo; it is applied here only when the allicin bioavailability is less than $40 \%$.

\section{Discussion}

\subsection{Unexpected Allicin Bioavailability from Garlic Supplements-Meal Effects}

Normal tablets and capsules were expected to disintegrate rapidly in the stomach under low $\mathrm{pH}$ conditions $(\mathrm{pH}<3)$ in which alliinase would be fully inhibited, resulting in little $(<5 \%)$ allicin bioavailability. On the contrary, all brands of normal tablets gave high allicin bioavailability even though they disintegrated rapidly and achieved Tmin and Tmax as rapidly as the raw garlic control capsules containing pre-formed, acid-stable allicin (Table 6). Supplement capsules also provided much higher allicin bioavailability than expected and did so almost as rapidly as the control, but the range in bioavailability was broader for the capsules (26-109\%) than it was for the normal tablets (73-111\%). Unlike the enteric tablets, allicin bioavailability for normal tablets and capsules was the same with both the low- and high-protein meals. Certainly, the main reason for these high results is the temporary buffering effect of the meals upon the gastric $\mathrm{pH}$. It has been shown that when a person 
begins to consume a meal that the basal gastric $\mathrm{pH}(1.4-1.9)$ rapidly increases in about 14 min to a maximum of $\mathrm{pH} 4.4-6.7$ (median 6.3) and that it requires an additional average of 106 min before gastric acid secretion can overcome the buffering effect of the meal and return the gastric $\mathrm{pH}$ to the basal level $[27,28]$. Garlic alliinase is inactive at pH 3.5 or below, has some activity at $\mathrm{pH} 4.0$, and has maximum activity at $\mathrm{pH} 4.5-6.5$ [14,60]; hence, when the gastric $\mathrm{pH}$ is at 4.0 or above alliinase will be active. Studies with typical meals for breakfast, lunch, and dinner have shown that the gastric $\mathrm{pH}$ is $\geq 4.0$ for an average of $0.7 \mathrm{~h}(0.3-1.2 \mathrm{~h}, n=6)$ after consumption [27,28,42]. Even consumption of a cup of tea or coffee can almost raise the gastric $\mathrm{pH}$ to 4.0 for about $5 \mathrm{~min}$ [28]. Complete formation of allicin from alliin in garlic powder suspended in aqueous medium takes place very rapidly: in $0.2 \mathrm{~min}$ at pH 6.3 and in $10 \mathrm{~min}$ at pH 4.5 [14]. Hence, both low-protein and high-protein meals would provide a gastric $\mathrm{pH} \geq 4.0$ for an ample amount of time for the alliinase in disintegrated normal tablets and capsules to convert most of the alliin to allicin in the stomach.

For enteric-coated tablets, the type of meal with which the tablets were consumed had a substantial effect on allicin bioavailability and tablet disintegration time (Table 6). This was true for all three of the brands that were consumed with both meal types. Compared to consumption with the low-protein meal, the high-protein meal caused an additional delay in the Tmin by 2-6.5 h, an additional delay in the Tmax by $2.3-5.6 \mathrm{~h}$, and a decrease in allicin bioavailability from an average of $65 \%$ to an average of $37 \%$. Similarly, a high-protein meal (compared to no meal) has been shown to substantially delay the disintegration of enteric-coated aspirin tablets by delaying the gastric emptying time [52,61,62]. When enteric aspirin was consumed with a high meat meal (58-70 g ham, 33-36 g protein, estimate), rather than with water only, the Tmin for plasma salicylate increased from $2 \mathrm{~h}$ to $5 \mathrm{~h}$ and the Tmax increased from $6 \mathrm{~h}$ to $9 \mathrm{~h}$, indicating a $3 \mathrm{~h}$ delay in gastric emptying time [61]. When enteric aspirin was consumed with a meal of fried egg, milk and cheese ( $22 \mathrm{~g}$ protein, estimate), rather than with water only, the gastric residence time was found to increase from $0.8 \mathrm{~h}$ (range 0.25 to $1.5 \mathrm{~h}$ ) to $5.9 \mathrm{~h}$ (range 3 to $12 \mathrm{~h}$ ), with increases in Tmin of $5.2 \mathrm{~h}$ and Tmax of $5.5 \mathrm{~h}$ [52]. The reason these high-protein meals delayed the gastric emptying time for enteric aspirin is related to the fact that food must be digested to particle sizes of $1 \mathrm{~mm}$ or less in order to exit the stomach through the pyloric sphincter, but it takes several hours for this amount of digestion to occur for meat chunks and other foods that are slow to digest [42]. Once the food has been sufficiently digested and expelled from the stomach, non-digestible objects, such as enteric tablets, are expelled by the final sweep of the interdigestive myoelectric contraction $[42,63]$.

Enteric tablets are designed to resist a low gastric $\mathrm{pH}$ for at least $2 \mathrm{~h}$, but when consumed with a high-protein meal, the tablets will be exposed to a low $\mathrm{pH}$ for about $6 \mathrm{~h}$ and perhaps as long as $12 \mathrm{~h}$, which probably makes the coating vulnerable to weakening, swelling, and possibly to partial disintegration, allowing gastric fluid of a low $\mathrm{pH}$ to come in contact with and at least partially inhibit alliinase. A second reason why a high-protein meal contributes to decreased allicin bioavailability is due to a temporary rise in the gastric $\mathrm{pH}$, caused by the buffering effect of meal protein, as mentioned previously, to a range (4.4-6.7) in which enteric coatings are meant to dissolve, 5.0-7.0 [64]. Hence, some compromise in the integrity of the coating would be expected to occur before the $\mathrm{pH}$ of the gastric juice returns to a low value and remains low for several hours, during which time it can penetrate the damaged tablets, inhibit alliinase, and reduce subsequent allicin formation in the small intestine.

The low-protein meal used in this study contained no meat, egg or cheese; therefore, it would have been digested much more rapidly than the high-protein meal, and the tablets would have passed rapidly through the stomach, perhaps at a rate similar to the $0.8 \mathrm{~h}$ gastric residence time observed when enteric aspirin tablets are consumed with water only (fasting) [52]. The rapid passage of E1 and E2 through the stomach when consumed with the low-protein meal is indicated by a Tmin for breath AMS of 2.2-2.6 h, which is similar to the Tmin of 2-2.7 $\mathrm{h}$ found for plasma salicylate when enteric aspirin tablets were consumed with water only $[52,61]$. The short gastric residence time would expose the tablets to a low $\mathrm{pH}$ for less time, with less likelihood for decay of the enteric coating and less inhibition of tablet alliinase activity. Furthermore, the smaller amount of protein in the low-protein meal would 
also mean less buffering of the basal gastric $\mathrm{pH}$, a lower temporary maximum $\mathrm{pH}$ in the stomach (perhaps no higher than 4-4.5), less compromising of the integrity of the coating, less inhibition of garlic alliinase activity in the stomach, and higher production of allicin in the small intestine, as was observed with most of the enteric products tested in this study.

The only known food component that interacts with allicin at body temperature is protein-derived cysteine. Allicin reacts quantitatively with cysteine, to form two moles of $S$-allylmercaptocysteine (allyl-S-S-Cys) [16,32]. This reaction probably occurs to some extent when the allicin released from garlic products in the gastrointestinal tract comes in contact with the cysteine released from digested meal protein. The formation of $S$-allylmercaptocysteine would increase with increased meal protein content. However, this reaction probably has little effect on allicin bioequivalence, because $S$-allylmercaptocysteine has been shown in human studies to also be quantitatively metabolized to AMS, at the same rapid rate as for allicin [17].

\subsection{Comparing Garlic Supplements and Garlic Foods through Allicin Metabolite Equivalence}

Clinical trials that explore the possible health benefits of garlic typically use garlic powder supplements in order to provide a consistent, stable and convenient dosage form that is usually also standardized to a specific allicin potential and/or alliin content. A common and important concern among consumers is the amount of a preferred garlic food, such as cooked garlic, that one needs to consume to obtain the health benefits indicated for the supplements used in clinical trials. A similar concern is the amount of a preferred supplement one needs to consume to obtain the possible health benefits reported for a different supplement. These concerns can be addressed by comparing their allicin metabolite equivalence through the AMS-AUC. This comparison assumes that allicin or its metabolite(s) are responsible for most of the observed health benefits of a garlic product.

Table 13 gives dose comparisons among garlic supplements and garlic foods based on allicin metabolite equivalence, compared to consuming $2 \mathrm{~g}$ of crushed raw garlic or three N1 tablets. Two grams of raw garlic is half of the therapeutic dose $(4 \mathrm{~g})$ recommended by the German Commission $\mathrm{E}$ [65]. Also, most clinical trials with garlic powder supplements have used the equivalent of 1-2 raw garlic, based on claimed alliin content of 7.8-17 mg or equivalent allicin potential of 3.6-7.8 mg [1]. The allicin potential of raw cloves varies from about 2.4 to $4.6 \mathrm{mg} / \mathrm{g} \mathrm{fr} \mathrm{wt}$, with an average of $3.6 \pm 0.9 \mathrm{mg} / \mathrm{g}$ fr wt $[19,20,30,66]$. The raw garlic control used in this study and shown in Table 13 had an allicin potential of $3.97 \mathrm{mg} / \mathrm{g}$ clove or $7.9 \mathrm{mg}$ for $2 \mathrm{~g}$. Hence, the raw garlic control contained a typical amount of allicin. Product N1 has also been shown in Table 13 for comparisons because it is the main product that has been used in clinical trials with garlic supplements, even though the results with N1 have been inconsistent [1-3,67]. Three tablets has been the most common dose used in these trials. The N1 tablets in these trials have been consistently standardized to contain $3.9 \mathrm{mg}$ alliin/tablet and to yield $1.8 \mathrm{mg}$ allicin/tablet [1,68-70]. Three N1 tablets represent about $1 \mathrm{~g}$ of typical raw garlic, with respect to alliin content $(11.7 \mathrm{mg}$ per 3 tablets vs. the average for raw garlic, $9.7 \pm 2.0 \mathrm{mg} / \mathrm{g} \mathrm{fr}$ wt $[49,50,71])$ and with respect to allicin metabolite equivalence ( $400 \mathrm{vs.} 435 \mathrm{ng}-\mathrm{h} / \mathrm{L}$, Table 13).

Among garlic supplements (Table 13), there is a large range in the amount required to obtain the same allicin metabolite equivalence as $2 \mathrm{~g}$ raw garlic (0.7-27 tablets/capsules) or three N1 tablets (0.3-12 tablets/capsules). This range is due to variation in tablet/capsule size (0.1-1.0 g garlic powder, Table 1), variation in alliin content $(6.5-49 \mathrm{mg} / \mathrm{g}$ garlic powder, Table 4$)$, and variation in allicin bioavailability (RRF, 22-111\%, Table 6); it highlights the need to carefully evaluate garlic supplements being considered for use in clinical trials. For alliinase-inhibited garlic foods, $5.9 \mathrm{~g}$ of roasted garlic and $11 \mathrm{~g}$ boiled garlic must be consumed to obtain the same equivalence as $2 \mathrm{~g}$ raw garlic. These are not unreasonable amounts, because it is often less objectionable (no throat burn, caused by allicin release from raw garlic) for most people to consume 6-11 g (2-3 average cloves) of cooked garlic than to directly consume $2 \mathrm{~g}$ of raw garlic. At 2.6-5.2 g, cooked garlic provides the same equivalence as three N1 tablets. For the three acidified commercial garlic foods (pickled, acid-minced, oil-chopped), 5.3 to $19 \mathrm{~g}$ or 2.4 to $8.6 \mathrm{~g}$ provide the same equivalence as $2 \mathrm{~g}$ raw garlic or three $\mathrm{N} 1$ tablets. 
Table 13. Equivalence among garlic products, based on the allicin metabolite, AMS.

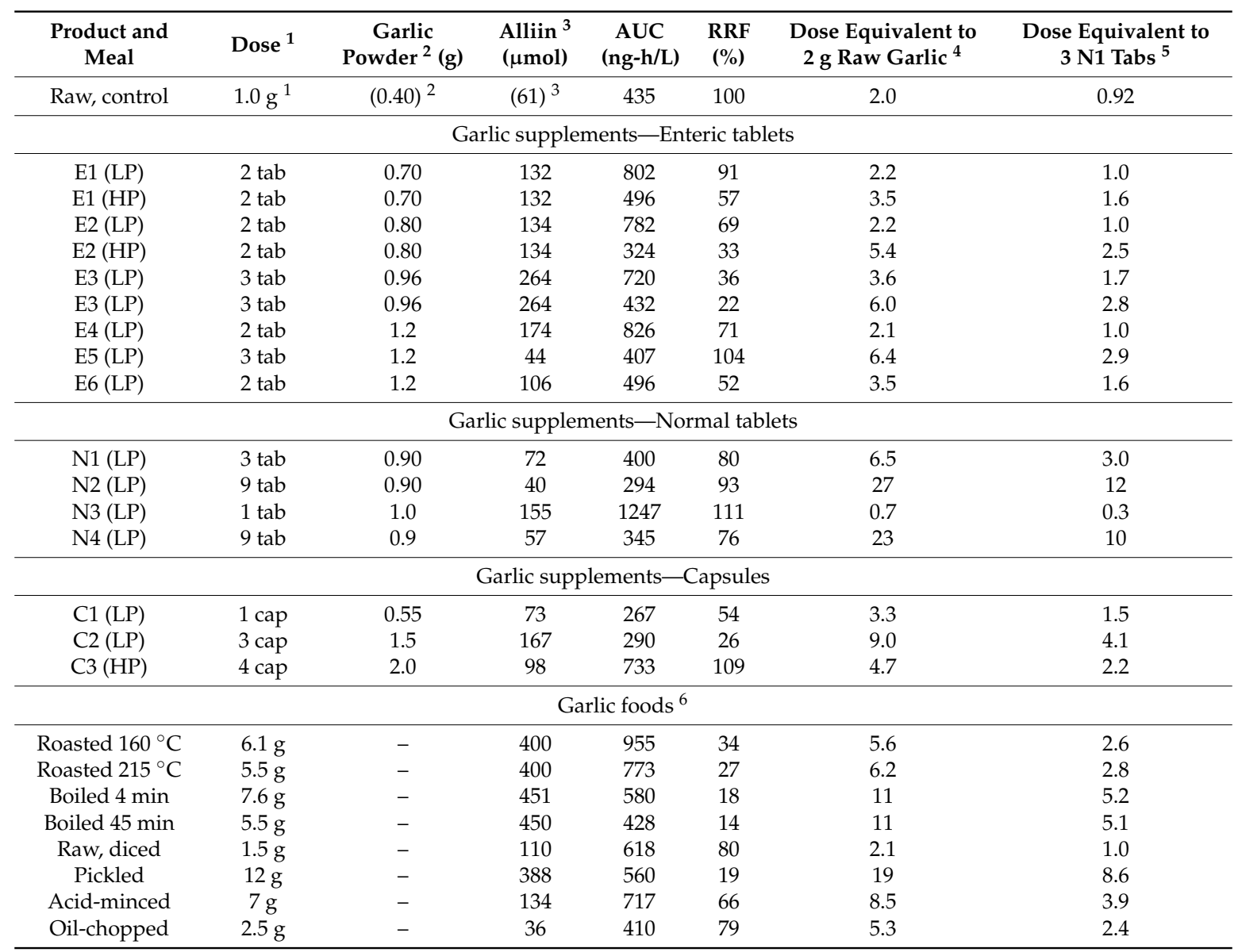

${ }^{1}$ Dose consumed, expressed as number of tablets or capsules or weight of garlic foods. For the raw garlic control, the dose is $1.0 \mathrm{~g}$ of clove, from which the homogenate was made, not $1.0 \mathrm{~g}$ of homogenate. ${ }^{2}$ Amount of garlic power claimed in the supplement dose consumed (see Table 1). For the raw garlic control, it represents the dry weight of the cloves $\left(0.395 \mathrm{~g}\right.$ dry wt $/ \mathrm{g}$ fr wt). ${ }^{3}$ Amount of alliin found in the consumed dose (Table 4). For the raw garlic control, all the alliin was transformed to allyl thiosulfinates upon homogenization; the value shown $(61 \mu \mathrm{mol}$ or $10.8 \mathrm{mg} / \mathrm{g} \mathrm{fr} \mathrm{wt}$ ) is the alliin that was present before homogenization, calculated from the allyl thiosulfinates (Section 3.5). ${ }^{4}$ The dose of garlic product (number of tablets/capsules or grams of garlic foods) needed to obtain the same AMS-AUC that is found after consuming $2 \mathrm{~g}$ of the raw garlic used as the control $=$ (dose of product consumed) $\times$ (AUC for $2 \mathrm{~g}$ of raw garlic, $870 \mathrm{ng}-\mathrm{h} / \mathrm{L}) /\left(\right.$ AUC of the product). ${ }^{5}$ The dose of garlic product needed to obtain the same AMS-AUC that is found after consuming three $\mathrm{N} 1$ tablets $=$ (dose of product consumed) $\times($ AUC for three N1 tablets, $400 \mathrm{ng}-\mathrm{h} / \mathrm{L}$ )/(AUC of the product). ${ }^{6}$ Garlic foods were all consumed with the LP meal.

\subsection{Garlic Supplements Used in Former Clinical Trials: Evaluation of Their Allicin Bioavailability}

When clinical trials with garlic products show positive effects with some products and null or fluctuating effects with other products, it is reasonable to question both the dose and the availability of the suspected active compound(s), especially because of the tenuous nature of allicin formation. Hence, the main garlic supplement (Kwai, N1) used in clinical trials on the possible cardiovascular effects of garlic has been criticized as not representing raw garlic, due to low allicin release found in vitro under USP-defined simulated gastrointestinal conditions [31]. However, upon evaluating allicin bioavailability from this garlic supplement in vivo through breath AMS production (Table 6), it was found to give high allicin bioavailability that was not significantly less than that of crushed raw garlic, regardless of meal type. Even Kwai tablets that were manufactured in 1992, in the middle of the time period that most of the clinical trials with these tablets were being conducted (1986-2000), were found to give equally high allicin bioavailability 19 years later (Table 6, product N4). Hence, the results of the many clinical trials that have been conducted with this consistently standardized garlic supplement 
can be considered as valid for representing crushed raw garlic. However, the frequently used daily dose of 3 Kwai tablets represents only a modest amount of typical raw garlic, $0.92 \mathrm{~g}$ (Table 13).

Garlicin (product E1), an allicin-standardized enteric tablet, has been used in a 2007 clinical trial that found no effect on serum lipids at a daily dose of 4 tablets, representing $4 \mathrm{~g}$ of raw garlic [72]. The product has been previously reported [37], and is again reported (Table 6) to have high allicin bioavailability, equivalent to that of crushed raw garlic. Hence, the results of this 2007 trial do represent a high dose of raw garlic. The only other garlic supplement that this study has investigated for allicin bioavailability that has also been used in a clinical trial is product N3 (GNC 1000), which consists of non-standardized non-enteric tablets. A clinical trial using this supplement at 2 tablets per day concluded that "garlic" has no effect on platelet function in vivo [73]. Even though it was presumptuous, not knowing the quality of the supplement, to extrapolate the results of the trial to garlic itself, the allicin bioavailability of the product was found to be high and equivalent to that of crushed raw garlic (Table 6). Additionally, the product had a high alliin content, such that 2 tablets represented a dose of $5.7 \mathrm{~g}$ of typical raw garlic (Table 13). Therefore, it can be confidently concluded that this clinical trial found no effect on platelet function by a garlic supplement that accurately represented a high dose of raw garlic.

\subsection{Possible Mechanisms for AMS Production from Alliin and GSAC and SAC (G/SAC) in the Absence of Active Garlic Alliinase}

One of the remarkable outcomes of this study has been the finding of unpredictably high allicin bioequivalence for alliinase-inhibited garlic foods (Table 9), as well as for garlic extracts from which alliin and alliin-derived compounds were selectively removed (AFHG, AFHS, Table 10), leaving G/SAC as the only source for AMS production. Hence, the body has metabolic pathways that lead to partial transformation of alliin and G/SAC to AMS without garlic alliinase. Three possible pathways for alliin and one pathway for G/SAC are presented in Figure 6.

(A) Alliin [allyl-S(O)-Cys] + alliinase from intestinal bacteria

$\Rightarrow$ allicin [allyl-SS(O)-allyl] + pyruvic acid $+\mathrm{NH}_{3}$

- allicin + glutathione $\Rightarrow 2$ allyl-SH (allyl mercaptan)

- allyl-SH + S-adenosyl methionine $\Rightarrow$ allyl-S-CH3 (AMS)

(B) Alliin [allyl-S(O)-Cys] + glutathione $\Rightarrow$ SAC [allyl-S-Cys]

- SAC $\Rightarrow$ pathway D $\Rightarrow$ allyl-S-CH3 (AMS)

(C) Alliin [allyl-S(O)-Cys] + S-adenosyl methionine $\Rightarrow$ allyl-S(O)-CH3 (allyl methyl sulfoxide, AMSO)

- allyl-S(O)-CH3 (AMSO) + glutathione $\Rightarrow$ allyl-S-CH3 (AMS)

(D) SAC [allyl-S-Cys] + S-adenosyl methionine $\Rightarrow$ allyl-S-CH3 (AMS)

Figure 6. Possible metabolic pathways for the partial transformation of alliin and SAC (S-allylcysteine) to AMS (allyl methyl sulfide) upon consuming alliinase-inhibited garlic. For structures, see Figures 1 and 2. Of the three proposals for alliin, only pathway $\mathrm{C}$ is likely to be relevant. 
Alliin pathway A. Since shortly after the discovery of alliin, it has been known that some bacteria, including some that are commonly found in the intestinal tract, possess alliinase activity [26,74-76]. It is also possible body organs could possess alliinase activity, although none has yet been reported; however, human serum has been shown to contain antibodies to alliinase [77]. As reported in Table 10, it was found that consumption of pure alliin resulted in only $4.6 \%$ conversion (allicin bioequivalence) to AMS. This small value represents the total contribution to AMS production from alliin through (a) intestinal bacterial alliinase; (b) any alliinase activity that the body organs might possess; and (c) non-alliinase metabolism of pure alliin to AMS. Hence, bacterial alliinase activity transforms only $0-4 \%$ of the alliin to allicin.

Alliin pathway B. One proposed pathway for the body to metabolize alliin to AMS without allicin as an intermediate is glutathione reduction of alliin to SAC, followed by metabolism of SAC to AMS by pathway D. However, this pathway would result in alliin being metabolized to AMS slower than SAC to AMS, but the opposite was found to be true, with the Tmax for pure alliin being $3.2 \mathrm{~h}$ and the Tmax for pure SAC being $8.4 \mathrm{~h}$ (Table 10). Furthermore, a study with dogs fed pure alliin has shown rapid and essentially complete absorption, but less than $0.1 \%$ of the administered alliin was found in the blood or urine as SAC or N-acetyl-SAC, while the $22 \%$ of the dose was found in the urine as $\mathrm{N}$-acetyl-alliin, $6 \%$ as alliin, and $72 \%$ as unidentified compounds [78]. It is assumed that dogs and humans metabolize alliin similarly because they have been shown to metabolize SAC similarly [79]. Hence, the body is probably not capable of reducing alliin to SAC. Therefore, pathway B probably does not occur to a significant extent in humans.

Alliin pathway C. Another proposed pathway from alliin to AMS, one without allicin or SAC as an intermediate, involves methyl transfer from $S$-adenosyl methionine (SAM) to the allyl-S(=O) group of alliin to form allyl methyl sulfoxide (AMSO), followed by glutathione reduction of AMSO to AMS. Formation of AMSO as a metabolite of an S-allyl compound derived from garlic was first demonstrated in rats fed diallyl disulfide, in which AMS and greater amounts of $\mathrm{AMSO}$ and $\mathrm{AMSO}_{2}$ (allyl methyl sulfone) were found in the liver, plasma, and urine [80]. Both rat and human liver microsomes were shown to oxidize AMS to AMSO and $\mathrm{AMSO}_{2}$ [81]. Allicin follows the same metabolic pathway as diallyl disulfide, as both are found to produce the same amount of human breath AMS when consumed as pure compounds [17]. AMS, AMSO, and AMSO2 have recently been found in the serum of rats fed aqueous garlic homogenate [82]. Hence, allicin is expected to be metabolized to AMS, AMSO, and $\mathrm{AMSO}_{2}$.

It also appears that alliin, in the absence of active garlic alliinase, is partially metabolized to AMS, $\mathrm{AMSO}$, and $\mathrm{AMSO}_{2}$. Recent studies have shown that when people consumed raw garlic cubes ( $3 \mathrm{~mm}$ cubes) that AMS, AMSO, and $\mathrm{AMSO}_{2}$ were rapidly formed and found in breast milk (Tmax about $2.5 \mathrm{~h}$ ) and urine (Tmax about 1.5 h) [83,84]. Based on how these studies were conducted, however, there was little opportunity for alliin to be transformed by alliinase to significant amounts of allicin, even though there were three opportunities to do so. Preparation of the garlic cubes probably resulted in minimal damage to the cell walls, allowing for little contact between alliin and alliinase. The current study found that only $3 \%$ of the alliin content of raw garlic was transformed to allyl thiosulfinates when the garlic was cut (diced) into $3 \mathrm{~mm}$ cubes (Section 3.5 and Table 4). Chewing the cubes would have caused the breakdown of cell walls and rapid formation of allicin before reaching the stomach, but the cubes were swallowed without chewing (Personal Communication) [85]. Furthermore, the cubes were consumed without a meal (with water only) and, therefore, without the $\mathrm{pH}$ buffering effect of a meal. Hence, the gastric $\mathrm{pH}$ was probably near 2.0 when the garlic cubes entered the empty stomach [27,28], which is well below the $\mathrm{pH}$ at which alliinase is fully inactivated $(\leq 3.5)$ [14]. Thus, garlic alliinase was probably inactivated in the stomach before alliin was released from the garlic cubes. This indicates that probably only a small percent of the alliin was ever transformed to allicin. Hence, the results of the garlic cube studies [83,84] mainly represent the metabolism of alliin in the absence of active garlic alliinase and validate the partial metabolism of alliin to AMSO in the body. 
SAC pathway D. The metabolism of pure SAC has been studied in dogs and humans, although no metabolites were initially found $[79,86]$. A more extensive study with dogs found SAC to be rapidly and completely absorbed, but only $13 \%$ of the administered dose of SAC was accounted for among the urinary metabolites: $12 \%$ as alliin plus $N$-acetyl-alliin and $1 \%$ as SAC plus $N$-acetyl-SAC [78]. Based on the presence of small amounts of breath AMS after consuming pure SAC (Table 10) and the mentioned finding of AMS, $\mathrm{AMSO}$, and $\mathrm{AMSO}_{2}$ in the urine after human consumption of garlic cubes [84], it is most likely that a significant portion of the $87 \%$ unknown SAC metabolites includes AMS, AMSO, and $\mathrm{AMSO}_{2}$. The simplest pathway from SAC to AMS would be methyl transfer from SAM to the allyl-S group of SAC. Although evidence for this transfer is currently lacking, the fact that SAM is involved in a large number of different types of methyl transfers [87] makes this pathway a reasonable possibility. Because the methylation reaction involves SAM-dependent methylase, it might be possible to explain the large difference in response factors between pure SAC and the G/SAC in garlic $(0.49 \mathrm{vs}$. 2.85 , Table 10) based on enhancement of SAM-dependent methylase activity by a currently unidentified compound in garlic.

\subsection{Effects and Side Effects of Odorous AMS}

As a metabolite of allicin, AMS has been used in this study as a tool to determine the ABB from garlic supplements and garlic foods. However, AMS has also been demonstrated to have several biological activities, including reduction of induced lipid peroxidation in mice [88], antibacterial activity [89], inhibition of cytochrome P450 2E1 [90], reduction of induced colon cancer in rats through modulation of cytochrome P450 enzymes [91,92], and increased human breath acetone levels [17]. Addionally, both AMS and AMSOhave been found to decrease induced hypertrophy in rat hearts [82]. AMS is responsible for most of the well-known breath odor that persists for several hours after consuming raw garlic, which odor is often more noticeable by close associates than by the consumer [36,93]. AMSO and $\mathrm{AMSO}_{2}$ have no odor [83], nor have they been found in the breath, using methods that could have detected them [34-36], indicating that they are too polar to be transferred to the breath. Even though many garlic supplements have been found to produce as much AMS as raw garlic, based on allicin bioavailability (Table 6), sustained breath odor perception from supplements appears to be less than that from raw garlic. In a study in which 49 participants ate sandwiches containing $4 \mathrm{~g}$ of crushed raw garlic daily for six-months, $57 \%$ of the participants reported "bad body and breath odor ... often or almost always", while none of the 47 participants who consumed four enteric E1 tablets daily for six months reported an odor problem [72]; it is possible that many of the E1 participants noticed a garlic breath odor, but did not consider it to be strong enough to qualify as a bad odor. Due to the numerous clinical trials with N1 tablets, there have been many reports in relation to breath odor. In a study with 123 participants who consumed three tablets, each containing $300 \mathrm{mg}$ of garlic powder (same dose as in Table 6), for 14 days, $20 \%$ reported moderate to strong breath odor, $25 \%$ reported slight odor and $55 \%$ reported no odor [94]. In another study with the same dose of N1 tablets for 16 weeks with 1997 participants, 4\% reported strong breath odor, $14 \%$ a definite odor, and $38 \%$ a slight odor [95]. Other studies with $\mathrm{N} 1$ tablets at this same dose have reported garlic breath odor in $11-60 \%$ of the subjects [96-99]. In a clinical trial with N3 tablets (2/d), it was stated that no side effects were found, but it is likely that breath odor was not considered to be a side effect [73].

Of the 13 garlic supplements examined in this study, the package labels for almost all of them made some type of claim in relation to dramatic reduction of the breath odor normally associated with consuming raw garlic (Table 1). The claims include "odor free" (E1, E2, E4, E5, N2, N4) or "odorless" $(E 6, N 3)$ or "no garlic breath" (E3) or "deodorized garlic" (C2). One product (C3) claimed that it was "odor controlled". Terms such as "odor controlled" or "reduced odor" represent more accurate statements that should be applied to most of the supplements, including some of the enteric products where the time before the appearance of AMS in the breath has been delayed, compared to consuming raw garlic (Table 6). Only two products made no claims related to odor: N1 and C1. The package 
insert to product $\mathrm{N} 1$ states that a side effect can be odor from the breath or skin, but it also states that the odor is linked to the product's effectiveness and recommends that the daily dose of three tablets be consumed as one tablet with each of the three main daily meals in order to reduce the eventual breath odor. Division of the recommended daily dose over 2-3 meals is also recommended on the labels for most of the products in Table 1, except for four brands of enteric tablets where the daily dose is only one tablet. Because the time to reach maximum breath AMS concentration (Tmax) is about $2-4 \mathrm{~h}$ for many of the supplements (Table 6) and because the breath AMS concentration rapidly declines after the Tmax (Figure 4), dividing the recommended dose over 2-3 meals compared to consuming all at one meal will certainly decrease the concentration of AMS in the breath and decrease the perceived breath odor.

\subsection{Recommendations}

Now that the bioavailability of allicin in humans has been determined through its metabolite, AMS, for a variety of types and brands of garlic supplements of known composition under two meal conditions, more accurate recommendations can be made for clinical trials and garlic supplement manufacturers than has been made or assumed in the past. These recommendations apply to garlic supplements that are intended to represent raw garlic in dried form. They assume that the possible health benefits being sought are mostly related to alliin-derived allicin.

\subsubsection{Alliin Content or Allicin Potential}

The German Commission E recommends $4 \mathrm{~g}$ of fresh garlic, or equivalent, for therapeutic effects [65]. This is also the average size of a garlic clove [22,100] (p. 46). The average allicin potential of garlic cloves is $3.6 \pm 0.9 \mathrm{mg} / \mathrm{g}$ fr wt or $10.8 \mathrm{mg} / \mathrm{g}$ dry $w \mathrm{t}[19,20,30,66]$. The average alliin content of garlic cloves is $9.7 \pm 2.0 \mathrm{mg} / \mathrm{g}$ fr wt or $27.7 \pm 5.8 \mathrm{mg} / \mathrm{g}$ dry wt [49-51]. Almost all clinical trials with garlic powder supplements have used a daily dose standardized at 3.6-7.8 mg allicin potential from $7.8-17 \mathrm{mg}$ alliin $[1,2]$, which represents $1-2 \mathrm{~g}$ of typical raw garlic. It is here proposed that the minimum daily dose of a garlic powder supplement for possible health benefits should have high allicin bioavailability and represent the equivalent of two grams of typical raw garlic by having an allicin potential of about 7-8 $\mathrm{mg}$ or an alliin content of 18-21 $\mathrm{mg}$ (includes an additional $19 \%$ alliin for the other allyl thiosulfinates, Figure 1), and that the preferred dose for clinical trials should be two times this amount. A dose that is substantially higher than the equivalent of $4 \mathrm{~g}$ fresh garlic may be difficult for most people to tolerate. The amount of allicin potential or alliin in a supplement will depend upon their concentration in the garlic powder and the amount of garlic powder in the supplement. Section 3.5 describes the allicin potential and alliin content of the garlic powders in the supplements used in this study. Of these supplements, five of six enteric brands were standardized on allicin potential or alliin content, but only one brand of normal tablets and one brand of capsules were standardized as such (Table 1).

\subsubsection{Allicin Bioavailability and Dosage Form}

It is recommended that the allicin bioavailability of garlic supplements should be at least $65 \%$, based on in vivo tests. For normal (non-enteric) tablets, allicin bioavailability was consistently above $65 \%$ for all brands tested, and it was not significantly affected by meal type (Table 6). Allicin bioavailability among enteric tablets was above $65 \%$ for four out of five brands consumed with the low-protein meal, but it was strongly affected by meal type, with an average of only $37 \%$ for the three brands consumed with the high-protein meal. If an enteric tablet is to used, its allicin bioavailability should be validated and limitations on meal contents described. Although allicin bioavailability from capsules was unaffected by meal type, only one of three brands gave higher than $65 \%$ and this brand was uniquely made with a coarse garlic powder, which coarseness was probably responsible for its high value. Hence, capsules should not be used unless high allicin bioavailability has been demonstrated. 


\subsubsection{Alliinase Activity}

Although alliinase activity is essential to high allicin bioavailability, no standard for alliinase activity is being recommended. Supplements with activity over the broad range of 250-13,000 $\mu$ g allicin $\min ^{-1} \mathrm{~g}^{-1}$ garlic powder had high allicin bioavailability (Table 6), demonstrating that only minimal activity is required. In a prior study, the alliinase activity of 24 brands of enteric tablets was found to give a similar range, $<100$ to 14,000 , with four brands giving less than 150 [30]. Because that study found low in vitro USP dissolution allicin release [29] to correlate with low alliinase activity, it was recommended that the minimum alliinase activity for supplements should be $4000 \mu \mathrm{g}$ allicin $\mathrm{min}^{-1}$ $\mathrm{g}^{-1}$ garlic powder [30]; however, now that high allicin bioavailability has been found for supplements with activity as low as 250 , the prior activity recommendation of 4000 is no longer valid.

\section{Conclusions}

The bioavailability of allicin from garlic powder supplements containing alliin and active alliinase can be as high as that from an equivalent amount of crushed raw garlic containing maximum allicin, when consumed with a meal. This was found to be true for all tested brands of normal (non-enteric) tablets, including the main garlic powder supplement, Kwai (N1), which has been used in a large number of clinical trials on the possible health benefits of garlic and validates the results of these trials as representing about $1 \mathrm{~g}$ of crushed raw garlic. Compared to non-enteric tablets, allicin bioavailability from enteric tablets was found to be much more variable (36-104\%) and to be strongly reduced $(22-57 \%)$ when consumed with a high-protein meal, due to delayed gastric emptying. The in vitro USP dissolution allicin release test was found to be unreliable for predicting allicin bioavailability from enteric tablets and to be only $20 \%$ accurate for predicting allicin bioavailability from non-enteric tablets and capsules, validating the importance of determining allicin bioavailability in vivo. Based on the allicin metabolite equivalence found for the 13 garlic powder supplements tested, a person would need to consume 0.7 to 27 tablets/capsules to obtain the same equivalence as consuming $2 \mathrm{~g}$ of crushed raw garlic; however, the recommended daily dose by the supplement manufacturers varied from 1-6 tablets/capsules per day, highlighting the need for more complete standardization. With a more correct understanding of allicin bioavailability, better standards are now being recommended for garlic powder supplements being used in future clinical trials and being consumed by the general public, which standards include a dosage form with sufficient allicin bioavailability and alliin content or allicin potential to represent a daily dose of $2-4 \mathrm{~g}$ of typical crushed raw garlic (Section 4.6).

Consumption of alliinase-inhibited cooked garlic was found to give higher than expected allicin bioequivalence, with AMS formation being about 30\% (roasted garlic) or 16\% (boiled garlic) that of crushed raw garlic. Hence, any health benefits found for raw garlic or garlic supplements representing raw garlic can probably be achieved by consuming higher amounts of cooked garlic, with the likely exception of antimicrobial effects in the gastrointestinal tract. The mechanism by which AMS can be formed when alliinase is inactive was explored. After selective removal of alliin and alliin-derived compounds from boiled garlic, allicin bioequivalence decreased by only about 50\% (AFHG vs. PFHA), indicating that the body possesses the ability to partly metabolize G/SAC to AMS, an ability which is enhanced about 6-fold when alliinase is inhibited. The metabolism of alliin to AMS was found to be enhanced about 2-fold, in the absence of active alliinase, compared to consuming pure alliin. Using in-garlic response factors, it was found that alliin and G/SAC contribute about equally to the breath AMS found after consuming alliinase-inhibited cooked garlic, but when alliinase is active, such as for garlic supplements having high allicin bioavailability, G/SAC accounts for only about $5 \%$ of the AMS. Possible mechanisms for the metabolism of G/SAC and alliin to AMS in the absence of active alliinase have been proposed but not experimentally verified. Unanswered questions for future research on the metabolism of alliinase-inhibited garlic include (a) identity of the metabolic pathways from alliin and SAC to AMS when alliinase is inactive and (b) the mechanism by which the metabolism of alliin, and especially SAC, to AMS is enhanced when alliinase is inactive. 
Author Contributions: L.D.L. did the following: conceptualization and design, acquired the funding, established the methodology, analyzed the data, and wrote the manuscript. S.M.H. did the following: data curation, methodology application, and reviewed the manuscript.

Funding: This research was funded by grant R21 AT004236 from the U.S. National Institutes of Health (National Center for Complementary and Alternative Medicine).

Conflicts of Interest: The authors declare no conflict of interest.

\section{References}

1. Ried, K.; Toben, C.; Fakler, P. Effect of garlic on serum lipids: An updated meta-analysis. Nutr. Rev. 2013, 71, 282-299. [CrossRef] [PubMed]

2. Ried, K. Garlic Lowers Blood Pressure in Hypertensive Individuals, Regulates Serum Cholesterol, and Stimulates Immunity: An Updated Meta-analysis and Review. J. Nutr. 2016, 146, 389S-396S. [CrossRef] [PubMed]

3. Kwak, J.S.; Kim, J.Y.; Paek, J.E.; Lee, Y.J.; Kim, H.R.; Park, D.S.; Kwon, O. Garlic powder intake and cardiovascular risk factors: A meta-analysis of randomized controlled clinical trials. Nutr. Res. Pract. 2014, 8 , 644-654. [CrossRef] [PubMed]

4. Rohner, A.; Ried, K.; Sobenin, I.A.; Bucher, H.C.; Nordmann, A.J. A systematic review and metaanalysis on the effects of garlic preparations on blood pressure in individuals with hypertension. Am. J. Hypertens. 2015, 28, 414-423. [CrossRef] [PubMed]

5. Khoo, Y.S.; Aziz, Z. Garlic supplementation and serum cholesterol: A meta-analysis. J. Clin. Pharm. Ther. 2009, 34, 133-145. [CrossRef] [PubMed]

6. Reinhart, K.M.; Talati, R.; White, C.M.; Coleman, C.I. The impact of garlic on lipid parameters: A systematic review and meta-analysis. Nutr. Res. Rev. 2009, 22, 39-48. [CrossRef] [PubMed]

7. Schwingshackl, L.; Missbach, B.; Hoffmann, G. An umbrella review of garlic intake and risk of cardiovascular disease. Phytomedicine 2016, 23, 1127-1133. [CrossRef] [PubMed]

8. Ackermann, R.; Mulrow, C.; Ramirez, G.; Gardner, C.; Morbidoni, L.; Lawrence, V. Garlic shows promise for improving some cardiovascular risk factors. Arch. Intern. Med. 2001, 161, 813-824. [CrossRef] [PubMed]

9. Zeng, T.; Zhang, C.L.; Zhao, X.L.; Xie, K.Q. The roles of garlic on the lipid parameters: A systematic review of the literature. Crit. Rev. Food Sci. Nutr. 2013, 53, 215-230. [CrossRef] [PubMed]

10. McRae, M.P. A review of studies of garlic (Allium sativum) on serum lipids and blood pressure before and after 1994: Does the amount of allicin released from garlic powder tablets play a role? J. Chiropr. Med. 2005, 4, 182-190. [CrossRef]

11. Posadzki, P.; AlBedah, A.M.; Khalil, M.M.; AlQaed, M.S. Complementary and alternative medicine for lowering blood lipid levels: A systematic review of systematic reviews. Complement. Ther. Med. 2016, 29, 141-151. [CrossRef] [PubMed]

12. Marchese, A.; Barbieri, R.; Sanches-Silva, A.; Daglia, M.; Nabavi, S.F.; Jafari, N.J.; Izadi, M.; Ajami, M.; Nabavi, S.M. Antifungal and antibacterial activities of allicin: A review. Trends Food Sci. Technol. 2016, 52, 49-56. [CrossRef]

13. Lawson, L.D. Garlic: A review of its medicinal effects and indicated active compounds. In Phytomedicines of Europe: Chemistry and Bological Activity; ACS Symposium Series 691; Lawson, L.D., Bauer, R., Eds.; American Chemical Society: Washington, DC, USA, 1998; pp. 176-209, ISBN 0-8412-3559-7.

14. Lawson, L.D.; Hughes, B.G. Characterization of the formation of allicin and other thiosulfinates from garlic. Planta Med. 1992, 58, 345-350. [CrossRef] [PubMed]

15. Cavallito, C.J.; Bailey, J.H. Allicin, the antibacterial principle of Allium sativum. I. Isolation, physical properties and antibacterial action. J. Am. Chem. Soc. 1944, 66, 1950-1951. [CrossRef]

16. Cavallito, C.J.; Buck, J.S.; Suter, C.M. Allicin, the antibacterial principle of Allium sativum. II. Determination of the chemical structure. J. Am. Chem. Soc. 1944, 66, 1952-1954. [CrossRef]

17. Lawson, L.D.; Wang, Z.J. Allicin and allicin-derived garlic compounds increase breath acetone through allyl methyl sulfide: Use in measuring allicin bioavailability. J. Agric. Food Chem. 2005, 53, 1974-1983. [CrossRef] [PubMed]

18. Shouk, R.; Abdou, A.; Shetty, K.; Sarkar, D.; Eid, A.H. Mechanisms underlying the antihypertensive effects of garlic bioactives. Nutr. Res. 2014, 34, 106-115. [CrossRef] [PubMed] 
19. Lawson, L.D.; Wood, S.G.; Hughes, B.G. HPLC analysis of allicin and other thiosulfinates in garlic clove homogenates. Planta Med. 1991, 57, 263-270. [CrossRef] [PubMed]

20. Block, E.; Naganathan, S.; Putnam, D.; Zhao, S.H. Allium chemistry: HPLC analysis of thiosulfinates from onion, garlic, wild garlic (ramsoms), leek, scallion, shallot, elephant (great-headed) garlic, chive, and Chinese chive. Uniquely high allyl to methyl ratios in some garlic samples. J. Agric. Food Chem. 1992, 40, 2418-2430. [CrossRef]

21. Lawson, L.D.; Wang, Z.J.; Hughes, B.G. Identification and HPLC quantitation of the sulfides and dialk(en)yl thiosulfinates in commercial garlic products. Planta Med. 1991, 57, 363-370. [CrossRef] [PubMed]

22. Lawson, L.D. The composition and chemistry of garlic cloves and processed garlic. In Garlic: The Science and Therapeutic Application of Allium sativum L. and Related Species, 2nd ed.; Koch, H.P., Lawson, L.D., Eds.; Williams \& Wilkins: Baltimore, MD, USA, 1996; pp. 37-108, ISBN 0-683-18147-5.

23. Block, E.; Ahmad, S.; Jain, M.K.; Crecely, R.W.; Apitz-Castro, R.; Cruz, M.R. The chemistry of alkyl thiosulfinate esters, VIII. (E,Z)-Ajoene: A potent antithrombotic agent from garlic. J. Am. Chem. Soc. 1984, 106, 8295-8296. [CrossRef]

24. Block, E. The organosulfur chemistry of the genus Allium-implications for the organic chemistry of sulfur. Angew. Chem. Int. Ed. Engl. 1992, 31, 1135-1178. [CrossRef]

25. Van Damme, E.J.M.; Smeets, K.; Torrekens, S.; Van Leuven, F.; Peumans, W.J. Isolation and characterization of alliinase cDNA clones from garlic (Allium sativum L.) and related species. Eur. J. Biochem. 1992, 209, 751-757. [CrossRef] [PubMed]

26. Stoll, A.; Seebeck, E. Chemical investigations on alliin, the specific principle of garlic. Adv. Enzymol. 1951, 11, 377-400. [CrossRef]

27. Malagelada, J.-R.; Longstreth, G.F.; Summerskill, W.H.J.; Go, V.L.W. Measurement of gastric functions during digestion of ordinary solid meals in man. Gastroenterology 1976, 70, 203-210. [CrossRef] [PubMed]

28. McLauchlan, G.; Fullarton, G.M.; Crean, G.P.; McColl, K.E.L. Comparison of gastric body and antral pH: A 24 hour ambulatory study in healthy volunteers. Gut 1989, 30, 573-578. [CrossRef] [PubMed]

29. United States Pharmacopeial Convention. Garlic delayed-release tablets. In United States Pharmacopeia 34/National Formulary 29; United States Pharmacopeial Convention, Inc.: Rockville, MD, USA, 2011; pp. 1143-1144, ISBN 1223005313.

30. Lawson, L.D.; Wang, Z.J. Low allicin release from garlic supplements: A major problem due to the sensitivities of alliinase activity. J. Agric. Food Chem. 2001, 49, 2592-2599. [CrossRef] [PubMed]

31. Lawson, L.D.; Wang, Z.J.; Papadimitriou, D. Allicin release under simulated gastrointestinal conditions from garlic powder tablets employed in clinical trials on serum cholesterol. Planta Med. 2001, 67, 13-18. [CrossRef] [PubMed]

32. Lawson, L.D.; Wang, Z.J. Pre-hepatic fate of the organosulfur compounds derived from garlic (Allium sativum). Planta Med. 1993, 59, A688-A689. [CrossRef]

33. Lawson, L.D.; Ransom, D.K.; Hughes, B.G. Inhibition of whole blood platelet aggregation by compounds in garlic clove extracts and commercial garlic products. Thromb. Res. 1992, 65, 141-156. [CrossRef]

34. Ruiz, R.; Hartman, T.G.; Karmas, K.; Lech, J.; Rosen, R.T. Breath analysis of garlic-borne phytochemicals in human subjects: Combined adsorbent trapping and short-path thermal desorption gas chromatography-mass spectrometry. In Food Phytochemicals for Cancer Prevention I Fruits and Vegetables; ACS Symposium Series 546; Huang, M.-T., Osawa, T., Ho, C.-T., Rosen, R.T., Eds.; American Chemical Society: Washington, DC, USA, 1994; pp. 102-119, ISBN 0-8412-2768-3.

35. Cai, X.J.; Block, E.; Uden, P.C.; Quimby, B.D.; Sullivan, J.J. Allium chemistry: Identification of natural abundance of organoselenium compounds in human breath after ingestion of garlic using gas chromatography with atomic emission detection. J. Agric. Food Chem. 1995, 43, 1751-1753. [CrossRef]

36. Taucher, J.; Hansel, A.; Jordan, A.; Lindinger, W. Analysis of compounds in human breath after ingestion of garlic using proton-transfer-reaction mass spectrometry. J. Agric. Food Chem. 1996, 44, 3778-3782. [CrossRef]

37. Lawson, L.D.; Gardner, C.D. Composition, stability, and bioavailability of garlic products used in a clinical trial. J. Agric. Food Chem. 2005, 53, 6254-6261. [CrossRef] [PubMed]

38. Lachmann, G.; Lorenz, D.; Radeck, W.; Steiper, M. The pharmacokinetics of the S35 labeled labeled garlic constituents alliin, allicin and vinyldithiine. Arzneim. Forsch. 1994, 44, 734-743. 
39. Miron, T.; Rabinkov, A.; Mirelman, D.; Wilchek, M.; Weiner, L. The mode of action of allicin: Its ready permeability through phospholipid membranes may contribute to its biological activity. Biochim. Biophys. Acta 2000, 1463, 20-30. [CrossRef]

40. Griffith, L.; Griffith, F. Garlic, Garlic, Garlic: Exceptional Recipes for the World's Most Indispensable Ingredient; Houghton Mifflin Co.: New York, NY, USA, 1998; pp. 41-102, ISBN 0-395-89254-6.

41. Wilen, J.; Wilen, L. Garlic: Nature's Super Healer; Prentice Hall: Englewood Cliffs, NJ, USA, 1997; pp. 139-224, ISBN 0-13-522871-2.

42. Davenport, H.W. Physiology of the Digestive Tract, 5th ed.; Year Book Medical Publishers: Chicago, IL, USA, 1982; pp. 65-66, 131-133, ISBN 0-8151-2330-2.

43. Phillips, M.; Herrera, J.; Krishnan, S.; Zain, M.; Greenberg, J.; Cataneo, R.N. Variation in volatile organic compounds in the breath of normal humans. J. Chromatogr. B Biomed. Sci. Appl. 1999, 729, 75-88. [CrossRef]

44. Arnault, I.; Christides, J.P.; Mandon, N.; Haffner, T.; Kahane, R.; Auger, J. High-performance ion-pair chromatography method for simultaneous analysis of alliin, deoxyalliin, allicin and dipeptide precursors in garlic products using multiple mass spectrometry and UV detection. J. Chromatogr. A 2003, 991, 69-75. [CrossRef]

45. Bradford, M.M. A rapid and sensitive method for the quantitation of microgram quantities of protein utilizing the principle of protein-dye binding. Anal. Biochem. 1976, 72, 248-254. [CrossRef]

46. Randle, W.M.; Block, E.; Littlejohn, M.H.; Putman, D.; Bussard, M.L. Onion (Allium cepa L.) thiosulfinates respond to increasing sulfur fertility. J. Agric. Food Chem. 1994, 42, 2085-2088. [CrossRef]

47. Kubec, R.; Cody, R.B.; Dane, A.J.; Musah, R.A.; Schraml, J.; Vattekkatte, A.; Block, E. Applications of direct analysis in real time-mass spectrometry (DART-MS) in Allium chemistry. (Z)-butanethial S-oxide and 1-butenyl thiosulfinates and their $S$-(E)-1-butenylcysteine $S$-oxide precursor from Allium siculum. J. Agric. Food Chem. 2010, 58, 1121-1128. [CrossRef] [PubMed]

48. Kubec, R.; Dadakova, E. Quantitative determination of $S$-alk(en)ylcysteine-S-oxides by micellar electrokinetic capillary chromatography. J. Chromatogr. A 2008, 1212, 154-157. [CrossRef] [PubMed]

49. Montano, A.; Beato, V.M.; Mansilla, F.; Orgaz, F. Effect of genetic characteristics and environmental factors on organosulfur compounds in garlic (Allium sativum L.) grown in Andalusia, Spain. J. Agric. Food Chem. 2011, 59, 1301-1307. [CrossRef] [PubMed]

50. Kubec, R.; Svobodova, M.; Velisek, J. Gas chromatographic determination of S-alk(en)ylcysteine sulfoxides. J. Chromatogr. A 1999, 862, 85-94. [CrossRef]

51. Ueda, Y.; Kawajiri, H.; Miyamura, N.; Miyajima, R. Content of some sulfur-containing components and free amino acids in various strains of garlic. J. Jpn. Soc. Food Sci. Technol. 1991, 38, 429-434. [CrossRef]

52. Mojaverian, P.; Rocci, M.L., Jr.; Conner, D.P.; Abrams, W.B.; Vlasses, P.H. Effect of food on the absorption of enteric-coated aspirin: Correlation with gastric residence time. Clin. Pharmacol. Ther. 1987, 41, 11-17. [CrossRef] [PubMed]

53. Wang, D.; Feng, Y.; Liu, J.; Yan, J.; Wang, M.; Sasaki, J.; Lu, C. Black garlic (Allium sativum) extracts enhance the immune system. Med. Aromat. Plant Sci. Biotechnol. 2010, 4, 37-40.

54. Zhang, X.; Li, N.; Lu, X.; Liu, P.; Qiao, X. Effects of temperature on the quality of black garlic. J. Sci. Food Agric. 2016, 96, 2366-2372. [CrossRef] [PubMed]

55. Nakagawa, S.; Kasuga, S.; Matsuura, H. Prevention of liver damage by aged garlic extract and its components in mice. Phytother. Res. 1989, 3, 50-53. [CrossRef]

56. Rahman, K.; Lowe, G.M.; Smith, S. Aged Garlic Extract Inhibits Human Platelet Aggregation by Altering Intracellular Signaling and Platelet Shape Change. J. Nutr. 2016, 146, 410S-415S. [CrossRef] [PubMed]

57. Rao, P.S.; Midde, N.M.; Miller, D.D.; Chauhan, S.; Kumar, A.; Kumar, S. Diallyl Sulfide: Potential Use in Novel Therapeutic Interventions in Alcohol, Drugs, and Disease Mediated Cellular Toxicity by Targeting Cytochrome P450 2E1. Curr. Drug Metab. 2015, 16, 486-503. [CrossRef] [PubMed]

58. Suman, S.; Shukla, Y. Diallyl Sulfide and Its Role in Chronic Diseases Prevention. Adv. Exp. Med. Biol. 2016, 929, 127-144. [CrossRef] [PubMed]

59. Ellmore, G.S.; Feldberg, R.S. Alliin lyase localization in bundle sheaths of the garlic clove (Allium sativum). Am. J. Bot. 1994, 81, 89-94. [CrossRef]

60. Jansen, H.; Müller, B.; Knobloch, K. Characterization of an alliin lyase preparation from garlic (Allium sativum). Planta Med. 1989, 55, 434-439. [CrossRef] [PubMed] 
61. Bogentoft, C.; Carlsson, I.; Ekenved, G.; Magnusson, A. Influence of food on the absorption of acetylsalicylic acid from enteric-coated dosage forms. Eur. J. Clin. Pharmacol. 1978, 14, 351-355. [CrossRef] [PubMed]

62. Blythe, R.; Grass, G.; MacDonnel, D.R. The formulation and evaluation of enteric coated aspirin tablets. Am. J. Pharm. Sci. Support. Public Health 1959, 131, 206-216. [PubMed]

63. Park, H.M.; Chernish, S.M.; Rosenek, B.D.; Brunelle, R.L.; Hargrove, B.; Wellman, H.N. Gastric emptying of enteric-coated tablets. Dig. Dis. Sci. 1984, 29, 207-212. [CrossRef] [PubMed]

64. Kokubo, H.; Obara, S.; Minemura, K.; Tanaka, T. Development of cellulose derivatives as novel enteric coating agents soluble at pH 3.5-4.5 and higher. Chem. Pharm. Bull. 1997, 45, 1350-1353. [CrossRef] [PubMed]

65. Blumenthal, M.; Busse, W.R.; Goldberg, A.; Gruenwald, J.; Hall, T.; Riggins, C.W.; Rister, R.S. The Complete German Commission E Monographs; Integrative Medicine Communications: Boston, MA, USA, 1998; p. 134, ISBN 096555550X.

66. Rybak, M.E.; Calvey, E.M.; Harnly, J.M. Quantitative determination of allicin in garlic: Supercritical fluid extraction and standard addition of alliin. J. Agric. Food Chem. 2004, 52, 682-687. [CrossRef] [PubMed]

67. Ashraf, R.; Khan, R.A.; Ashraf, I.; Qureshi, A.A. Effects of Allium sativum (garlic) on systolic and diastolic blood pressure in patients with essential hypertension. Pak. J. Pharm. Sci. 2013, 26, 859-863. [PubMed]

68. Jain, A.K.; Vargas, R.; Gotzkowsky, S.; McMahon, F.G. Can garlic reduce levels of serum lipids? A controlled clinical study. Am. J. Med. 1993, 94, 632-635. [CrossRef]

69. Ashraf, R.; Aamir, K.; Shaikh, A.R.; Ahmed, T. Effects of garlic on dyslipidemia in patients with type 2 diabetes mellitus. J. Ayub. Med. Coll. Abbottabad. 2005, 17, 60-64. [PubMed]

70. Ashraf, R.; Khan, R.A.; Ashraf, I. Garlic (Allium sativum) supplementation with standard antidiabetic agent provides better diabetic control in type 2 diabetes patients. Pak. J. Pharm. Sci. 2011, 24, 565-570. [PubMed]

71. Brewitt, B.; Lehmann, B. Lipidregulierung durch standardisierte Naturarzneimittel. Multizentrische Langzeitstudie an 1209 Patienten. Kassenarzt 1991, 5, 47-55.

72. Gardner, C.D.; Lawson, L.D.; Block, E.; Chatterjee, L.M.; Kiazand, A.; Balise, R.R.; Kraemer, H.C. Effect of Raw Garlic vs Commercial Garlic Supplements on Plasma Lipid Concentrations in Adults With Moderate Hypercholesterolemia: A Randomized Clinical Trial. Arch. Intern. Med. 2007, 167, 346-353. [CrossRef] [PubMed]

73. Beckert, B.W.; Concannon, M.J.; Henry, S.L.; Smith, D.S.; Puckett, C.L. The effect of herbal medicines on platelet function: An in vivo experiment and review of the literature. Plast. Reconstr. Surg. 2007, 120, 2044-2050. [CrossRef] [PubMed]

74. Murakami, F. Studies on the nutritional value of Allium plants. XXXVII. Decomposition of alliin homologues by acetone-powdered enzyme preparation of Bacillus subtilis. Bitamin 1960, 20, 131-135.

75. Nomura, J.; Nishizuka, Y.; Hayaishi, O. S-alkylcysteinase: Enzymatic cleavage of S-methyl-L-cysteine and its sulfoxide. J. Biol. Chem. 1963, 238, 1441-1446.

76. Yutani, M.; Taniguchi, H.; Borjihan, H.; Ogita, A.; Fujita, K.; Tanaka, T. Alliinase from Ensifer adhaerens and Its Use for Generation of Fungicidal Activity. AMB Express 2011, 1, 2. [CrossRef] [PubMed]

77. Tchernychev, B.; Rabinkov, A.; Mirelman, D.; Wilchek, M. Natural antibodies to dietary proteins: The existence of natural antibodies to alliinase (Alliin lyase) and mannose-specific lectin from garlic (Allium sativum) in human serum. Immunol. Lett. 1995, 47, 53-57. [CrossRef]

78. Amano, H.; Kazamori, D.; Itoh, K.; Kodera, Y. Metabolism, excretion, and pharmacokinetics of S-allyl-L-cysteine in rats and dogs. Drug Metab. Dispos. 2015, 43, 749-755. [CrossRef] [PubMed]

79. Kodera, Y.; Suzuki, A.; Imada, O.; Kasuga, S.; Sumioka, I.; Kanezawa, A.; Taru, N.; Fujikawa, M.; Nagae, S.; Masamoto, K.; et al. Physical, chemical, and biological properties of $S$-allylcysteine, an amino acid derived from garlic. J. Agric. Food Chem. 2002, 50, 622-632. [CrossRef] [PubMed]

80. Germain, E.; Auger, J.; Ginies, C.; Siess, M.-H.; Teyssier, C. In vivo metabolism of diallyl disulphide in the rat: Identification of two new metabolites. Xenobiotica 2002, 32, 1127-1138. [CrossRef] [PubMed]

81. Germain, E.; Chevalier, J.; Siess, M.-H.; Teyssier, C. Hepatic metabolism of diallyl disulphide in rat and man. Xenobiotica 2003, 33, 1185-1199. [CrossRef] [PubMed]

82. Khatua, T.N.; Borkar, R.M.; Mohammed, S.A.; Dinda, A.K.; Srinivas, R.; Banerjee, S.K. Novel Sulfur Metabolites of Garlic Attenuate Cardiac Hypertrophy and Remodeling through Induction of $\mathrm{Na}^{+} / \mathrm{K}^{+}$-ATPase Expression. Front. Pharmacol. 2017, 8, 1-11. [CrossRef] [PubMed]

83. Scheffler, L.; Sauermann, Y.; Zeh, G.; Hauf, K.; Heinlein, A.; Sharapa, C.; Buettner, A. Detection of Volatile Metabolites of Garlic in Human Breast Milk. Metabolites 2016, 6, 18. [CrossRef] [PubMed] 
84. Scheffler, L.; Sauermann, Y.; Heinlein, A.; Sharapa, C.; Buettner, A. Detection of Volatile Metabolites Derived from Garlic (Allium sativum) in Human Urine. Metabolites 2016, 6, 43. [CrossRef] [PubMed]

85. Buettner, A.; Scheffler, L.; (Friederich-Alexander-Universität, Erlangen-Nürnberg, Germany). Personal communication, 2018.

86. Nagae, S.; Ushijima, M.; Hatano, S.; Imai, J.; Kasuga, S.; Matsuura, H.; Itakura, Y.; Higashi, Y. Pharmacokinetics of the garlic compound S-allyl cysteine. Planta Med. 1994, 60, 214-217. [CrossRef] [PubMed]

87. Roje, S. S-Adenosyl-L-methionine: Beyond the universal methyl group donor. Phytochemistry 2006, 67, 1686-1698. [CrossRef] [PubMed]

88. Lee, E.K.; Chung, S.W.; Kim, J.Y.; Kim, J.M.; Heo, H.S.; Lim, H.A.; Kim, M.K.; Anton, S.; Yokozawa, T.; Chung, H.Y. Allylmethylsulfide Down-Regulates X-Ray Irradiation-Induced Nuclear Factor-kappaB Signaling in C57/BL6 Mouse Kidney. J. Med. Food 2009, 12, 542-551. [CrossRef] [PubMed]

89. Becker, P.M.; van Wikselaar, P.G.; Mul, M.F.; Pol, A.; Engel, B.; Wijdenes, J.W.; van der Peet-Schwering, C.M.; Wisselink, H.J.; Stockhofe-Zurwieden, N. Actinobacillus pleuropneumoniae is impaired by the garlic volatile allyl methyl sulfide (AMS) in vitro and in-feed garlic alleviates pleuropneumonia in a pig model. Vet. Microbiol. 2012, 154, 316-324. [CrossRef] [PubMed]

90. Rahman, M.A.; Gong, Y.; Kumar, S. In vitro evaluation of structural analogs of diallyl sulfide as novel CYP2E1 inhibitors for their protective effect against xenobiotic-induced toxicity and HIV replication. Toxicol. Lett. 2018, 292, 31-38. [CrossRef] [PubMed]

91. Davenport, D.M.; Wargovich, M.J. Modulation of cytochrome P450 enzymes by organosulfur compounds from garlic. Food Chem. Toxicol. 2005, 43, 1753-1762. [CrossRef] [PubMed]

92. Wargovich, M.J. Diallyl sulfide and allyl methyl sulfide are uniquely effective among organosulfur compounds in inhibiting CYP2E1 protein in animal models. J. Nutr. 2006, 136, 832S-834S. [CrossRef] [PubMed]

93. Suarez, F.; Springfield, J.; Furne, J.; Levitt, M. Differentiation of mouth versus gut as site of origin of odoriferous breath gases after garlic ingestion. Am. J. Physiol. 1999, 276, G425-G430. [CrossRef] [PubMed]

94. Schulz, V.; Hänsel, R.; Blumenthal, M.; Tyler, V. Side effects and garlic odor. In Rational Phytotherapy: A Reference Guide for Physicians and Pharmacists, 5th ed.; Springer-Verlag: Berlin, Germany, 2004; pp. 163-171, ISBN 3-540-40832-0.

95. Beck, E.; Grünwald, J. Allium sativum in der Stufentherapie der Hyperlipidämie. Med. Welt 1993, 44, 516-520.

96. Isaacsohn, J.L.; Moser, M.; Stein, E.A.; Dudley, K.; Davey, J.A.; Liskov, E.; Black, H.R. Garlic powder and plasma lipids and lipoproteins. Arch. Intern. Med. 1998, 158, 1189-1194. [CrossRef] [PubMed]

97. Simons, L.A.; Balasubramaniam, S.; Konigsmark, M. On the effect of garlic on plasma lipids and lipoproteins in mild hypercholesterolaemia. Atherosclerosis 1995, 113, 219-225. [CrossRef]

98. Neil, H.A.W.; Silagy, C.A.; Lancaster, T.; Hodgeman, J.; Vos, K.; Moore, J.W.; Jones, L.; Cahill, J.; Fowler, G. Garlic powder in the treatment of moderate hyperlipidaemia: A controlled trial and meta-analysis. J. R. Coll. Phys. Lond. 1996, 30, 329-334.

99. Adler, A.J.; Holub, B.J. Effect of garlic and fish-oil supplementation on serum lipid and lipoprotein concentrations in hypercholesterolemic men. Am. J. Clin. Nutr. 1997, 65, 445-450. [CrossRef] [PubMed]

100. Koch, H.P. “Knoblauch”: Wie dosiert man richtig? Dtsch. Apoth. Ztg. 1988, 128, 408-412.

(C) 2018 by the authors. Licensee MDPI, Basel, Switzerland. This article is an open access article distributed under the terms and conditions of the Creative Commons Attribution (CC BY) license (http://creativecommons.org/licenses/by/4.0/). 